\title{
AN EXPERIMENTAL STUDY ON A DENSITY DRIVEN SOLAR WATER HEATING SYSTEM USING SUPERCRITICAL $\mathrm{CO}_{2}$ AS WORKING FLUID
}

\author{
A Thesis \\ Submitted to the Graduate Faculty \\ of the \\ North Dakota State University \\ of Agriculture and Applied Science
}

\author{
By \\ Ruchi Shukla \\ In Partial Fulfillment of the Requirements \\ for the Degree of \\ MASTER OF SCIENCE
}

Major Department:

Mechanical Engineering and Applied Mechanics

November 2013

Fargo, North Dakota 
North Dakota State University

Graduate School

Title

An Experimental Study on a Density Driven Solar Water Heating System Using Supercritical $\mathrm{CO}_{2}$ as Working Fluid

By

Ruchi Shukla

The Supervisory Committee certifies that this disquisition complies with

North Dakota State University's regulations and meets the accepted standards

for the degree of

MASTER OF SCIENCE

\section{SUPERVISORY COMMITTEE:}

Dr. Sumathy Krishnan

Chair

Dr. Majura Selekwa

Dr. Om Yadav

Dr. Yildirim Suzen

Approved:

11/26/2013

Date

Dr. Alan Kallmeyer

Department Chair 


\begin{abstract}
For supercritical carbon dioxide, a small change in temperature or pressure can result in large change in density, especially close to its critical point. At this pseudocritical region, density decreases rapidly with increase in temperature which aids the thermosyphon flow. Encouraged by this idea, an experimental investigation has been performed to investigate the feasibility and performance of thermosyphon solar water heating $(\mathrm{SWH})$ system using $\mathrm{R}-744\left(\mathrm{CO}_{2}\right)$ as the working fluid. Experimental results have shown that it is possible to induce the natural convective flow even during solar-adverse conditions. Although during winter this proposed density driven system was not possible to extract any useful heat gain, the system did show some promising results when operated during spring. The time-averaged collector and heat recovery efficiencies for summer were about $58 \%$ and $45 \%$, respectively.
\end{abstract}




\section{ACKNOWLEDGEMENTS}

First and foremost, I am truly grateful to my honored supervisor Dr. K. Sumathy, for her invaluable guidance, continual encouragement and patience throughout my studies. Needless to say, the thesis would not be in the present form, without her help and involvement. Her encouragement helped me to discover the true attitude of learning and working.

I would also like to thank Shannon Viestenz for his assistance, cooperation and willingness to carry out the difficult fabrication task. He is the man I can always rely upon and has always supported me at different stages of the system fabrication.

I owe thanks to the staff of the Mechanical Engineering machine shop in Dolve hall for their assistance, and the entire staff and faculty of the Department of Mechanical Engineering at North Dakota State University.

On a more personal level, I take this opportunity to express my deep sense of gratitude to my grand ma (Ram Pyaari Shukla) resting in peace for her endless love and care. She has been the most loving person in my life. I would like to dedicate my thesis to her. I am very grateful to my parents for all the encouragement and strength; they provided me throughout my life. Thank you to God for curiosity, learning, knowledge, and for this opportunity

Last but not least, special thanks to all my family members and friends, for their immense support. 


\section{TABLE OF CONTENT}

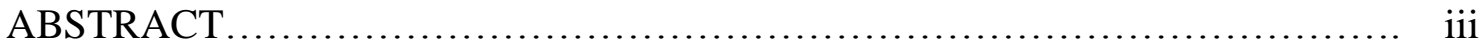

ACKNOWLEDGEMENTS ........................................... iv

LIST OF TABLES ........................................................ viii

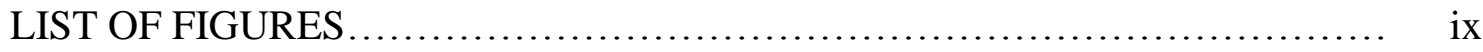

NOMENCLATURE........................................................ xi

1. INTRODUCTION .................................................... 1

1.1. General Introduction.................................................. 1

1.2. Objectives and Scopes of the Projects................................... 3

1.3. System Description....................................................... 4

1.4. Outline of the Thesis.......................................................... 5

2. LITERATURE SURVEY .................................................. 7

2.1. Passive Solar Water Heating Systems................................... 7

2.2. Active Solar Water Heating Systems................................... 11

2.3. Component Designs......................................................... 16

2.3.1. Solar Collectors ................................................. 16

2.3.1.1. Flat Plate Collectors................................... 16

2.3.1.2. Evacuated Tube Collector.............................. 21

2.3.1.3. Compound Parabolic Collector........................... 24

2.3.2. Storage Tank .................................................... 24

2.3.3. Heat Exchanger.............................................. 25

2.3.4. Heat Transfer Fluid............................................... 26

3. SELECTION OF WORKING FLUID (HEAT TRANSFER FLUID)............. 32

3.1. Desirable Properties............................................... 32

3.2. Properties of Carbon Dioxide......................................... 33

3.2.1. Superior Environmental Qualities.............................. 34

3.2.2. Thermodynamic Properties..................................... 34

3.2.3. Transport Properties........................................... 39

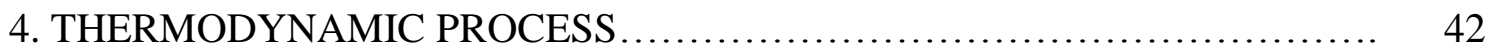

4.1. Governing Equations................................................. 42 
4.1.1. Evacuated Tube Collector.............................................. 42

5. EXPERIMENTAL INVESTIGATION ................................. 46

5.1. Component Design................................................. 47

5.1.1. Evacuated Tube Collector................................................ 47

5.1.1.1. U-Tube Design................................... 50

5.1.1.2. Header Design.......................................... 50

5.1.2. Hot Water Storage Tank ...................................... 51

5.1.3. Heat Exchanger/Condenser................................... 56

5.2. Data Acquisition and Processing System.............................. 60

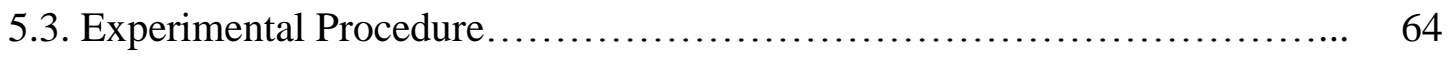

6. RESULTS AND DISSCUSSIONS ................................... 67

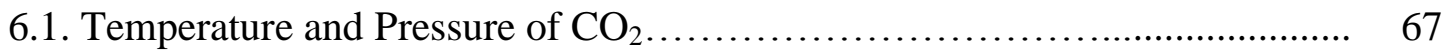

6.2. Performance of ETC ............................................. 70

6.3. Typical Results.................................................. 72

6.4. Effect of Various Parameters on the System................................ 79

6.4.1. Effect of Storage Tank Volume................................. 80

6.4.2. Effect of Inlet Tank Temperature ................................ 82

6.4.3. Seasonal Performance of the System.............................. 85

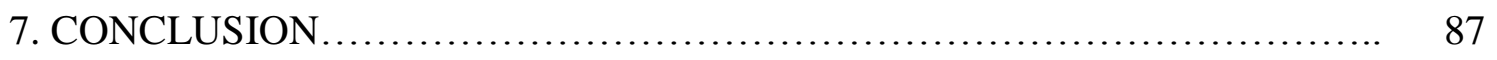

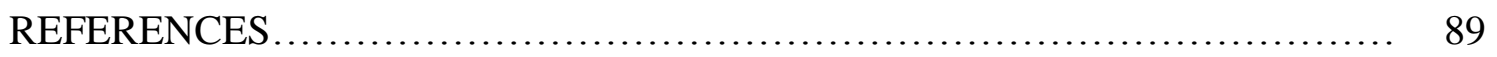

APPENDEX A. WIRING OF CR1000 .................................. 103

APPENDEX B. SENSOR CALIBRATION .................................. 106

APPENDEX C. LIST OF PUBLICATIONS .................................. 107 


\section{LIST OF TABLES}

$\underline{\text { Table }}$

$\underline{\text { Page }}$

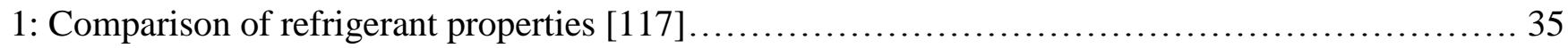

2: Parameters for the glass evacuated tube solar collector.................................... 49

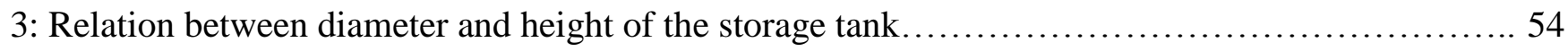

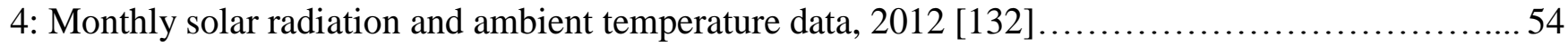

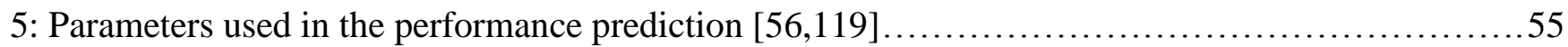

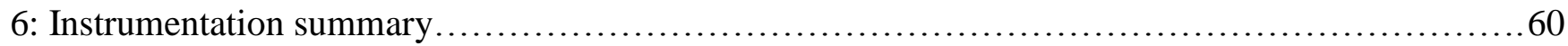

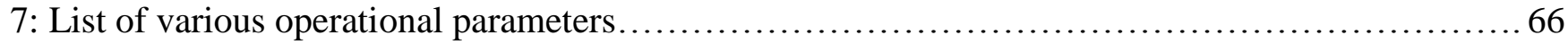

8: Typical experimental values...................................................... 70

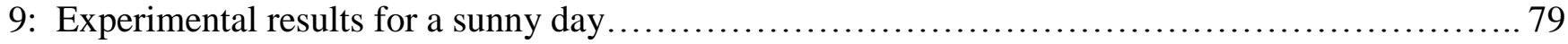




\section{LIST OF FIGURES}

Figure

$\underline{\text { Page }}$

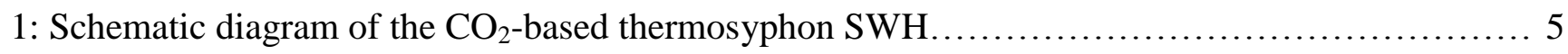

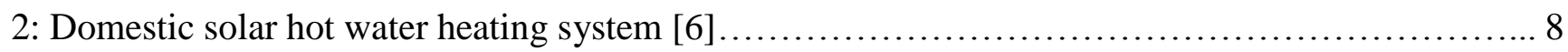

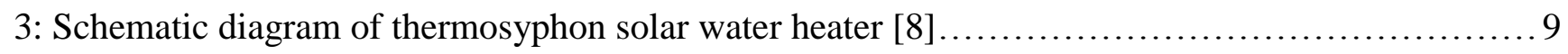

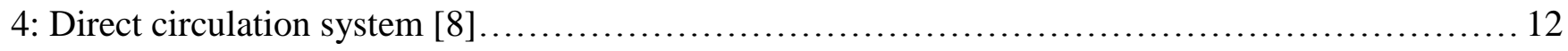

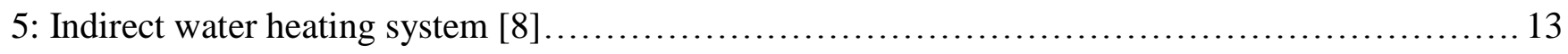

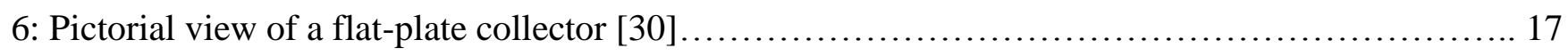

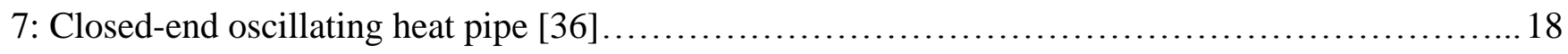

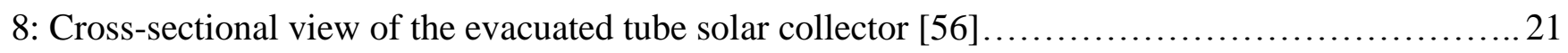

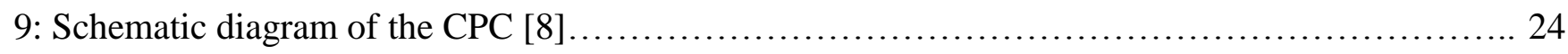

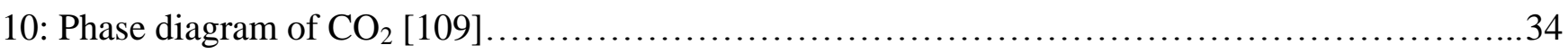

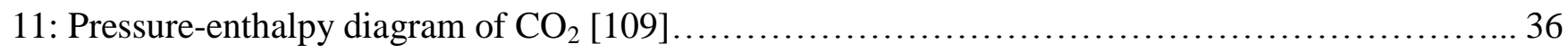

12: (a) Variation of specific heat for $\mathrm{CO}_{2}$ (b) Specific heat of different refrigerants [120].......... 37

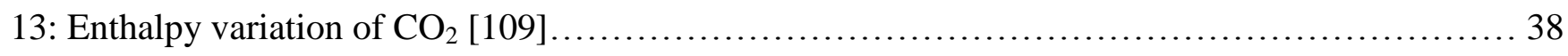

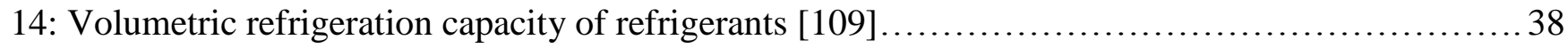

15: (a) Comparison of thermal conductivity[125] (b) Variation of $\mathrm{k}$ for $\mathrm{CO}_{2}[122] \ldots \ldots \ldots \ldots . . . \ldots . . . . .39$

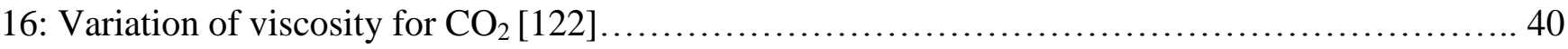

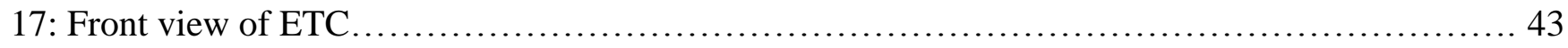

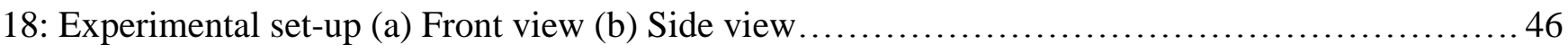

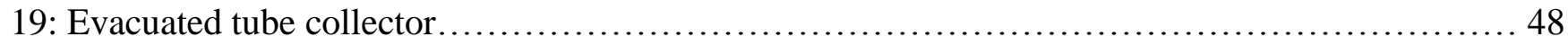

20: U-tubes design ............................................................... 51

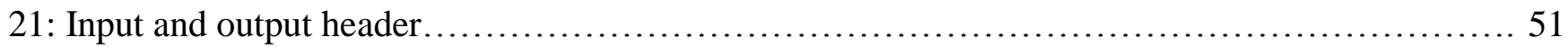


22: Picture and schematic of the designed storage tank.

23: Picture and schematic of the designed Condenser and the cooling coil 56

24: System testing set-up........ 61

25: Schematic and Picture of temperature sensor installed into the flow 62

26: Wiring of the pressure sensor with the Resistor. 63

27: RSR CR1000 logger net software used in the prototype 63

28: Variation of $\mathrm{CO}_{2}$ temperatures with time. 69

29: Variation of $\mathrm{CO}_{2}$ pressure with time. 69

30: Performance of an evacuated tube collector. 71

31: Variation of solar radiation and ambient temperature Vs Time of Day.... .73

32: Variation of $\mathrm{CO}_{2}$ temperature and pressure Vs Time of Day. 74

33: $\mathrm{CO}_{2}$ Pressure-enthalpy diagram showing $\mathrm{CO}_{2}$ fluid stated during the test period. .75

34: Variation of storage tank water temperature Vs Time of Day 76

35: Variation of collector useful heat gain and recovered heat quantity Vs Time of Day..... 77

36: Variation of collector efficiency and heat recovery efficiency Vs Time of Day.... 78

37: Effect of storage volume on the useful heat gain.... 81

38: Effect of storage tank volume on heat recovery efficiency.

39: Effect of storage volume on solar collector efficiency. 82

40: Effect of initial tank temperature on rise in tank water temperature.

41: Effect of initial tank temperatures on the system performance 84

42: $\mathrm{CO}_{2}$ temp and the correspondence avg rise in tank temp for typical days of different month. 85

43: Time-avg collector and heat recovery efficiencies for typical days of different month.... 86 


\section{NOMENCLATURE}

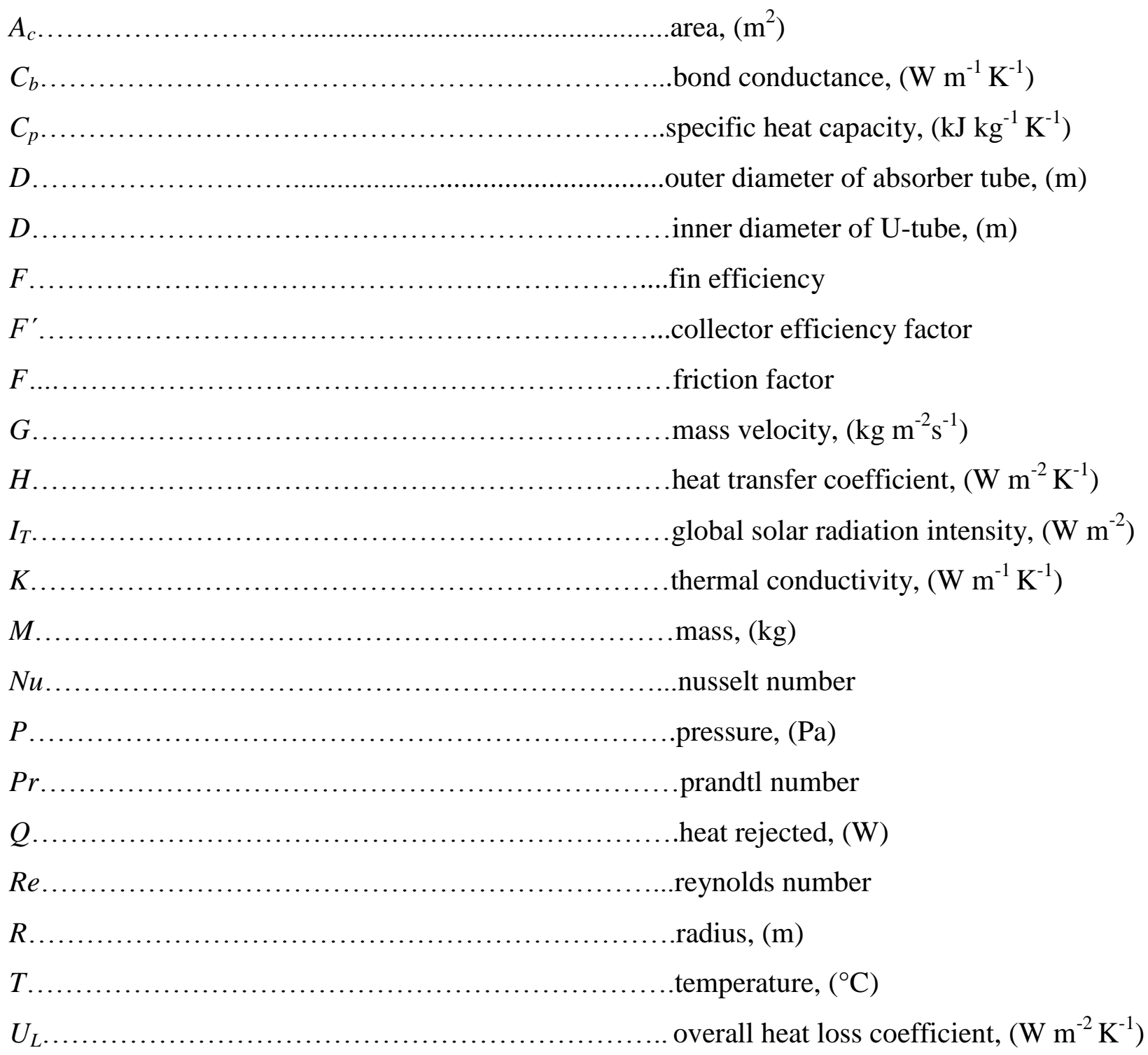

\section{Subscripts}

A.

Co. ambient

$R$. coil

C. .refrigerant collector

Con. .condenser

Col. collector 


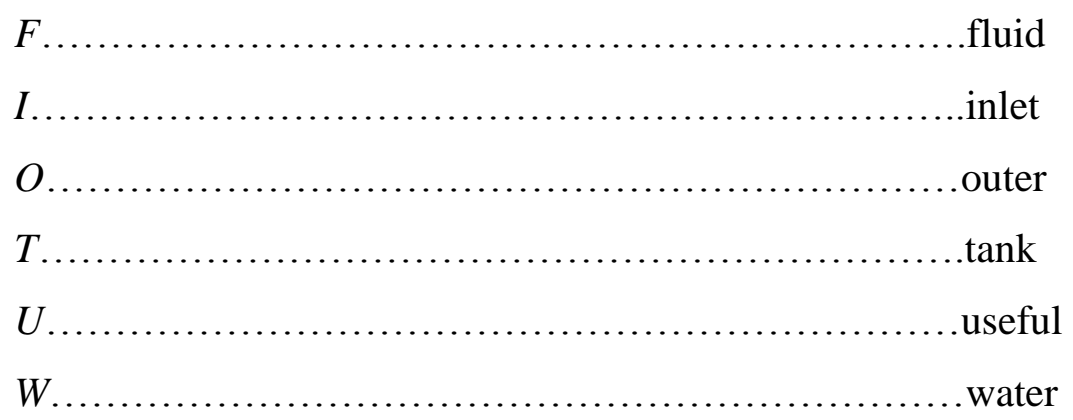




\section{INTRODUCTION}

\subsection{General Introduction}

Cost effective energy acquisition and consumption will continue to be essential factors in determining a nation's economic prosperity and growth. Energy can be obtained through several resources, but in the past, fossil fuel has been the most profitably gathered and consumed source. However, the destructive environmental consequences of fossil fuel consumption were not fully understood or fully addressed. As technology and awareness have grown and evolved, society is now showing keen interest to identify solutions to the problems generated by fossil fuel consumption. The solution steps need to meet constraints in terms of profitability and feasibility such that, an import-independent, inexhaustible, and clean energy acquisition method could be developed.

Among different renewable energy resources, solar power is import-independent, inexhaustible, and clean and is one of the best candidates for fossil fuel replacement. One application of solar power is water heating. In the United States, water heating accounts for $20 \%$ of all household energy use [1]. There are several types of water heating systems, but the most predominately used is the conventional water heater. The majority of conventional water heaters are powered by electricity derived from fossil fuels. One emerging alternative water heating method is solar water heating (SWH). These systems have widespread use and applications in both the domestic and industrial sectors. According to data collected in 2010 by the Renewable Energy Policy Network, 70 million houses worldwide were reported to utilize SWH systems [1]. The growing popularity of SWH is fueled by its environmentally friendly operation, with minimal system maintenance and operational costs compared to conventional water heating systems. The low operational costs offset the comparatively high initial startup cost of a SWH 
system. Depending on the size and type of system, SWH systems can be profitable from energy savings with a payback period of 2-4 years [2]. In order to optimize profitability and maintain environmental responsibility, extensive investigations were done both as theoretical and experimental studies to improve the thermal efficiency of the SWH system.

Most of the conventional SWH systems utilize water as the heat transfer fluid which cannot be used in solar-adverse regions [3]. This is due to the fact that water-based collectors are susceptible to freezing. Researchers have tried other types of working fluids such as fluorocarbon and hydro-fluorocarbon refrigerants. Although these refrigerants do not damage the ozone layer, many of them do have high greenhouse warming potential (GWP). R134a for instance, has GWP that is 1300 times more than that of $\mathrm{CO}_{2}$. To overcome the said issue, natural refrigerants such as $\mathrm{CO}_{2}$, ammonia, and propane may serve as a new alternative.

The selection of a working fluid plays a very significant role in the development of an efficient, cost effective, and environmentally friendly SWH system that can function even when exposed to low ambient conditions. In the proposed study, environmental benign carbon dioxide $\left(\mathrm{CO}_{2}\right)$ is selected as the working fluid because of its zero ozone depletion potential (ODP) and negligible GWP. $\mathrm{CO}_{2}$ is a non-freezing, non-volatile, non-flammable, non-corrosive, and nontoxic natural substance [4]. In addition, it does not need to be recovered or reclaimed when repairing or disposing the equipment, but can be released into the atmosphere with negligible impact. More importantly, the thermodynamic and transport properties of $\mathrm{CO}_{2}$ are favorable in terms of heat transfer [4]. One property of $\mathrm{CO}_{2}$ which distinguishes it from other refrigerants is its low critical point $\left(31.1{ }^{\circ} \mathrm{C}\right.$ at $\left.7.3 \mathrm{MPa}\right)$. These properties make $\mathrm{CO}_{2}$ an ideal working fluid to be used in sub-zero temperatures with low solar radiation. 
Several studies have been initiated utilizing $\mathrm{CO}_{2}$ as the working fluid. Recently, Zhang et al. [4] have made a detailed study on the collector characteristics with $\mathrm{CO}_{2}$ as the working fluid and investigated the influence of $\mathrm{CO}_{2}$ in a U-pipe inserted glass evacuated tube solar collector. It has been reported that the annually-averaged collector efficiency was above $60 \%$ in the case of supercritical $\mathrm{CO}_{2}$ as the working fluid, which is much higher than that of water-based collectors where annually averaged efficiency reached only up to $50 \%$.

Literature shows that most of the $\mathrm{CO}_{2}$ utilized SWH systems are active systems. In this study, an attempt has been made to design and fabricate a simple thermosyphon solar water heater using supercritical $\mathrm{CO}_{2}$ as working fluid to investigate for its feasibility in operating when exposed to solar adverse regions like those found in North Dakota, USA.

\subsection{Objectives and Scopes of the Projects}

The project is intended to raise public awareness of sustainable energy acquisition by demonstrating the promising utilization of solar energy as a heat source for water heating in Fargo. It will also lessen the energy crises threat by providing an energy alternative for basic domestic needs which are currently met by electricity and firewood. The main objectives of the project are outlined below:

(1) To investigate the performance of a modified evacuated tube solar collector using $\mathrm{CO}_{2}$ as the working fluid to harness solar thermal energy in the solar adverse Fargo region.

(2) To develop a reliable and efficient thermosyphoning system integrated with an evacuated tube collector. This system is expected to provide hot water steadily even when the collecting temperature is lower than the required temperature. Initially the project was intended to operate the system with heat pump assistance, which requires a pump and a 
compressor. Due to the high costs involved towards the $\mathrm{CO}_{2}$-pump and the $\mathrm{CO}_{2}$ compressor, it was decided to operate a density driven system.

(3) To develop a cost effective energy alternative that can cater to the domestic needs of the Fargo region compared to conventional sources, such as electricity and firewood.

The scopes of the projects are:

(1) Optimizing the collector design in order to obtain as high of a thermal efficiency as possible.

(2) Indentifying key operational parameters to achieve high overall performance of the thermosyphon system.

(3) Testing the system under low insolation values and evaluating its performance.

\subsection{System Description}

Figure 1 shows the schematic diagram of the $\mathrm{CO}_{2}$ assisted thermosyphon $\mathrm{SWH}$ system being investigated in this study. The system consists of an evacuated tube collector as a heat collecting device, a hot water storage tank with an immersed heat exchanger (HX) as a condenser, a set of valves, high-accuracy sensors, and a data acquisition system.

R744 $\left(\mathrm{CO}_{2}\right)$, set in motion by thermosyphon action, is heated in the evacuated tube solar collector. The heating in the solar collector aids a rise in $\mathrm{CO}_{2}$ temperature, creating a supercritical $\mathrm{CO}_{2}$ high temperature state. This supercritical $\mathrm{CO}_{2}$ passes through the outlet header pipe to the storage tank. The high temperature and high pressure $\mathrm{CO}_{2}$ vapor then rejects the heat to the water through the condenser in the storage tank. Once heat is transferred, low temperature and high pressure $\mathrm{CO}_{2}$ exit the condenser and move back down to the collector system through the inlet header pipe. One cycle of the operation is thus completed and the system is now ready 
for the next cycle. Circulation of $\mathrm{CO}_{2}$ from the collector to the storage tank and vice-versa is affected by buoyancy forces.

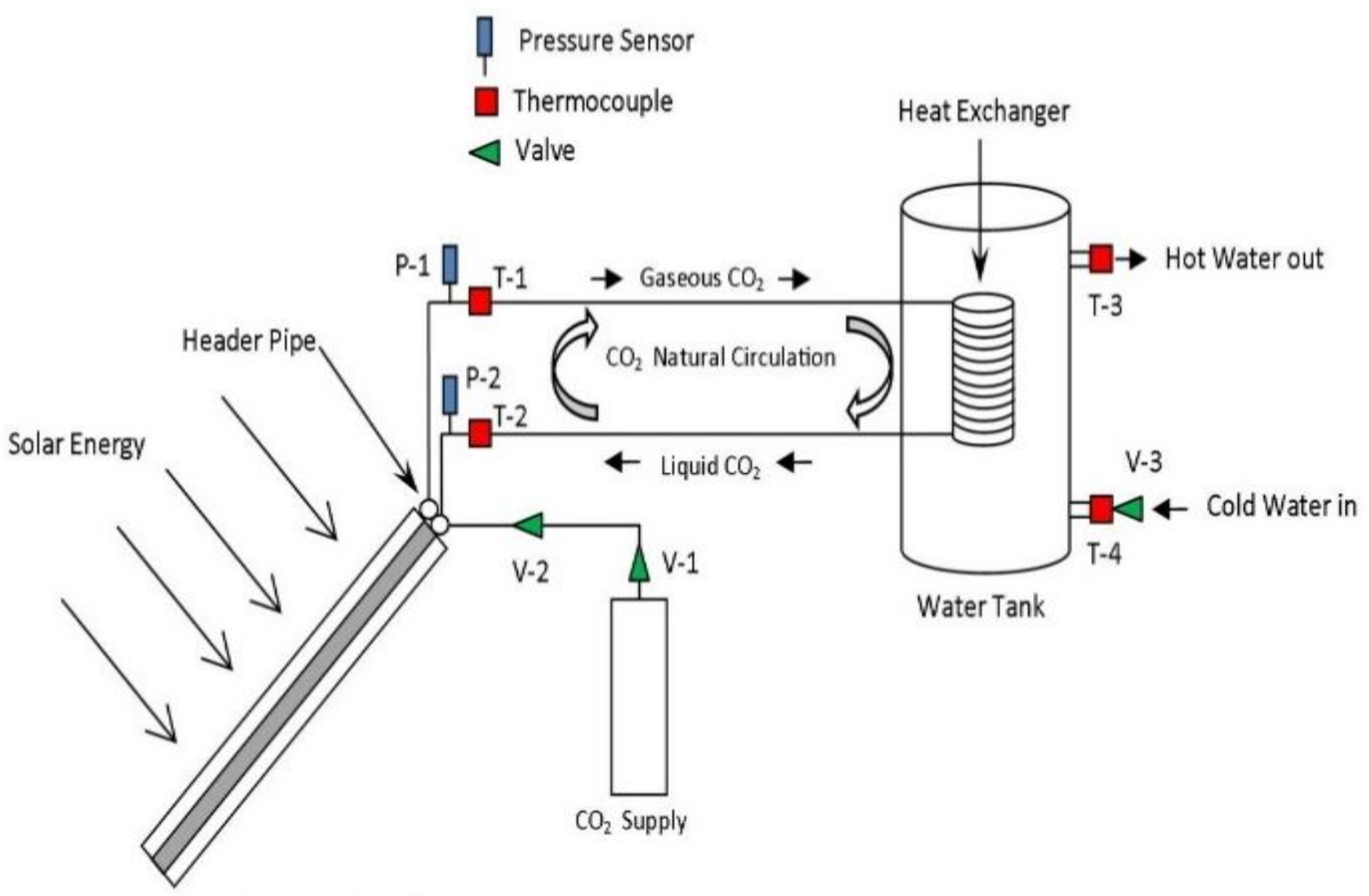

Evacuated Tube Solar Collector

Figure 1: Schematic diagram of the $\mathrm{CO}_{2}$-based thermosyphon $\mathrm{SWH}$

\subsection{Outline of the Thesis}

The thesis is presented in six chapters. Following the introduction, Chapter 2 proceeds with a review of the variety of SWH systems and technologies which are incorporated into the system being studied. Chapter 3 provides an outline of the selection of the working fluid. 
Chapters 4 and 5 give a detailed description of the system analysis and the experimental set-up, respectively. Chapters 6 highlight the important findings of this study. 


\section{LITERATURE SURVEY}

Solar water heating systems harness solar and, in some cases, are supplemented by ambient energy to heat water. The first commercial SWH, named "Climax," was patented in the US by Clarence M. Kemp in 1891 [5]. In the early 1900s, several researchers focused their attention to improving the design of the SWH systems to make them durable and efficient. SWH systems were commercialized on a wider scale in the early 1960s. In the sections below, a variety of SWH systems are reviewed and classified in terms of circulation methods and applications, with a discussion on the designs and modifications in recent years. These systems can be broadly categorized as passive solar water heating systems and active solar water heating systems.

\subsection{Passive Solar Water Heating Systems}

Passive solar water heating systems depend on heat driven convection to circulate water or heating fluid in the system (Fig. 2). These passive systems can be divided into the two main categories, integrated collector storage and thermosyphon SWH systems.

Integrated collector storage solar water heaters (ICSSWH) use a tank that acts as both a storage and solar collector apparatus. This system is also popularly known as a batch SWH system. One of the simplest designs of ICSSWH system is in which a tank is enclosed with a glass cover, so it performs as a collector, as well. However, one of the main drawbacks of this design is the heat loss, which is more pronounced at night. To reduce heat losses, effective measures such as selective absorber surface coatings, insulating materials, and additional glazed glass covers can be appropriately utilized. The first detailed study on closed and exposed single tank systems was carried out by Brooks at the University of California Agricultural Experimental 
station in the US in 1936 [6]. While the investigations showed promising potential, further research was eclipsed by the increased use of natural gas and oil in the US, but the research in solar water heating gained momentum in Japan [7].

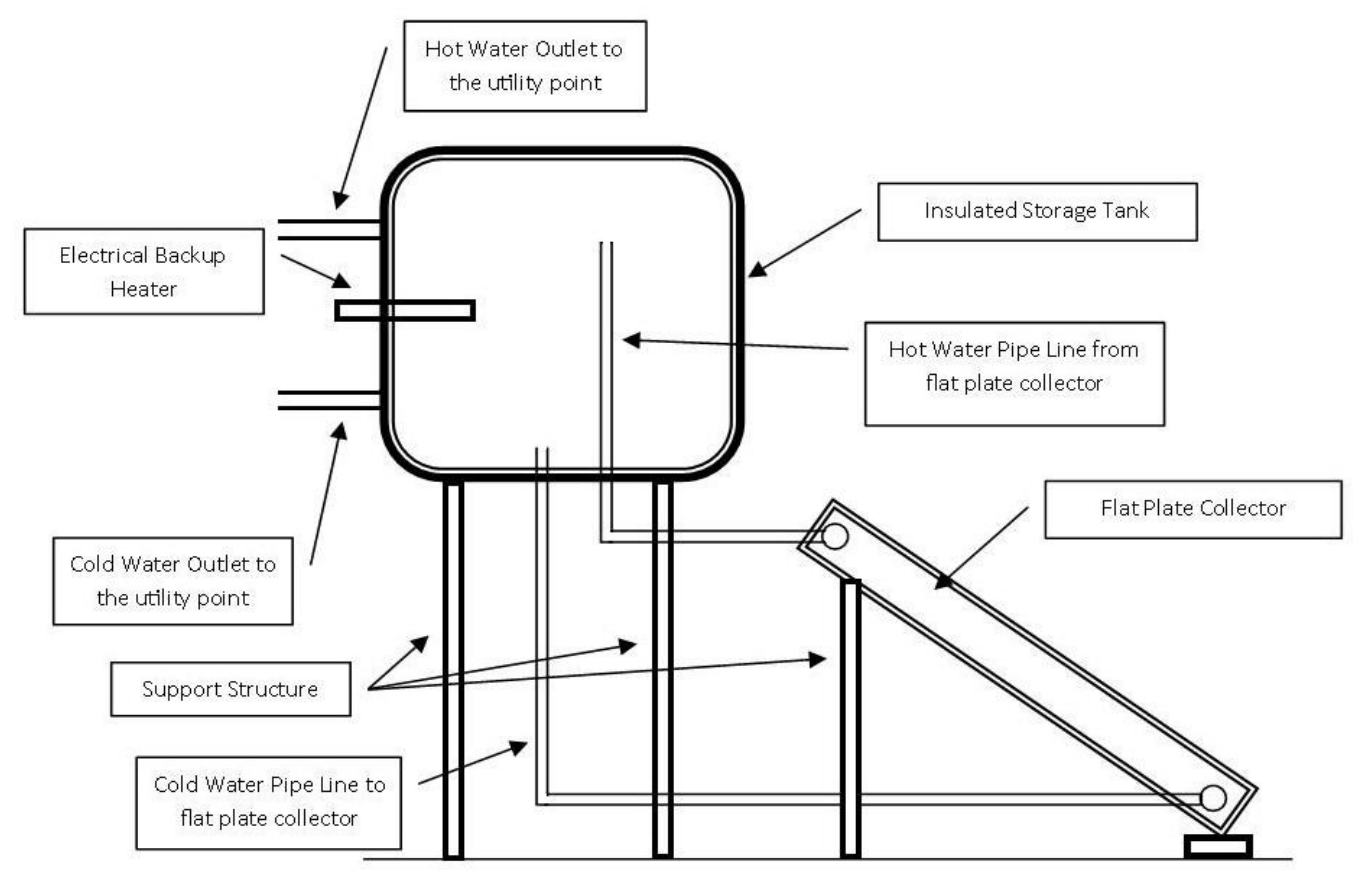

Figure 2: Domestic solar hot water heating system [6]

In the late $19^{\text {th }}$ century, batch heaters were displaced due to their pertinent heat loss issues by thermosyphon systems. This design is not only popular in developing countries that experience power issues, it is also utilized in other countries (eg: Cyprus) which have conducive climatic conditions. A simple open-loop thermosyphon system relies on the principle of density differences to effect circulation [8]. That is, the system uses natural convection flow to transport the heat transfer fluid or water from the collector to the storage tank (Fig.3). 


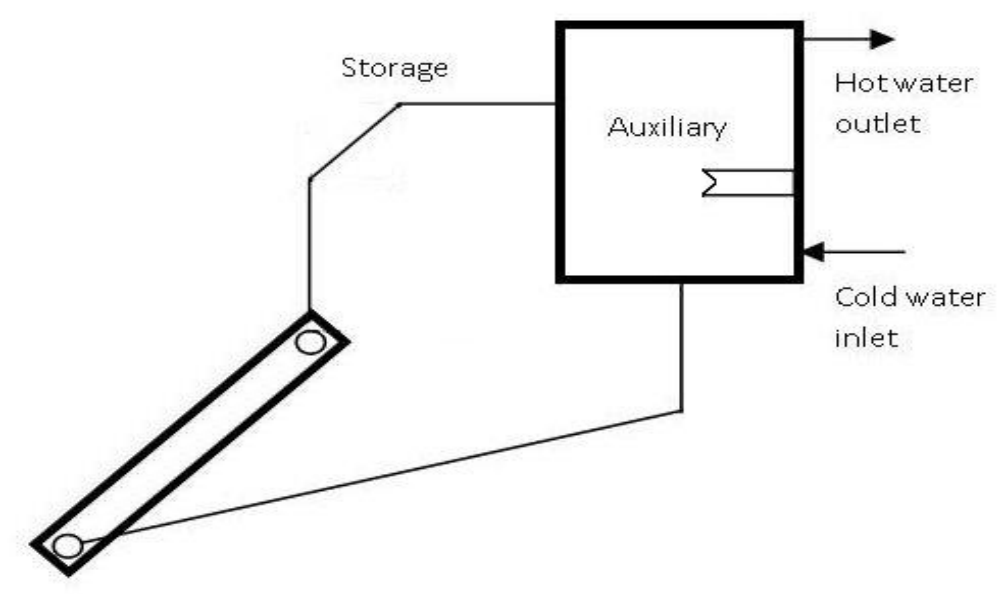

Figure 3: Schematic diagram of thermosyphon solar water heater [8]

Numerous analytical and experimental studies have been intensively carried out on the thermosyphon SWH system to analyze its performance [9-19]. Fundamental models to estimate the thermal performance of the natural circulation for SWH systems were developed to predict the heat gain in the thermosyphon-driven SWH, when subjected to no drain-off conditions. The models were validated with experimental data [9]. Yet another mathematical approach utilizing "finite-difference method" (FDM) was carried out by Ong [10] to evaluate the thermal performance of a natural-recirculation SWH system. However, the measured experimental data were contradictory to the theoretical predictions. Hence, the model was modified by taking into account the experimental conditions and used the FDM to predict the gain in the temperature at a given time step. Similarly, Sodha and Tiwari [11] used explicit expression to analyze the performance of a SWH system with natural thermosyphon circulation between the storage tank and the collector. The results confirmed that the SWH system's performance can be predicted accurately by using simple explicit equations.

To further analyze the effect of flow circulation in a thermosyphon system, Grossman et al. [12] carried out a study on a parallel plate absorber type SWH system which was subjected to 
forced or natural circulation of water between the storage tank and the absorber plate. This design offered the maximum area of contact between the fluid and the collecting surface exposed to the Sun and may therefore serve as a reference for comparison with other less efficient geometries. Haung [13] developed a more general theory for a parallel plate absorber type system with natural circulation of water between the plate and the tank by representing solar radiation as a sine function of time.

Other than investigations on conventional solar flat-plate collector, studies have been carried out on the use of heat-pipes in the evacuated tube collector to affect SWH systems. $\mathrm{Ng}$ et al. [14] developed and experimentally confirmed a theoretical model to predict the performance of an evacuated-tube heat-pipe solar collector. Performance parameters such as the collector efficiency and useful energy gain were analyzed. For a range of expected coolant temperatures, the heat loss coefficient and efficiency of the collector could be sufficiently represented by a simple linear expression. Redpath et al. [15] carried out an experimental study on a heat-pipe evacuated tube SWH system. A two dimensional particle imaging velocimetry (PIV) was used to visualize the thermosyphon fluid regime. It was concluded from the study that the overall cost of the heat-pipe evacuated tube SWH system can be reduced by using thermosyphonic flow instead of forced circulation.

One of the widely-used forms of evacuated tube collector for thermosyphon systems is the water-in-glass tube design because of its high thermal efficiency. Budihardjo and Morrison [16] carried out thorough simulation studies on the said design to analyze the optical and heat loss characteristics of a single-ended tube. The study concluded that the system's performance was less dependent on tank size compared to the commonly used flat-plate collector system; 
however, the system has a limitation as it can be used only in low ambient conditions due to its limited tolerance for high pressure.

A flat-plate collector integrated with a mantle heat exchanger was attempted by Haung et al. [17], to show its applicability of inherent freeze protection. It was observed that the mean daily efficiency of the SWH system using a mantle heat exchanger was up to $50 \%$. While this is lower than the efficiency of a thermosyphon flat-plate system without a heat exchanger, it is higher than the all-glass evacuated tube SWH system.

To further improve the collector design, Jaisanker et al. [18] in 2009 used a collector with twisted tape inserts to effect higher heat transfer rates. Both the heat transfer and the friction factor characteristics were analyzed based on the experimental data to study the effect of a spacer being incorporated along with the helical insert. It was found that the inclusion of a spacer decreased the heat transfer (Nusselt number) and the frictional factor by about $11 \%$ and $19 \%$ respectively [19].

\subsection{Active Solar Water Heating Systems}

Unlike passive systems, active systems use one or more pumps to circulate the working fluid in the system. Active systems can be categorized into direct circulation and indirect water heating systems. In the direct or open-loop systems, water from the storage tank is directly circulated to the collector to be heated by solar energy, whereas in the indirect active system the heat transfer fluid is circulated through the collector and rejects heat through a heat exchanger to the water in the storage tank [7].

Direct systems are simple in operation (Fig.4.), but they are sensitive to freezing conditions and could provide hot water of moderate temperature $\left(\sim 50-60{ }^{\circ} \mathrm{C}\right)$ [8]. To overcome 
the freezing issues, some design modifications have been adopted. One such modification is to operate the direct circulation system in drain-back mode, in which a differential controllerintegrated pump is used to circulate water from the storage tank to the solar collectors [7]. While there are numerous research papers related to the direct mode of SWH systems, some of the more recent investigations are discussed here.

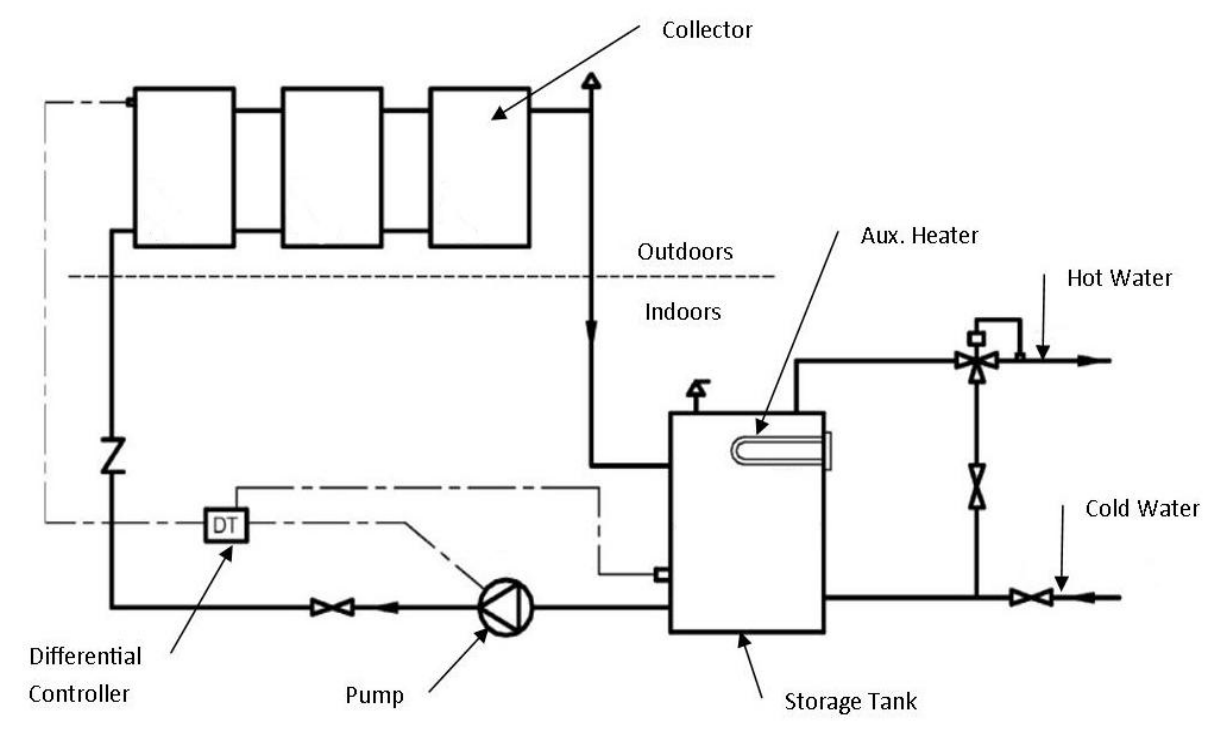

Figure 4: Direct circulation system [8]

More recently, vacuum tube collectors have been used for domestic water heating purposes and it has been observed that the performance of vacuum tube collectors are much higher than flat-plate collector because of low convection heat losses from the absorber. A heat transfer model to evaluate the performance of all-glass vacuum tube collectors incorporated in a direct circulation system was developed by Li et al. [20]. This simplified model takes into account of natural circulation in single glass tube as well as forced flow circulation in the manifold header. Flow equations were obtained by analyzing the friction losses and buoyancy 
forces inside the tube. A good agreement was observed between the predicted and computed collector outlet temperatures, and the deviation was within $5 \%$.

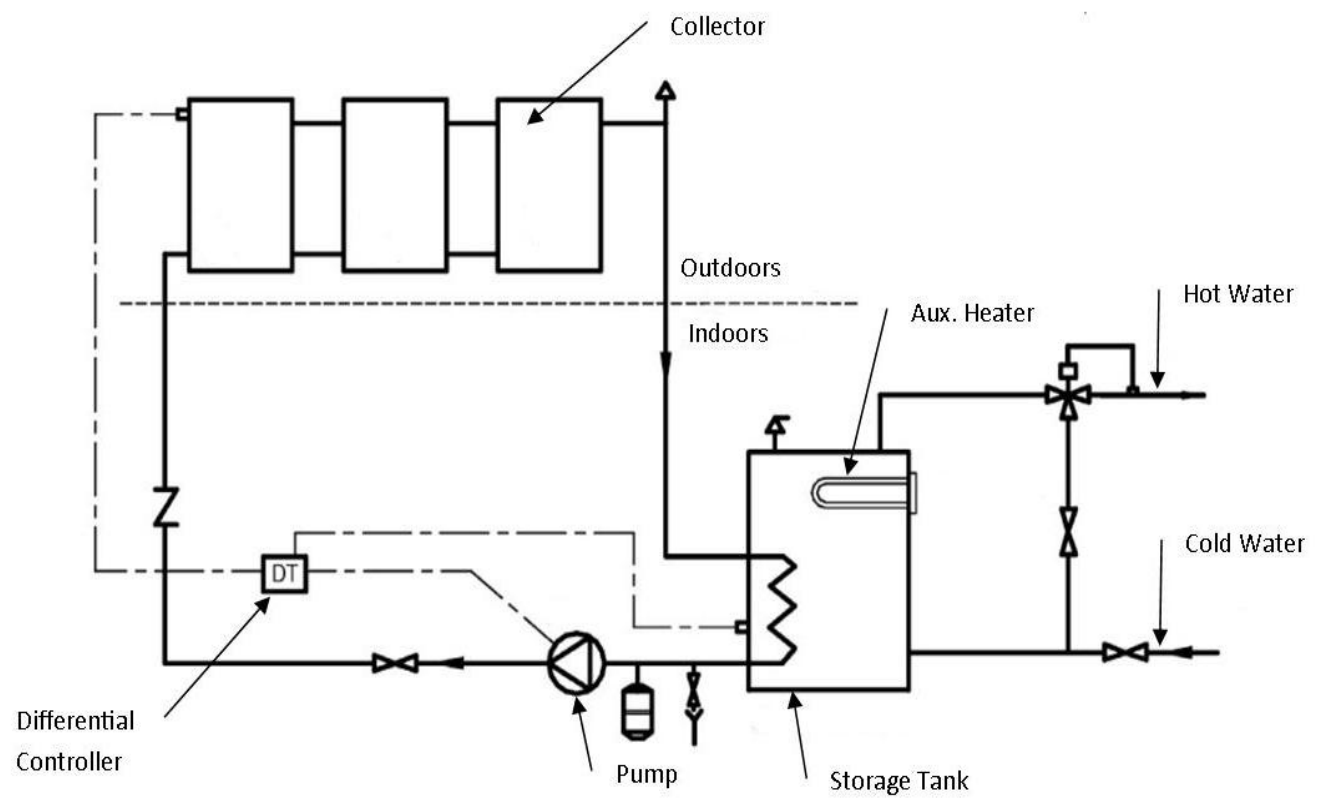

Figure 5: Indirect water heating system [8]

Apart from the above discussed collector types, a relatively new V-trough SWH system is also now commercially available. Chong et al. [21] researched a cost-effective new V-trough SWH system that employed direct circulation. It was observed that the thermal performance of SWH could substantially improve by integrating solar absorber with a V-shaped trough reflector. The system was tested with and without glazing and different insulating materials. It was reported that the prototype could achieve an optical efficiency of $71 \%$ with a maximum outlet water temperature of $82^{\circ} \mathrm{C}$ and $67^{\circ} \mathrm{C}$ with and without insulation, respectively.

In general, direct heating systems are commonly employed in regions with ample sunshine and experience moderate ambient conditions. For regions with less sunshine hours and low ambient conditions, indirect water heating systems are employed (Fig.5). These systems are 
reliable in operation and ensure effective freezing protection [8]. Heat transfer fluid (HTF), such as ethylene glycol and other refrigerants is circulated between the collector and the storage tank through the heat exchanger. Indirect SWH systems operate on a heat pumps (HP) mode, to supplement the solar energy gain in the collector. These HP based SWH systems have shown several design improvements during last 20 years. The hot water is generated utilizing waste heat or other low temperature sources, in which an exclusive working fluid is circulated in the collector and the heat gain is rejected through a heat exchanger to the storage-water. The solar assisted heat pump is a commonly used type; however one of the challenges is that its performance is very low when the ambient temperature is low. There exists numerous studies [22-27] related to the indirect mode of SWH systems to improve its performance, and some of the recent research is discussed.

A variable capacity direct expansion solar-assisted HP system (DX-SAHPS) for water heating purposes was tested by Chaturvedi et al. [22]. A bare solar collector acting as an evaporator was used for the heat pump system. The system was tested for the widely varying ambient conditions, and accordingly, the compressor speed was varied through a variable frequency drive. The observational results showed that the coefficient of performance (COP) of the system can be enhanced extensively by lowering the speed of the compressor when the ambient temperatures were higher. Hence, such systems perform better in summer compared to winter.

Yet another design of DX-SAHPS was proposed by Kuang et al. [23], in which a $2 \mathrm{~m}^{2}$ bare flat-plate collector acted as a source as well as an evaporator for the refrigerant (Fig. 4). From the simulation model it was concluded that the monthly average COP varied between 4 and 6, and the collector efficiency was about 40-60\% [23]. Similar to this work, Li et al. [24] 
presented another experimental study on the DX-SAHP. The results showed that the proposed system can attain a COP of 6.61 on a clear sunny day $\left(\mathrm{T}_{\mathrm{a}}=17.1^{\circ} \mathrm{C}, \mathrm{I}=955 \mathrm{~W} / \mathrm{m}^{2}\right)$. Even during cloudy and rainy nights, the system could perform moderately with a COP of 3.11 .

An integral-type solar assisted heat pump water heating system (ISAHP) was studied by Chyng et al. [25]. Experiments were conducted for over a year to record the annual performance. Simulations were performed based on the assumption that all the components are at steady-state except for the storage tank. The model agreed well with the experimental data and the predicted results were within $10 \%$ of the measured data. It was observed that the daily total COP for the system was about 1.7-2.5.

Apart from heat pumps, heat pipes were also introduced to further enhance the system's performance. A heat-pipe water heater was fabricated and tested/modeled by Huang et al. [26]. The performance of the combined solar heat pipe collector and conventional HP were examined to calculate the overall COP of the system. When solar radiation was low, the system operated in HP mode. However, during clear sunny days, the heat-pipe mode operated independently of electrical energy input, for higher thermal efficiency. The results showed that the COP of the hybrid-mode of operation could attain as high as 3.32, and as such its performance was higher by about $28.7 \%$ compared to the HP mode of operation.

Guoying et al. [27], worked on an air-source assisted solar HP system to effect water heating. This system employed a specially designed flat-plate collector provided with spiralfinned tubes (which also act as an evaporator), to harness energy from ambient air as well as solar radiation. From the simulated results it was observed that a SAS-HPWH could efficiently heat the water to $55^{\circ} \mathrm{C}$, under varying weather conditions. 


\subsection{Component Designs}

The main components of SWH system, such as the collector, heat exchanger, and storage tank, have been improved over the years. Also, different working fluids have been attempted by several researchers to improve the system efficiency as well as make the system functional under different operating conditions. Significant studies on the design modifications are reported below in the respective subsections.

\subsubsection{Solar Collectors}

A solar collector is a heat exchanger that converts solar energy to useful heat which is transferred to the fluid flowing through the collector. It was first developed by Hottel and Whiller in 1950 [28]. The design parameters such as efficiency factor $\left(F^{\prime}\right)$ and heat removal factor $\left(F_{R}\right)$ were developed, which significantly reduced the empiricism associated in the design

of a solar collector [29]. The efficiency of a SWH system depends mainly on the effectiveness of the flat-plate collector, and thus most research has been concentrated in improving the performance of the collector; specifically the absorber plate design and glazing material

\subsubsection{Flat Plate Collector}

A flat-plate collector (FPC) is the heart of a SWH system and it is commonly used for harvesting solar thermal energy at low ambient temperatures (Fig. 6). It consists of the following components: a selectively coated a flat-plate absorber plate, a transparent cover to reduce top heat-losses from the absorber plate, heat-transport fluid (HTF) to remove heat from the absorber plate, tubes/passages for the flow of the HTF, a heat insulating support to reduce heat loss from the collector, and a protective casing to ensure the components are free from dust and moisture [14]. 


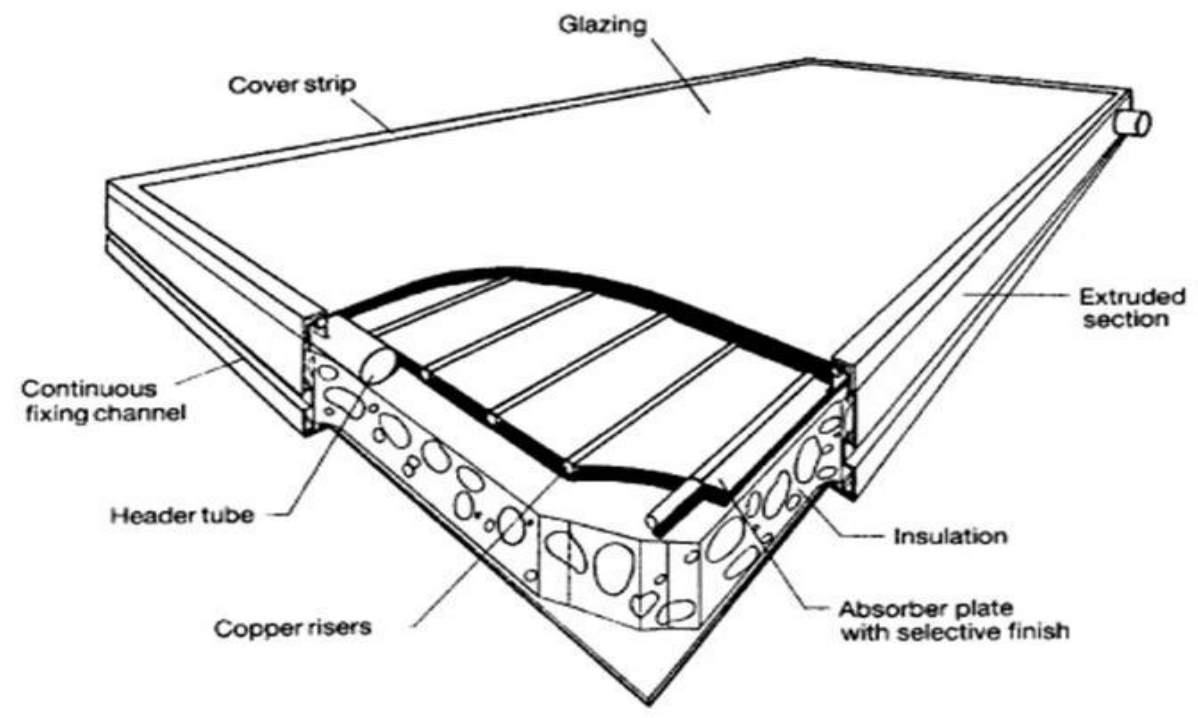

Figure 6: Pictorial view of a flat-plate collector [30]

Several researchers have worked on the design and development of FPC. Matrawy and Farkas reported that the configuration of the collector plays an important role in dictating its thermal performance [31]. The parallel-tube collector design is one of the most commonly used configurations, in which tubes (risers) are integrated to the absorber plate, forming an integral part of the plate structure. Hottel and Whiller [29] were the first to analyze the thermal performance of parallel tube collectors. The thermal analysis comprised of a simple two-step procedure where the heat conduction from the plate to the flow duct was evaluated based on the fin efficiency factor and the transportation of heat to the fluid in the duct was predicted based on the heat removal factor [32,33]. Some of the disadvantages of this design were: non-uniform temperature distribution over the absorbed plate surface, unequal distribution of the working fluid through the collector risers, and the increase in the collector's heat loss caused by the higher temperature of the absorber plate in low flow rate conditions. To overcome these issues a serpentine tube collector was introduced. This design was typically used to compensate low flow 
rate conditions; the design enables the total mass flow rate to pass through the tube, increasing the heat transfer coefficient [31]. In an attempt to further improve the thermal performance of a parallel-tube collector, two parallel tube collectors were connected in parallel and this system was compared to a serpentine tube collector having an equivalent exposed area [31]. It was found that the efficiency was about $6 \%$ more than a serpentine tube collector and $10 \%$ more than a single parallel tube collector, under similar ambient conditions.

Other geometric designs [34, 35] include a fin-and-tube collector, in which fluid is circulated through a corrugated channel which is in direct contact with the absorbing surface. It was found that the serpentine geometry showed better thermal performance than the parallel one.

In 2006, yet another new design [36] was proposed by Rittidech and Wannapakne (Fig. 7). A flat-plate solar collector operating in conjugation with a closed-end oscillating heat pipe (CEOHP) was investigated. The collector system using a CEOHP offers a reasonably efficient and cost-effective alternative method compared to the conventional solar collector system that utilizes heat pipe. This cost effective collector system could attain a $62 \%$ efficiency which is comparable to the performance of a heat pipe.

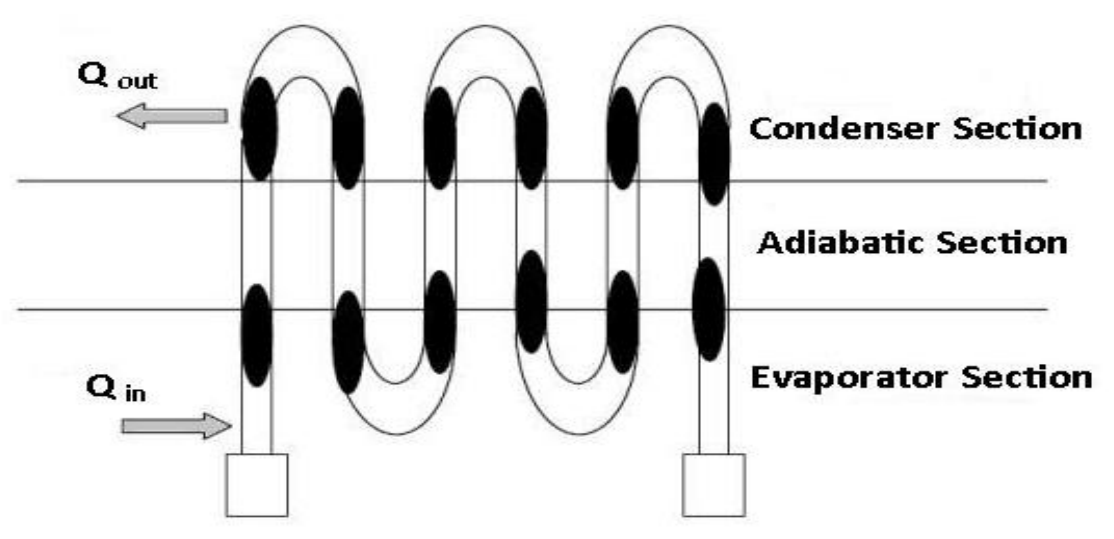

Figure 7: Closed-end oscillating heat pipe [36] 
The core component of the flat-plate collector is the absorber plate, and its thermal performance depends on the material properties as well as on the design parameters. Numerous absorbing plate designs have been proposed in recent years [37-39]. Among different absorber plate profiles, parabolic shape is one of the most efficient, since heat output per unit volume is higher than other geometries [37]. Holland and Stedman [38] introduced a rectangular profile with a step-change in local thickness. A thermal analysis was carried out to optimize the absorber plate fin, and reported that to maximize energy transfer the fin area should be increased for the given volume of the fin $\left(\mathrm{m}^{2} / \mathrm{m}^{3}\right)$. Instead of a rectangular fin design, Kundu [39] introduced a new recto-trapezoidal (RT) shaped fin. Simulation results confirmed that the RT profile absorber plate fin was superior to other profiles such as rectangular, triangular, or trapezoidal, with respect to heat transfer rate per unit volume.

Metal absorbers are more prone to corrosion; hence, to maintain performance, an absorber must be resistant to both internal and external corrosion. The use of polymer-based absorbers has increased because they are non-corrosive, light weight, cheaper, and easier to fabricate. Recent advances in polymer technology have resulted in the development of suitable materials which can withstand long exposure to sunlight, such as ethylene propylene diene monomer (EPDM) [40]. In 2002, Sopian et al. [41] experimentally studied the thermal performance of flat-plate solar collector with a thermoplastic natural rubber tubing (TPNR) for the absorber plate. A commercial blend of TPNR was used for the parallel-type absorber plate. The experimental results confirmed that this natural rubber can be used as an alternative to other materials.

In Europe, new polymer flat-plate collectors have been introduced to replace metal collectors. Polymers collectors are flexible and tolerant to expansion during freezing; therefore 
they polymer tubes tend to contain plain water without the need for antifreeze. As such these collectors can be directly connected to the storage tank, instead of using heat exchangers that lower the thermal efficiency of the system. Use of polymeric components has also reduced the fabrication cost, when compared to metal components [28]. Liu et al. [42] presented that the cost of a conventionally-designed nylon solar absorber was roughly $80 \%$ of the cost of a similar copper unit.

Though polymer collectors are corrosion resistant, they do have several limitations such as low thermal conductivity and can be used only for moderate temperature applications. To overcome these limitations, to a certain extent, an extruded parallel plate absorber design has been proposed [43]. It is one of the most promising designs, which comprises of a pair of parallel plates, with water flowing between the two plates. The gap between the plates can be varied from a few millimeters to a few centimeters, according to the design parameters. Tsilingiris [43] evaluated the performance of a similar parallel polymer plate collector. This design facilitates the absorption of radiation at the back polymer plate in the flowing water stream, which helps to eliminate the adverse effects of the top absorbing plate conductance and results in improved collector efficiency. Results had indicated that the collector efficiency factor for a backabsorbing plate absorber was $20 \%$ higher and the collector loss coefficient was reduced by about $15 \%$ compared to a top-absorbing plate collector.

Collectors' efficiency can be further improved by incorporating appropriate transparent insulation materials. Glazing is generally used to reduce the top heat losses from the panel to the environment by convection and radiation and to ensure higher thermal performance [44]. Whereas unglazed flat-plate collectors are not as common as solar collectors with glazing [33]. One of the widely-used glazing materials in solar collectors is glass, which is low in cost and has 
a solar transmittance up to $90 \%$ [8]. By applying an anti-reflected coating, the solar transmittance of glass can be increased, resulting in improved efficiency [45]. Use of multiple glass layers can also help in reducing heat loss, creating air gaps that act as insulation [46]. Another type of glazing material is plastic, available as thin films or sheets, having shortwave and long wave transmittance as high as 0.40 [8]. Literature shows that in recent years, polymeric materials are also used as upper glazing in solar collectors [47].

\subsubsection{Evacuated Tube Collector}

Evacuated tube collectors (ETC) have been commercially available for more than 20 years. Though they have better performance in producing high temperatures when compared to flat-plate collectors, they are not competitive because of high initial costs. ETC consists of: evacuated tubes (glass-glass seal) to minimize heat losses, copper heat pipes for rapid heat transfer, and aluminum casing to provide durability and structural integrity to the system (Fig. 8) [48]. ETC minimizes the heat losses due to convection and radiation [49].

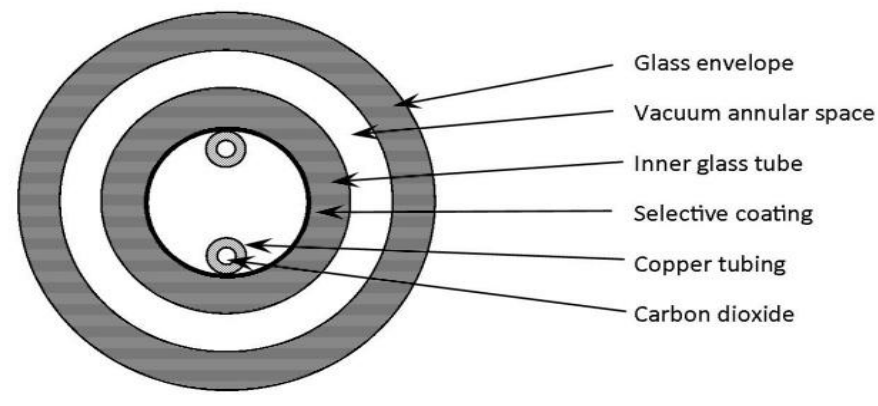

Figure 8: Cross-sectional view of the ETC [56]

At present, glass ETC have become a key component in solar thermal utilization, as they can have high heat extraction efficiencies and considerably less heat loss issues compared to flat- 
plate solar collectors. One of the important design factors for the glass ETC is the shape of absorber tube [50].

Recently, Kim and Seo [50] introduced a few efficient designs of the absorber tube and investigated the performance of the four different shapes of absorber tubes. The absorber tubes investigated were: finned tube, an U-tube welded inside a circular fin, an U-tube welded on a copper plate, and an U-tube welded inside a rectangular duct. The results indicated that U-tube welded inside a circular fin gave the best performance among the four different collectors.

Shah and Furbo [51] introduced yet another absorber tube design. A parallel-connected evacuated double glass tube collector design using a tubular absorber was found to absorb incident radiation from all directions. The experimental and numerical studies on the tubular collector design confirmed that the design is very promising especially in higher latitudes. However, one of the major problems of all-glass ETC designs is the heat extraction through the long, narrow, single-ended absorber tube. Over the years, different designs of ETC have been reported in several research papers $[52,53]$. Two basic ETC designs are the simple fluid-in-glass and fluid-in-metal designs. The fluid-in-metal design can be further classified into heat pipe ETC and U-tube ETC. Heat pipe ETC and U-tube glass ETC are the two most widely-used solar collectors in domestic water heating. Research on the different designs of ETC has focused on the enhancement of the solar collector's performance. Details on some of the recent studies on heat pipe ETC are discussed below.

In 2009, Rittidech et al. [54] constructed a simple closed-loop, oscillating, heat-pipe ETC to overcome issues concerning corrosion and icing (during winter). The system attained a comparable efficiency of about $76 \%$. For a heat-pipe, a vacuum environment is essential to attain high thermal frequency [53]. However, there exist several issues in providing perfect 
vacuum conditions since the non-condensable gases, released during the operation, remain in the heat-pipe and affect its performance. Hence, there exists a limitation for the usage of heat-pipe ETC systems.

Apart from ETC heat-pipes, U-tube glass ETC are also commonly used collectors. In contrast to the all-glass evacuated tube and the heat-pipe ETC, the U-tube ETC has a simple structure and is also tolerant to high pressure. Diaz [55] introduced a novel design of a minichannel-based ETC which was found to improve thermal efficiency at the expense of power consumption. The collector design consisted of a U-shaped flat-plate selectively coated absorber provided with fins to enhance heat transfer area between tube walls and the working fluid. The study showed that the mini-channel tube collector attained better efficiency compared to the standard U-tube collector. Similar to Diaz's work, Ma et al. [56] investigated the thermal performance of a double-layered glass ETC. The heat efficiency factor and heat loss coefficient were examined using a one-dimensional analytical solution. The study reported the influence of an air layer on the heat efficiency and an increase of $10 \%$ was noticed when the air layer thickness was increased such that its resistivity was at $40 \mathrm{~W} / \mathrm{m} \mathrm{K}$. It was also noticed that when the synthetical conductance was increased from 5 to $40 \mathrm{~W} / \mathrm{m} \mathrm{K}$, solar collector efficiency increased by $10 \%$ and the fluid outlet temperature increased by $16 \%$. In 2010, Ma et al [53] extended their work to study the effectiveness of filled-type ETC of a U-tube design. Different filler materials like air and graphite were attempted. Results had shown that the thermal performance of the filled-type ETC were similar, if the thermal conductivity of the filled layer was around $10 \mathrm{~W} / \mathrm{m} \mathrm{K}$, whereas the performance increased by $12 \%$ if the filler material (graphite) thermal conductivity was around $100 \mathrm{~W} / \mathrm{m} \mathrm{K}$. 


\subsubsection{Compound Parabolic Collector}

Flat-plate collectors and evacuated tube collectors are widely used in solar thermal applications, mainly to provide low to intermediate temperatures $\left(20^{\circ} \mathrm{C}\right.$ to $\left.120^{\circ} \mathrm{C}\right)$. However, to attain temperatures above this range, concentrators and reflectors have to be employed to maximize the incident radiation to affect high temperatures. Compound parabolic concentrators (CPC) solar collectors are non-imaging concentrators, having the ability to reflect most of the incident radiation to the absorber. The schematic diagram of the most common type, Winston's CPC, is shown in Fig. 9, in which the lower sections of the reflector are circular (BA and BC), and the upper sections (AE and $\mathrm{CD}$ ) are parabolic [8].

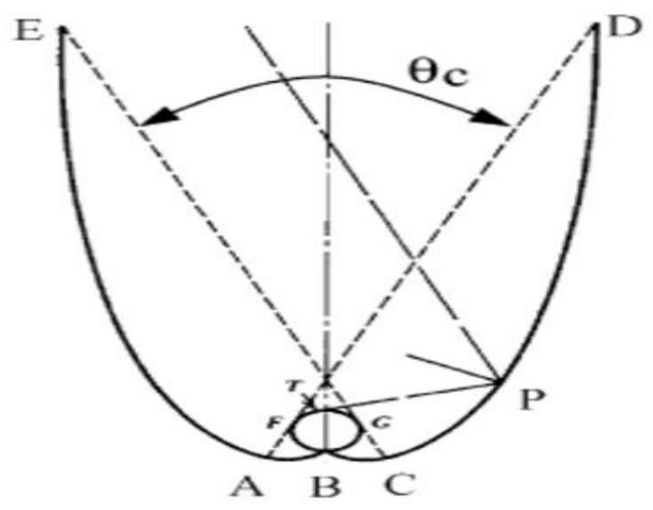

Figure 9: Schematic diagram of the CPC [8]

\subsubsection{Storage Tank}

The storage tank is an important component of the SWH system which plays a major role in dictating the system performance. A storage tank is commonly used to store the collected solar thermal energy providing the required hot water at the preferred temperature to the end uses [67]. Storage tanks are generally constructed using steel, concrete, plastic, fiber glass or other 
suitable materials used to store hot water. Among all the types mentioned, steel tanks are most commonly employed since they are easy to install.

One of the main problems experienced with the storage tank is heat losses due to the mixing of hot and cold water. To minimize the mixing and aid thermal stratification, several designs of storage tanks have been proposed. Stratification is essential to minimize the mixing and thereby affects the harvesting of maximum energy from the collector [68]. To evaluate the performance of stratified storage tanks, several experimental and theoretical studies were conducted for different geometrical designs and operational conditions [69-78]. Geometrical factors include different orientations such as horizontal or vertical tanks, thickness of the wall, tank height to diameter ratio, and material of the tank. Operational factors include the temperature difference between inlet and outlet fluid stored in the tank, climatic conditions and the flow rate at the inlet and the outlet of the tank [69-70].

\subsubsection{Heat Exchanger}

In an indirect type of SWH system, a heat exchanger $(\mathrm{HX})$ is utilized to transfer absorbed solar heat from the working fluid to the storage tank. The HXs are generally made from conductive material such as aluminum, stainless steel, cast iron, copper, steel, and bronze. To ensure good thermal conductivity and resistance to corrosion, copper is popularly used in SWH system. Several configurations of HXs have been designed for indirect water heating storage tanks and the most common configurations are: the immersed coil-in-tank, the shell-and-tube, and the mantle heat exchanger [72]. Several configurations of HXs have been proposed to improve the overall performance of the SWH system [79-90]. 


\subsubsection{Heat Transfer fluid}

Heat transfer fluid (HTF) plays a very significant role in a solar collector system. In a SWH system, HTF absorbs energy in the collector and transmits the energy through the heat exchanger to the water in the storage tank. Some of the common HTFs used are air, water, hydrocarbon oils, Glycol/water mixture, and refrigerants/phase-change liquids [91, 92].

Air and water have been commonly used as HTFs in SWH systems. Air has certain advantages compared to water such as being non-corrosive nature and has no issues such as boiling/freezing. However, it's very low heat capacity enforces limitation to low temperature applications and not used for domestic water heating purposes. On the other hand, water's high specific heat, low viscosity, non-toxic, and less expensive features have positioned water to be the most popular working fluid in SWH systems. However, its corrosive nature (especially at high temperatures) as well as freezing and scaling issues poses a challenge in collector tubing and plumbing. To overcome relatively high freezing point of water, a glycol additive is used along with water to act as an antifreeze [92].

Refrigerants are generally used as HTFs in heat pumps, refrigerators, and air conditioners. The use of refrigerant-filled solar collectors in a heat pump system is one of the important developments in the heat pump and solar technology. Refrigerants are more effective than other fluids especially during cloudy conditions because of their low boiling points, and high heat capacities. Several research projects have been conducted to study the effectiveness in operating the SWH system involving 2-phase heat transfer process. The fundamental thermal performance of two thermosyphon solar collectors, charged with acetone, and petroleum-ether, was studied by Soin et al. [93, 94]. It was reported that the efficiency of a two-phase collector 
was only about $6 \%$ to $11 \%$ which is considerably lower compared to a direct thermosyphon SWH system.

In indirect (closed-loop) SWH systems, chlorofluorocarbon (CFC) refrigerants are more commonly used as HTFs for their stability, nonflammable, and noncorrosive properties, low toxicity and low freezing point. Specific examples include: R-11, R-12, R-13, R-113, R-114, and $\mathrm{R}-115$.

Schreyer [95] investigated the effectiveness of R-11 refrigerant in the thermosyphon collector for domestic applications. Experimental results proved that the peak instantaneous efficiency for a two-phase refrigerant was higher than using the hydronic fluid. Similar work was carried out by Farrington et al. [96] for a single-family residence; the SWH system when operated based on forced circulations, could realize an efficiency of about 35\%. Joudi and AlTabbakh [97] also confirmed that the collector efficiency of two-phase system was about $20 \%$ higher than a single phase collector. The system could attain instantaneous efficiency as high as $60 \%$, which was in the range of conventional solar water collectors [98]. To further analyze the R-11 driven SWH system, Fanny and Terlizzi [99] had developed correlations to predict the heat transfer by R-11 and were validated with experimental data.

One of the disadvantages of refrigerants being used for closed-loop systems is their low efficiency compared to the conventional open-loop systems [100]. However, it is possible to increase the efficiency of the SWH systems by charging the collector to the fullest ensuring the fluid levels in the inlet of the tubes to be nearly the same as the outlet [101]. Radhwan and Zaki [95] depicted the thermal non-equilibrium vapor generation process with fully R-11 refrigerant filled collector tubes and showed the dependency of the thermophysical properties (temperature, pressure) of the refrigerant on the circulation flow rate while in phase change. 
CFCs are harmful to the global environment due to their chlorine content, chemical stability, and they have both ozone depletion potential (ODP) and Global Warming Potential (GWP). Thus, the use of CFCs was phased out and hydrochlorofluorocarbons (HCFC) were introduced [125]. These HCFC also contain chlorine but have much lower ODP and GWP than CFCs, typically $2-5 \%$ and $20 \%$, respectively, in comparison to CFC-12. Examples of HCFC refrigerants include R-22, R-401, R-402, R-403, R-408, etc. [102].

HCFCs and hydroflurocarbon (HFC) heat transfer fluids were also tested for their effectiveness on the SWH system performance. Some of the significant studies are mentioned in this section. Payakaruk et al. [103] investigated refrigerants, such as R-22, R-123, R134a, ethanol, and water at different filling ratios of $50 \%, 80 \%$, as well as $100 \%$ and reported their influence on the thermal efficiency of the system. It was reported that the heat transfer characteristics of the system depend on the latent heat of vaporization of the HTF; that is, the lower the latent heat of vaporization the higher the heat transfer rate.

Esen and Esen [98] also studied the thermal performance of a closed two-phase thermosyphon heat pipe based solar collector using the refrigerants R-134a, R-407C, and R410A. Results showed that the performance of each of the refrigerants were similar with a maximum collection efficiency of around 50\%, which was much higher compared to R-22. This may be due to the fact that, these refrigerants posses properties of high thermal conductivity, latent heat as well as low viscosity, which are conducive in effecting improved COP.

Yet another comparative study was performed by Kim [104] who tested R-22 and four other alternative fluids such as a R-134a, R-32/134a (30/70\%), R-407C and R-410A. The study was conducted in an experimental breadboard water-to-water heat pump in which a 
water/ethylene glycol mixture was used as a heat transfer fluid. R-410A was found to have the highest COP, provided the thermal capacities were maintained the same.

HCFCs and HFCs are considered to be short-term HTFs. Recently; natural fluids have been considered as long-term HTF and have successfully replaced the HCFC and HFC refrigerants, which are still harmful to the environment. Long-term HTF are halogen-free natural working fluids. They are environmentally benign because of their very low or near zero ODP and GWP [105]. Some of the common examples of natural HTFs are propane (R-290), butane (R600), iso-butane (R-600a), propylene (R-600), ammonia (R-717) and carbon dioxide (R-744) [102].

Natural working fluids are good substitutes for R-22 and researchers have proved this through various studies. Theoretical performance calculations for three refrigerants such as R-12, R-22, and propane for low and medium ranges of evaporating temperatures were compared by Charters et al. [106]. The three refrigerants showed that their COPs were the same at low evaporating temperatures $\left(-20^{\circ} \mathrm{C}\right.$ to $\left.-10^{\circ} \mathrm{C}\right)$, whereas at medium evaporating temperatures $\left(0^{\circ} \mathrm{C}\right.$ to $\left.-10^{\circ} \mathrm{C}\right), \mathrm{R}-12$ was found to have the highest COP. Further, Urma [107] conducted an experimental study and confirmed that it was feasible to use propane as a drop-in substitution for R-12 in small domestic refrigeration units. Another comparative study was conducted by Stoecker [108] where R-717 was compared with other refrigerants such as R-22, R-123, and R134a and confirmed that R-717 is a viable candidate as a refrigerant for district cooling plant water chiller.

Another promising natural fluid is carbon dioxide $\left(\mathrm{CO}_{2}\right)$ as it is non-flammable, noncorrosive, and non-toxic to the environment. $\mathrm{CO}_{2}$ can be used as a refrigerant in a transcritical heat pump cycle as is has a low critical point $\left(31.1^{\circ} \mathrm{C}\right.$ at 73.7 bars $)$ [109]. Research on $\mathrm{CO}_{2}$ has 
gained momentum in recent years and the main objective is to investigate the possibility of applying $\mathrm{CO}_{2}$ to heat pump SWH systems and also to investigate the performance of a transcritical $\mathrm{CO}_{2}$ heat pump. Neska et al. [110] recognized that heating tap water is one of the promising applications for a transcritical $\mathrm{CO}_{2}$ system. A $\mathrm{CO}_{2}$ heat pump water heater may produce hot water temperature up to $90^{\circ} \mathrm{C}$ without any operational problems and the primary energy consumption can be reduced by more than $75 \%$ compared to electrical systems.

Further, the performance of a water-source transcritical $\mathrm{CO}_{2}$ heat pump for water heating was examined by White et al. [111]. The theoretical analysis showed that it was possible to produce hot water at temperature around $120^{\circ} \mathrm{C}$ with $\mathrm{COP}$ of about $21 \%$. Cecchinato et al. [112], also carried out a similar study on $\mathrm{CO}_{2}$ and reported that the transcritical cycle was efficient only if its characteristics were exploited through a suitable design.

The performance of transcritical $\mathrm{CO}_{2}$ cycle with an internal heat exchanger was further investigated by Kim et al. [113]. The study relayed that optimum discharge pressures to affect maximum COP for a given internal HX length. However, the optimum pressure values decreased, if the length of the HX was increased. Also, it impacted the flow rate and compressor power to lower values. In addition to the both above observation, it was also noticed that with an increase in the HX length, though COP was enhanced, the heating capacity had decreased marginally due to the trade-off between the effectiveness and pressure drop in the internal HX.

Yet another simulation study on an air-source heat pump water heater using $\mathrm{CO}_{2}$ as $\mathrm{HTF}$ was conducted by Laipradit et al. [114]. The effects of compressor speed, the temperature of inlet water at the gas cooler and the mass flow rate ratio of water and $\mathrm{CO}_{2}$ on an air source heat pump were analyzed. The temperature of water was between $55^{\circ} \mathrm{C}$ and $75^{\circ} \mathrm{C}$ for the system investigated which had a $4 \mathrm{~kW}$ compressor. For, hot water with a high temperature, higher compressor speed 
and higher compression work were required, which led to lower COP. The study concluded that, a decrease in the inlet water temperature and an increase in the air temperature would increase the COP. It was recommended that a suitable flow rate ratio of water and refrigerant should be used to obtain high COP level at the required hot water temperature.

The potential of the supercritical $\mathrm{CO}_{2}$-based collector in the field of solar thermal utilization was further studied by Zhang and Yamaguchi [115]. The experimental data showed that the temperature, pressure and mass flow rate of $\mathrm{CO}_{2}$ increased with solar radiation. The study also showed that its performance, when operated in transcritical condition was much higher compared to the water-based collector.

From the literature review, several observations have been made: (i) $\mathrm{CO}_{2}$ is a refrigerant with low environmental impact (ii) evacuated tube collector have more efficiency compared to flat plate solar collector, mainly in colder regions, (iii) technology has advanced to a point where density driven $\mathrm{SWH}$ using transcritical $\mathrm{CO}_{2}$ as a working fluid can deliver performance similar to that using conventional refrigerants. In light of these observations, this study investigates the performance of a simple thermosyphon solar water heater using supercritical $\mathrm{CO}_{2}$ as working fluid in regions like those found in North Dakota, USA. In the next chapter a considerable amount of time was spent researching scientific articles exclusively to study the properties of $\mathrm{CO}_{2}[116]$ 


\section{SELECTION OF WORKING FLUID (HEAT TRANSFER FLUID)}

Heat transfer fluid (HTF) plays a very significant role in a solar collector system. In a SWH system, HTF absorbs energy from the collector and transmits the energy through the heat exchanger to the water in the storage tank. The HTF properties such as boiling point, freezing point, flash point, viscosity, and thermal capacity play a major role in the selection of a working fluid for a SWH system. For example, to ensure high performance of a SWH system, HTF with a low freezing point is recommended for cold climatic regions and similarly working fluid with high boiling point would be suitable for hot climatic regions. Some of the common HTFs used are air, water, hydrocarbon oils, Glycol/water mixture, and refrigerants/phase-change liquids [91, 92]. From the viewpoint of thermodynamics and heat transfer, the selected fluid should have maximum desirable properties, such as:

\subsection{Desirable Properties}

(i) Low Greenhouse Warming Potential (GWP)

(ii) Low Ozone Depletion Potential (ODP)

(iii) No need for refrigerant recovery or reclamation

(iv) Non-Toxic

(v) Non-Volatile

(vi) Non-Corrosive

(vii) Non-Flammable

(viii) High specific heat

(ix) High thermal conductivity

(x) Low viscosity

(xi) High heat transfer coefficient 
(xii) Low critical temp

(xiii) Boiling point below target (end-use) temperature

Several conventional refrigerants have been chosen and taken into consideration, but in many cases these refrigerants are toxic, cause pollution, and are damaging greenhouse gases. There is a growing demand in technology based - ecologically safe "natural" refrigerants, like ammonia, hydrocarbons, carbon dioxide water, and air. Among these, $\mathrm{CO}_{2}$ is the only one which is non-flammable, non-toxic, and can also operate in a vapor compression cycle below $0{ }^{\circ} \mathrm{C}$. Therefore, $\mathrm{CO}_{2}$ was chosen as a working fluid for the current study, as it could satisfy most of the desirable properties mentioned above. In this section, the properties of supercritical $\mathrm{CO}_{2}$ and how its influence on the system's performance is detailed.

\subsection{Properties of Carbon Dioxide}

The refrigerant properties play a very significant role in the development of an efficient, cost effective, and environmentally friendly SWH system that can function even when exposed to low ambient temperature and poor solar radiation conditions. In this study, carbon dioxide is selected as the working fluid because its properties are fairly different compared to the conventional refrigerants. One property of $\mathrm{CO}_{2}$ which distinguishes it from other refrigerants is its low critical point, i.e. $31.1{ }^{\circ} \mathrm{C}$ at $7.3 \mathrm{Mpa}$. Figure 10 illustrates the phase diagram of $\mathrm{CO}_{2}$ and clearly shows that the temperature and pressure for the triple point are $-56.6{ }^{\circ} \mathrm{C}$ and $0.52 \mathrm{MPa}$, respectively, and the saturation pressure is $3.5 \mathrm{MPa}$ at $0{ }^{\circ} \mathrm{C}$. For $\mathrm{CO}_{2}$, the low-side conditions will be much closer to the critical point than with conventional refrigerants because of its low critical temperature and high-reduced pressure [117]. 


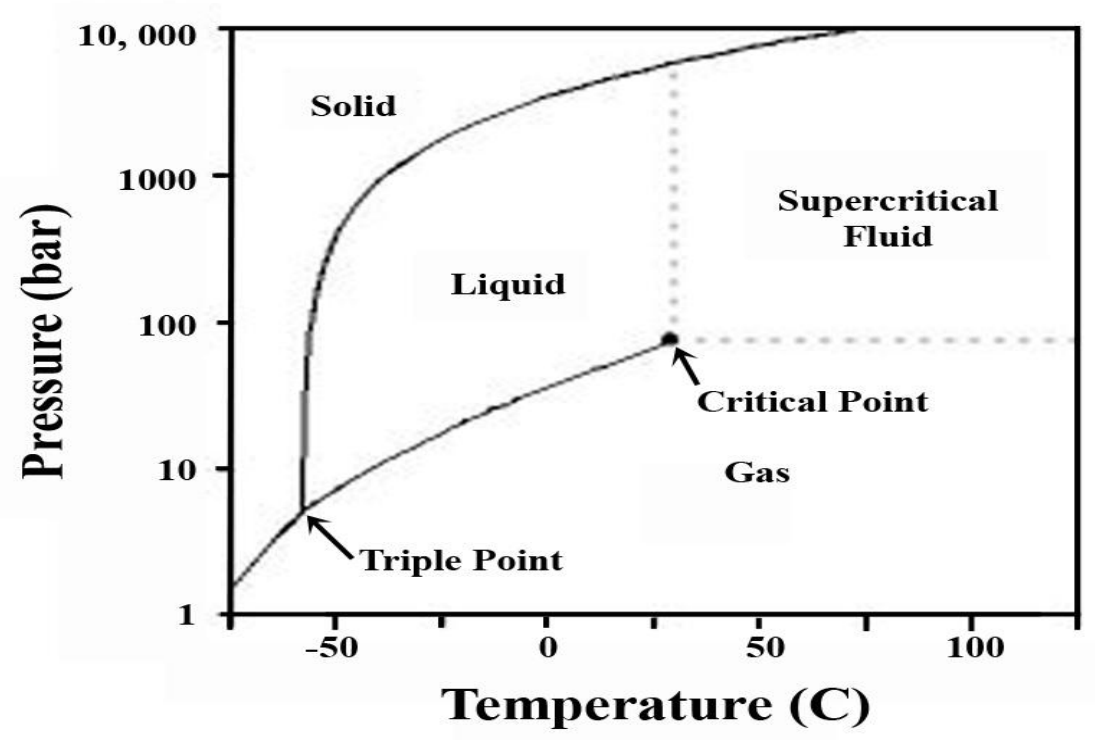

Figure 10: Phase diagram of $\mathrm{CO}_{2}[109]$

\subsubsection{Superior Environmental Qualities}

Carbon dioxide is one of the most promising alternative natural refrigerants as it is nonflammable, non-corrosive, and non-toxic to the environment [118]. It does not need to be recovered or reclaimed when repairing or disposing of the equipment, and can be exhausted into the atmosphere with negligible impact. Although $\mathrm{CO}_{2}$ has a minimal effect on the global warming potential, it is a natural refrigerant which has no impact on ozone depletion, as mentioned in Table 1 [117].

\subsubsection{Thermodynamic Properties}

The performance of a SWH system is very much influenced by the thermophysical properties of the refrigerant being used. The thermophysical properties of $\mathrm{CO}_{2}$ are well known and are quite different from other refrigerants which make it one of the most promising natural refrigerants for water heating [109]. 
Table 1: Comparison of refrigerant properties [117]

\begin{tabular}{|c|c|c|c|c|}
\hline Refrigerant & R134a & R-404A & Ammonia & CO $_{2}$ \\
\hline $\begin{array}{c}\text { Natural } \\
\text { Substance }\end{array}$ & No & No & Yes & Yes \\
\hline $\begin{array}{c}\text { ODP (Ozone } \\
\text { Depletion Potential) }\end{array}$ & 0 & 0 & 0 & 0 \\
\hline $\begin{array}{c}\text { GWP (Global } \\
\text { Warming Potential) }\end{array}$ & 1300 & 3260 & None & 1 \\
\hline Critical Point & $101.1^{\circ} \mathrm{C}$ & $71.7^{\circ} \mathrm{C}$ & $132.2^{\circ} \mathrm{C}$ & $31.1^{\circ} \mathrm{C}$ \\
\hline Triple Point & $-103{ }^{\circ} \mathrm{C}$ & $-100{ }^{\circ} \mathrm{C}$ & $-77.8^{\circ} \mathrm{C}$ & $-56.6^{\circ} \mathrm{C}$ \\
\hline $\begin{array}{c}\text { Flammable or } \\
\text { Explosive }\end{array}$ & No & $.0028 \mathrm{Mpa}$ & $.0060 \mathrm{Mpa}$ & $.518 \mathrm{Mpa}$ \\
\hline Toxic & No & No & Yes & No \\
\hline
\end{tabular}

This section will present an insight into the properties of supercritical $\mathrm{CO}_{2}$. The relationships between temperature, pressure, and enthalpy are shown in the pressure enthalpy diagram in the Fig. 11. As stated earlier, one property which differentiates $\mathrm{CO}_{2}$ from other refrigerants is that it exists in supercritical state above the critical point, $31.1^{\circ} \mathrm{C}$ and $7.3 \mathrm{Mpa}$. As shown in the Fig. 11, the critical point is positioned at the peak of the dome. In the supercritical region, some properties of the fluid are similar to values of the vapor region. However, other properties are closer to values of the liquid region. Substantial changes in thermo physical properties occur even for small changes in temperature and pressure. The region where such rapid change in properties takes place is known as the "pseudo-critical region" (PC). The PC region has a pressure dependent temperature range that centers on the pseudo critical temperature $\left(\mathrm{T}_{\mathrm{PC}}\right) . \mathrm{T}_{\mathrm{PC}}$ is the temperature at which the specific heat capacity reaches a maximum for a given 
pressure [119]. Figure 12 depicts the temperature-dependent variation in specific heat at different pressure conditions. Enthalpy change serves as a good example to reflect this effect.

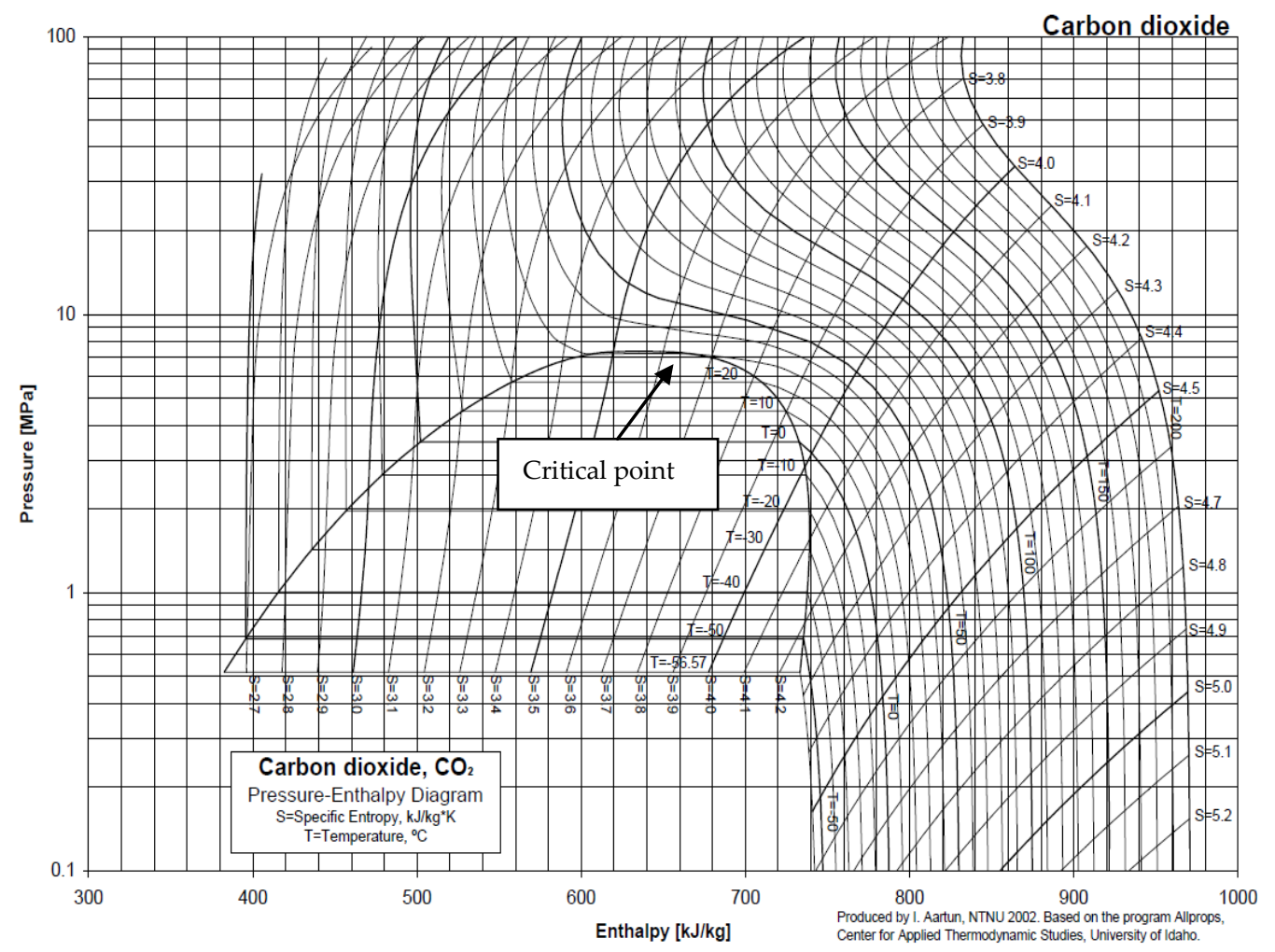

Figure 11: Pressure-enthalpy diagram of $\mathrm{CO}_{2}[109]$

Figure 13 demonstrates $\mathrm{CO}_{2}$ enthalpy variation. This figure shows that, for any given pressure, the change in enthalpy per degree Celsius is maximum in the PC region. High pressures result in a high vapor density, which again results in high volumetric refrigerating capacity. $\mathrm{CO}_{2}$ volumetric refrigeration capacity is 3-10 times higher than $\mathrm{CFC}$, HCFC and HFC refrigerants as shown in Fig. 14 [122, 123]. 


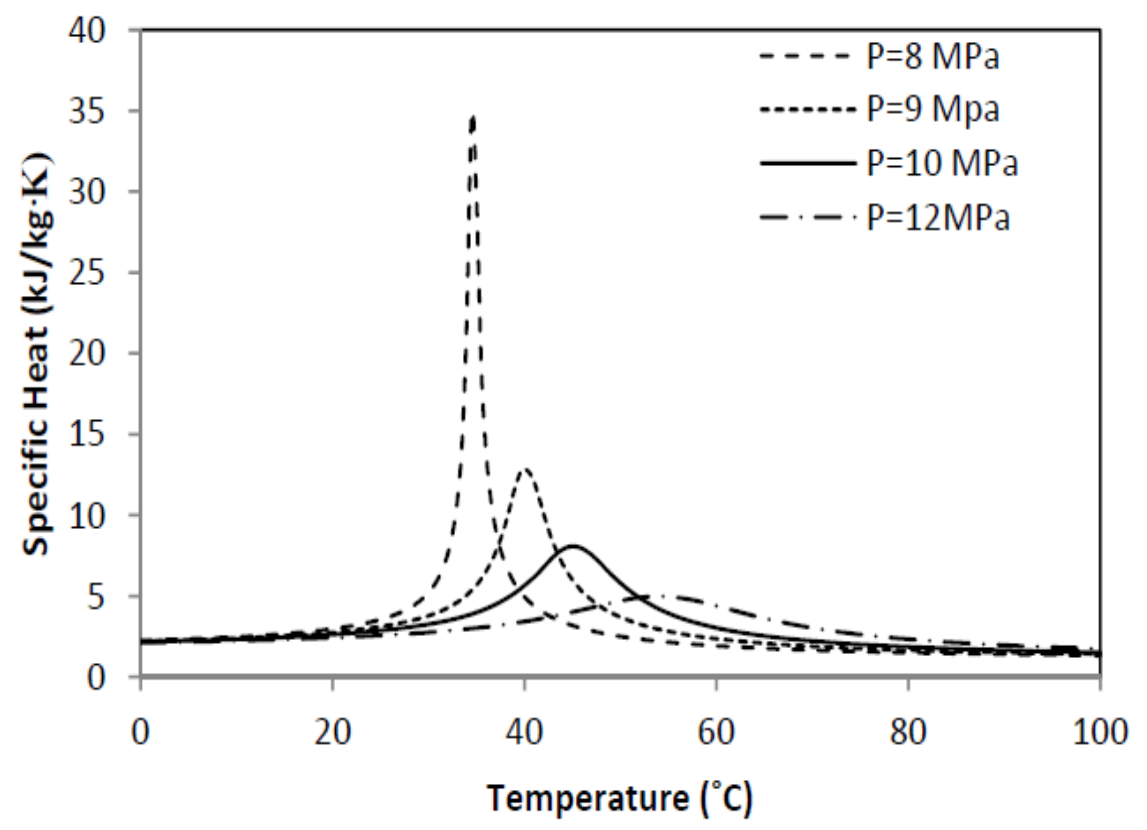

(a)

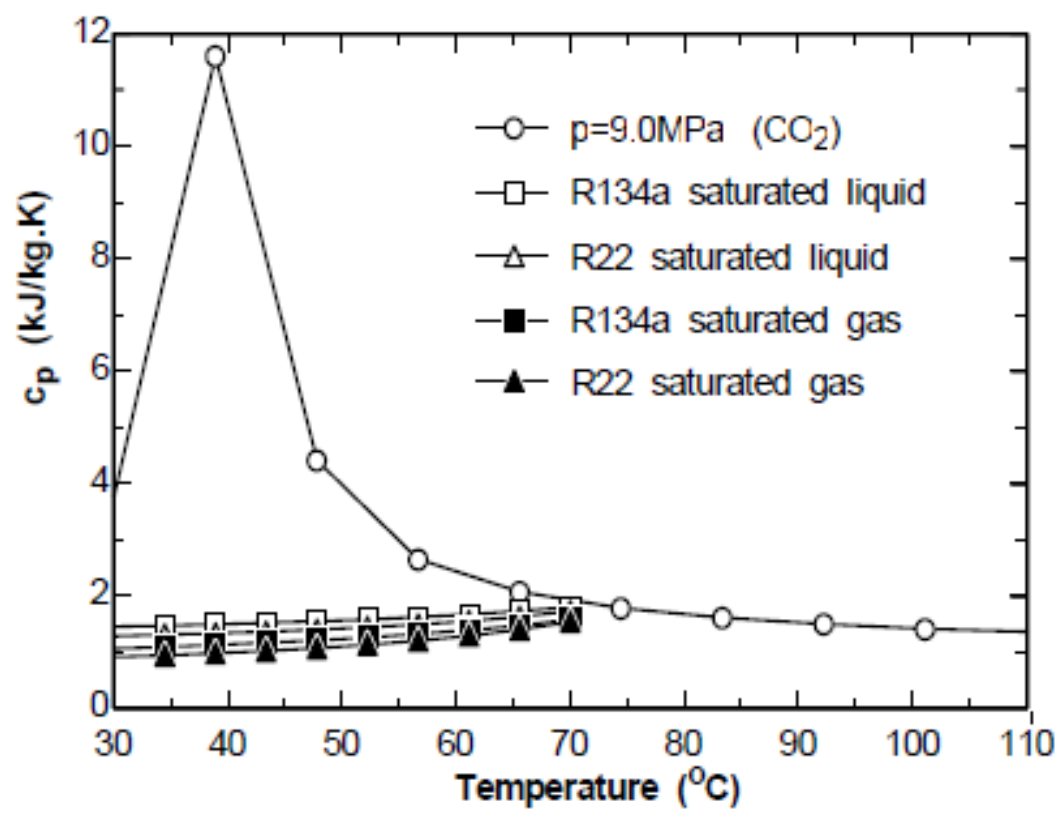

(b)

Figure 12: (a) Variation of specific heat for $\mathrm{CO}_{2}$

(b) Specific heat of different refrigerants [120] 


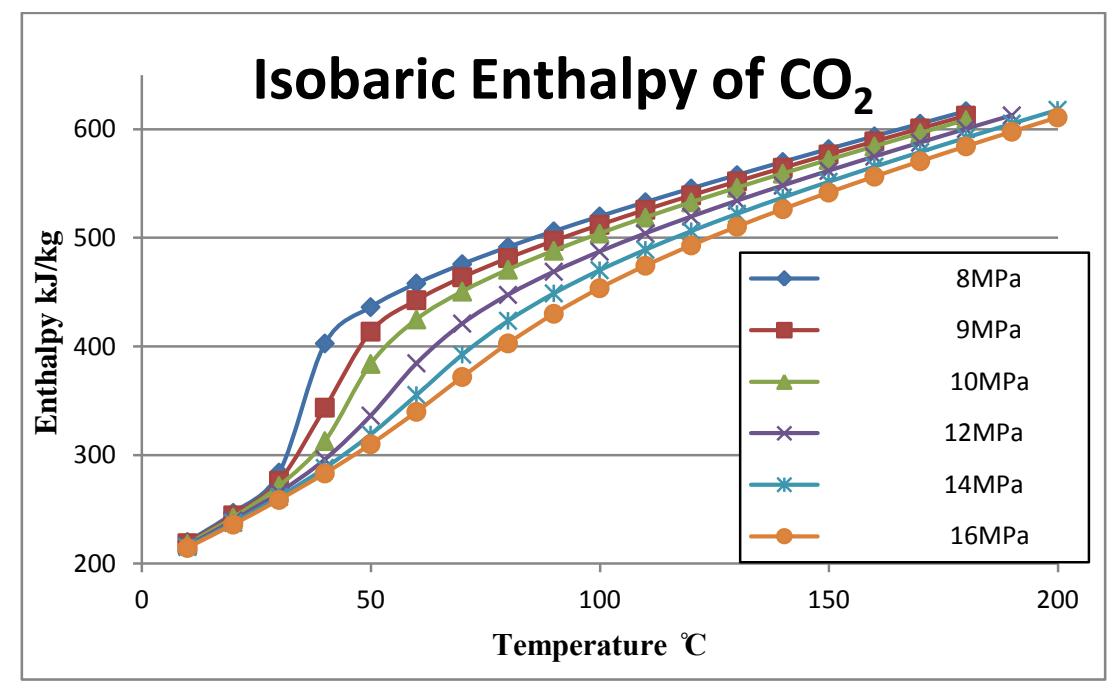

Figure 13: Enthalpy variation of $\mathrm{CO}_{2}$ [109]

Another significant property of $\mathrm{CO}_{2}$ that distinguishes it from other refrigerants is the operating pressure. To develop an efficient, cost effective and environmental friendly SWH system that can function even when exposed to low ambient condition, a working fluid with high working pressure is suggested. $\mathrm{CO}_{2}$ operates at much higher pressures compared to other conventional refrigerants. For example, saturation pressure at $0{ }^{\circ} \mathrm{C}$ is $3.5 \mathrm{MPa}$ for subcritical $\mathrm{CO}_{2}$, and $0.29 \mathrm{MPa}$ for R134a. Operating pressures for supercritical $\mathrm{CO}_{2}$ typically range from 8 to $11 \mathrm{MPa}$ while $\mathrm{R} 134 \mathrm{a}$ has a saturation pressure of $1.318 \mathrm{MPa}$ at $50{ }^{\circ} \mathrm{C}$ [121].

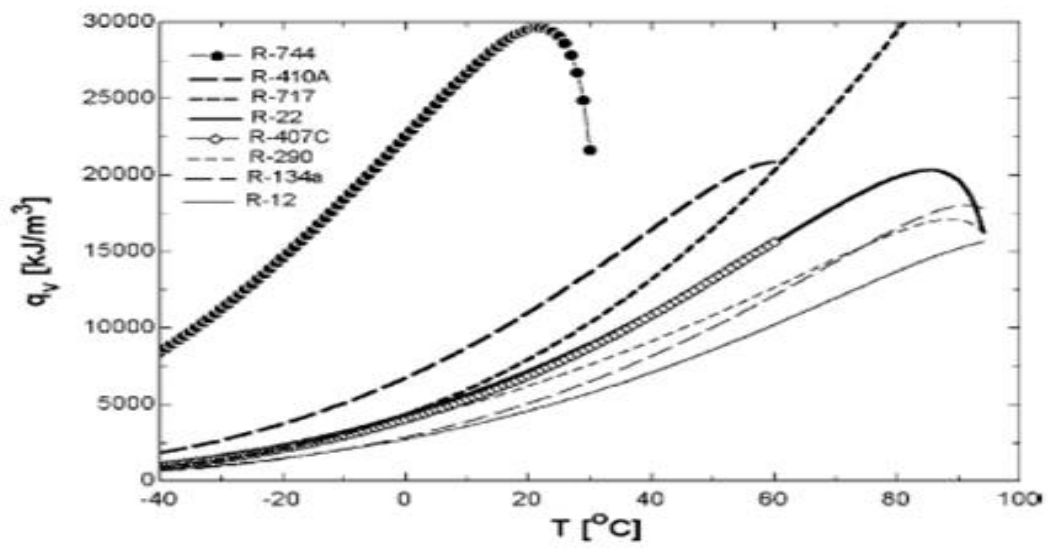

Figure 14: Volumetric refrigeration capacity [109] 


\subsubsection{Transport Properties}

The transport properties of refrigerant play a significant role in heat transfer and pressure drop characteristics. The heat transfer coefficient between the working fluid and tube wall in the collector must be high for obvious reasons. Therefore, to achieve a high value of heat transfer coefficient, it is desirable to have a working fluid with low viscosity and high thermal conductivity.

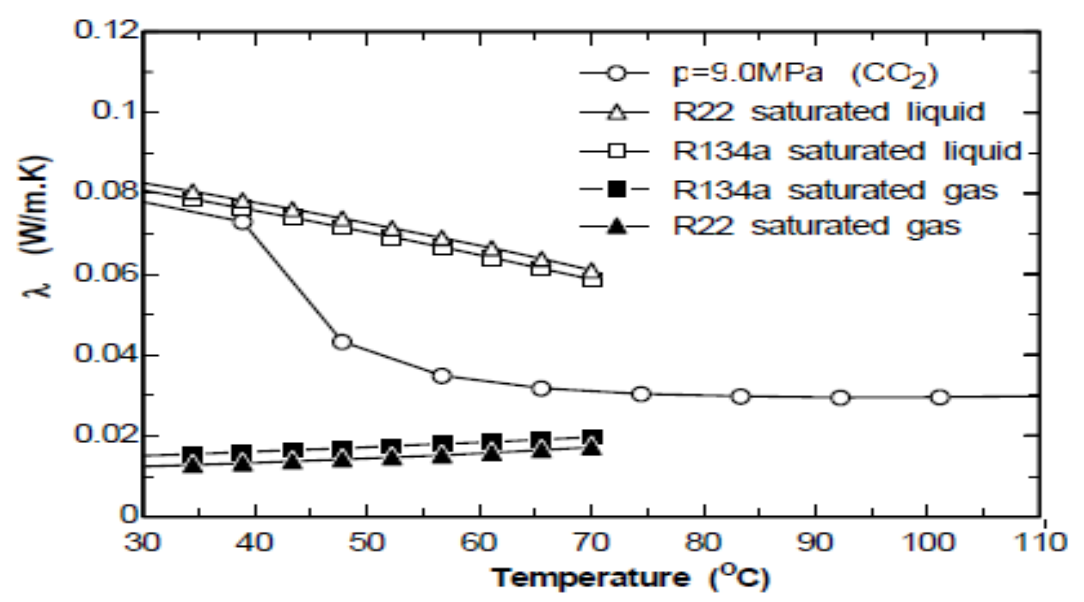

(a)

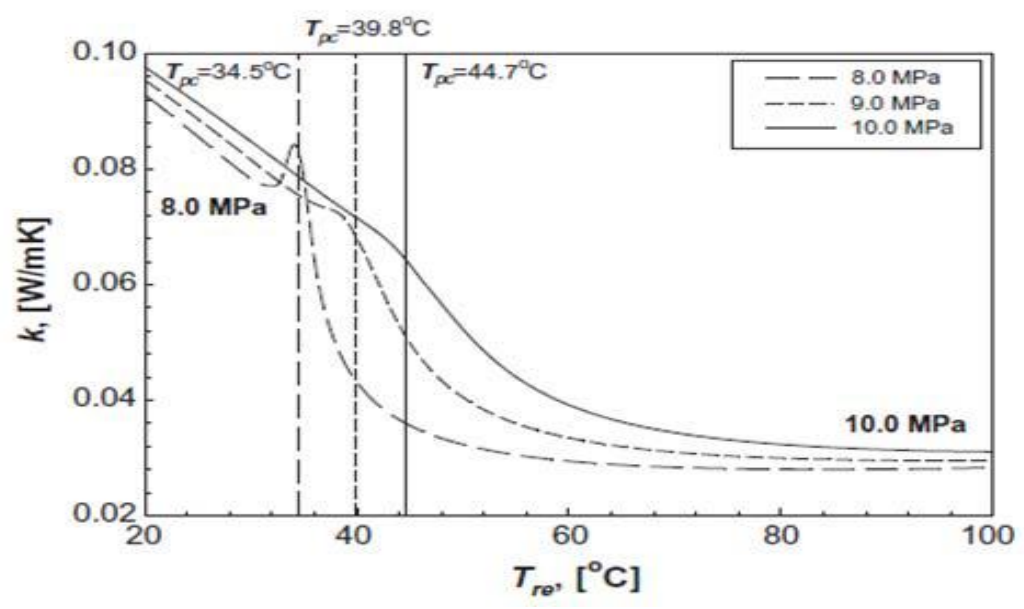

(b)

Figure 15: (a) Comparison of thermal conductivity [122]

(b) Variation of $\mathrm{k}$ for $\mathrm{CO}_{2}$ 
The viscosity and thermal conductivity play an imperative role in determining the heat transfer characteristics of a refrigerant. Comparing $\mathrm{CO}_{2}$ and $\mathrm{R} 134 \mathrm{a}$ at $0{ }^{\circ} \mathrm{C}, \mathrm{CO}_{2}$ 's thermal conductivity is $20 \%$ greater at saturated liquid condition and $60 \%$ greater at saturated vapor condition (Fig. 15.a). Comparing the viscosity of the two fluids at a given temperature, $\mathrm{CO}_{2}$ 's liquid viscosity is $40 \%$ lower and vapor values remain similar [124]. These characteristics result in favorable heat transfer rates.

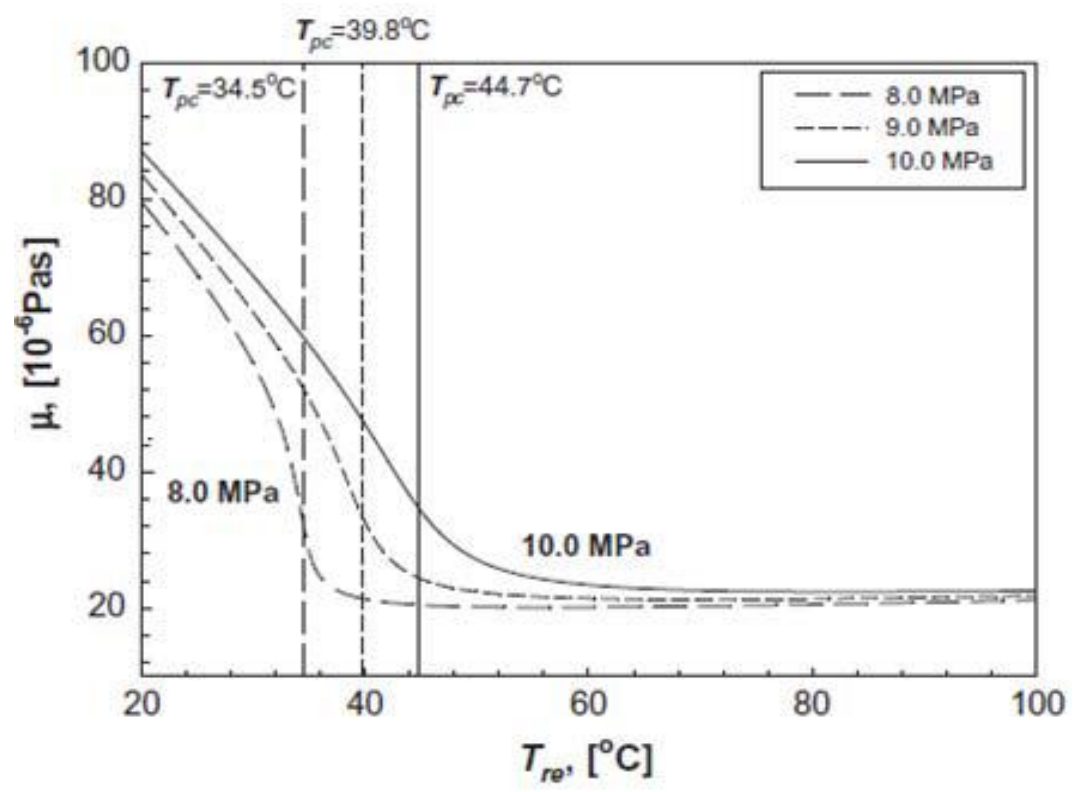

Figure 16: Variation of viscosity for $\mathrm{CO}_{2}[122]$

Figure 16 shows the viscosity change of $\mathrm{CO}_{2}$. As could be seen, the viscosity decreases rapidly through the $\mathrm{PC}$ region. The most rapid change happens at lower pressures in $\mathrm{PC}$ region. However, at higher pressures, thermo physical properties do not differ as significantly. Another important parameter that influences the heat transfer coefficient is the Prandtl number. The Prandtl number is maximum at the PC region associated with the corresponding specific heat, and the maximum value decreases with pressure. In short, compared to any other typical 
refrigerants, the thermodynamic and transport properties of $\mathrm{CO}_{2}$ are favorable and comparable in terms of heat transfer and pressure drop [122]. 


\section{THERMODYNAMIC PROCESS}

As far as thermodynamic properties of carbon dioxide are concerned, the phase envelopes of $\mathrm{CO}_{2}$ in pressure-enthalpy coordinate, is shown in Fig. 11. The figure depicts clearly illustrates both the critical data and phase envelopes of $\mathrm{CO}_{2}$ in pressure-enthalpy curve. The heat transfer process in the solar collector subjects $\mathrm{CO}_{2}$ to surpass the critical point resulting in a transcritical cycle. The process curve below the critical point is the subcritical zone and the process curve beyond the critical point refers to the supercritical zone [126]. In the transcritical cycle condition, the change in temperature and pressure of $\mathrm{CO}_{2}$ are mostly close to the critical point of $\mathrm{CO}_{2}\left(\mathrm{~T}_{\mathrm{c}}=31.1{ }^{\circ} \mathrm{C}, \mathrm{P}_{\mathrm{c}}=7.38 \mathrm{MPa}\right)$. However, at supercritical pressures, $\mathrm{CO}_{2}$ thermodynamic and transport properties' value vary rapidly with temperature in a region near the pseudo-critical temperature [127].

\subsection{Governing Equations}

\subsubsection{Evacuated Tube Collector}

Conventionally flat-plate collector (FPC) and ETC collector are employed to effect heating. However, it is more desirable to use ETC for cold regions, because ETC's vacuum insulation reduces thermal losses thereby enabling them to have high heat extraction efficiency. In addition, ETC has a lower absorber plate area to the gross area ratio compared to FPC [128].

They are commonly used in residential applications because ETC could provide high temperature water depending on the end-use requirement. Heat loss is minimized due to the vacuum conditions, which creates an effective isolation mechanism to contain the heat inside the tubes [128]. ETCs have proven to collect heat even in environments below freezing. Because of 
the advantages mentioned above, an all-glass evacuated solar collector with U-tube heat removal system (Fig. 17) is employed in the present study.

Figure 8 depicts the cross section of the evacuated tube collector. The U-pipe inserted glass evacuated tube solar collector used in this study has the following essential elements: (a) the outer and inner glass tubes placed concentrically to provide the vacuum space in between them, (b) selective absorber coating painted inside the inner tube and (c) copper U-pipe placed inside the inner glass tube with a fin connected together. Solar radiation passes through both the glass tubes to be absorbed by the selective surface. The absorbed heat is then transferred to the U-tube by conduction and to the working fluid inside the U-tube by convection heat transfer method. The loss of heat to the ambient air will follow the direction opposite to that of the incident solar radiation.

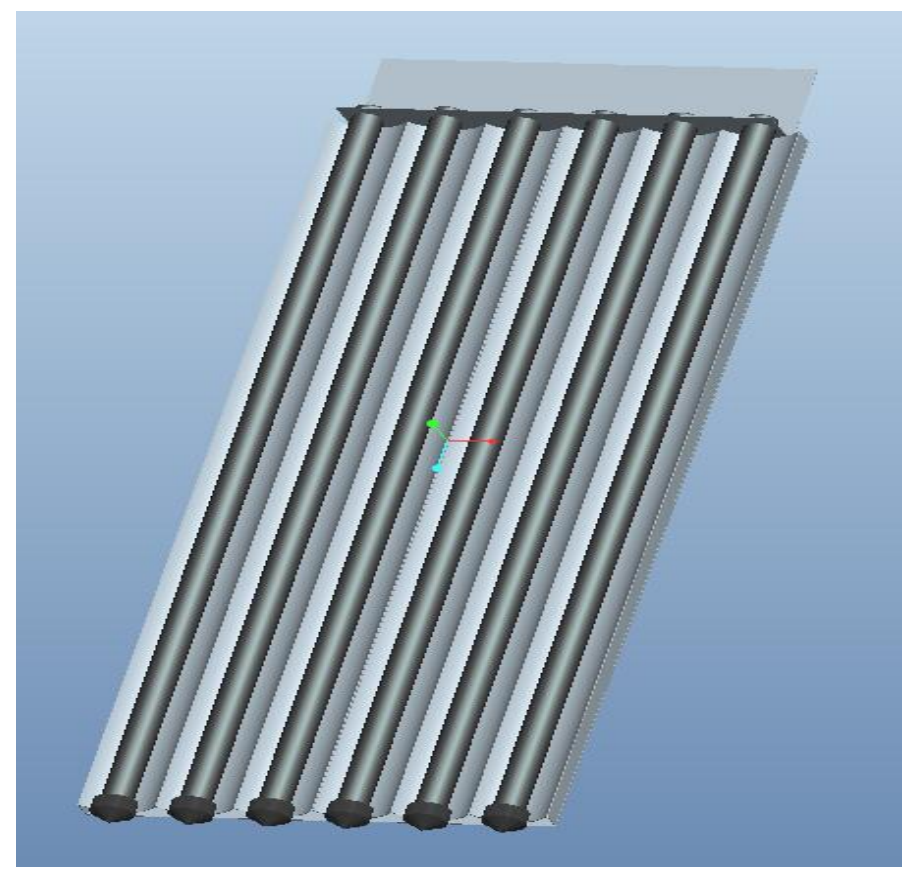

Figure 17: Front view of ETC 
A detailed thermodynamic analysis of the cycle is discussed in this section. Each process of the cycle must confirm to the First Law of Thermodynamics. Hence, the analysis begins by detailing the 1st Law energy balance equations for each process. The generalized 1st Law Energy Balance is as follows:

The useful heat gain $\left(Q_{u}\right)$ of the solar collector is defined as:

$$
Q_{u}=F^{\prime} A_{c}\left[I_{T}(\alpha \tau)-U_{L}\left(T_{f}-T_{a}\right)\right]
$$

In Eq (1), $I_{T}$ is the global solar radiation input, $U_{L}$ is the overall heat loss coefficient, $T_{f}$ is the temperature of the working fluid and $F^{\prime}$ is the collector efficiency factor which is expressed as [56]

$$
F^{\prime}=\frac{\frac{1}{U_{L}}}{W\left[\frac{1+\frac{U_{L}}{C_{b}}}{U_{L}[d+(W-d) F]}+\frac{1}{C_{b}}+\frac{1}{h_{f} \pi d}\right]}
$$

where $h_{f}$ is the heat transfer coefficient between the fluid and the tube wall. $C_{b}$ represents the bond conductance, and $d$ is the U-tube diameter. The circumferential distance between U-tubes is given by $W=P / 2$, where $P$ is the perimeter of the cross-sectional area of the tube. The function $F$ is the standard fin efficiency for fin and is expressed as

$$
F=\frac{\tanh [m(W-d) / 2]}{m(W-d) / 2}
$$

where $m$ is a constant estimated by the following expression: 


$$
m=\left[\frac{U_{L}}{\lambda \delta\left(1+U_{L} / C_{b}\right)}\right]^{1 / 2}
$$

The instantaneous collector efficiency $\left(\eta_{c o l}\right)$ is defined as the ratio of the useful heat gain $\left(Q_{u}\right)$ delivered to the available solar energy at the solar collector $\left(I_{T}\right)$.

$$
\eta_{\text {col }}=\frac{Q_{u}}{I_{T} A_{c}}
$$

Hot Water Storage Tank: Heat quantity recovered $\left(Q_{w}\right)$ by the storage tank can be expressed in the form of following equation:

$$
Q_{w}=M_{w} C_{p}\left(T_{w o}-T_{w i}\right)
$$

In Eq (6), $M_{w}$ represents the mass of water within the storage tank, $T_{w o}$ and $T_{w i}$ refer to the water temperatures at the inlet and the outlet of the storage tank, and $C_{p}$ is the specific heat of water.

Finally, the heat recovery efficiency $\left(\eta_{R E}\right)$ of the system can be evaluated based on the ratio of the heat quantity recovered by the water flow through the heat exchanger $\left(Q_{w}\right)$ to the useful heat gain

$$
\eta_{R E}=\frac{Q_{w}}{Q_{u}}
$$




\section{EXPERIMENTAL INVESTIGATION}

An experimental thermosyphon solar water heater has been designed, fabricated and tested in this study. Figures 18(a) and 18(b) shows the front and side view of the solar water heater respectively. The evacuated tube collector, the storage tank, pressure and temperature gauges, valves, and the external insulated line that facilitates the thermosyphon flow can be clearly seen in Fig. 18 (a). Figure 18 (b) shows the $\mathrm{CO}_{2}$ tank (reservoir), which is used for charging the collector system.

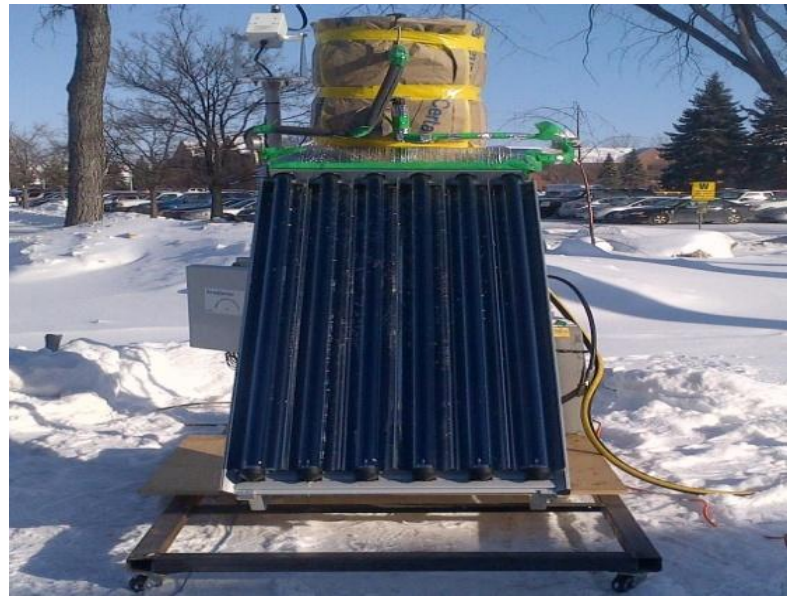

(a)

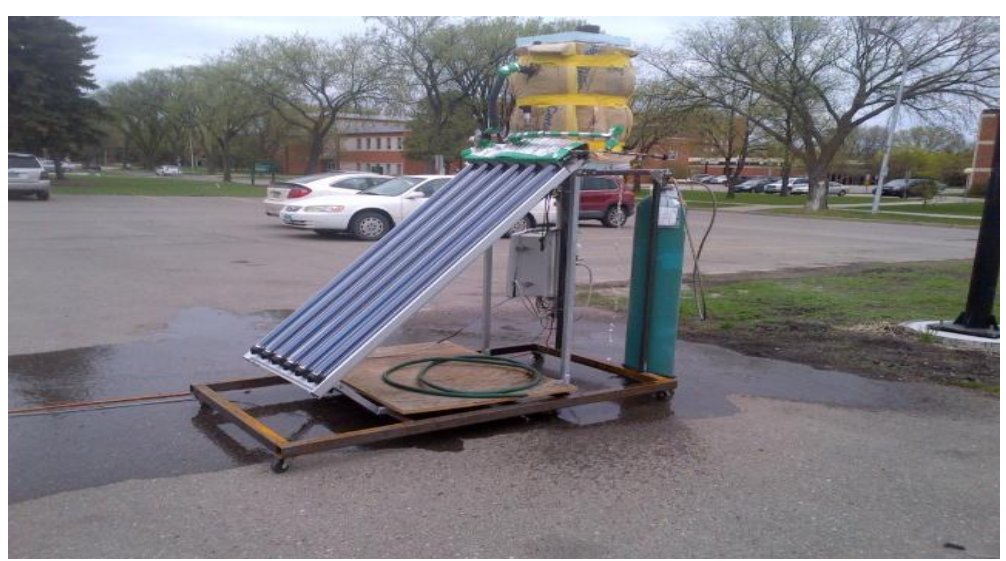

(b)

Figure 18: Experimental set-up (a) Front view (b) Side view 


\subsection{Component Design}

The main design consideration while developing the overall system design in this research is based on the freeze protection strategy. This is because, it is intended to develop a SWH system to suit harsh winter weather conditions experienced in solar adverse regions like Fargo, ND. If proper precautions are not taken, the working fluid would be susceptible to freezing which might cause serious damage to the SWH system. Therefore, to develop a reliable and efficient SWH system for winter conditions in solar adverse regions, constraints derived from low ambient temperatures and low solar radiation intensity has to be met.

This section describes the design processes followed in the project. Design processes are performed in two distinct phases: the system design and the component design. The overall system design was finalized based on the following needs/facts: (i) to suit solar adverse regions which experience-low ambient temperatures and low solar insolation conditions, (ii) the system's working principle; that is, it was intended to have the working fluid be circulated in natural convection mode (density driven) in contrast to the conventional forced convection mode using pump and, (iii) to build a residential water heating system to meet the domestic hot water demand. Accordingly, in component design phase, the proper sizing of the individual components such as evacuated tube collector, heat exchanger, and storage tank of the SWH system was carried out.

\subsubsection{Evacuated Tube Collector}

The efficiency of a SWH system depends mainly on the effectiveness of the collector. Thus, several researchers have worked on the design and development of the collectors. In general, the main design variables that influence the collector effectiveness are: the collector type and collector size. With regard to the type of collector, there exists several kinds of solar 
collectors, among which, evacuated tube collector (ETC) and a flat-plate collector (FPC) are more commonly used for domestic water heating purposes. For the given constraint of low ambient and solar insolation conditions, ETCs are generally employed. ETC has proven to aid inherent maximum operating temperatures and low heat loss at high temperatures relative to the ambient temperature. They are a natural fit for colder regions since ETC's have proven to minimize heat losses. The ETC tubes are constructed in multiple layers to produce desirable heat transfer qualities. The selective coating aids in maximizing solar absorption, to effect higher thermal efficiency even under diffuse sunlight conditions. Compared to the conventional flat plate collectors, whose thermal efficiency range about 50-70\%, the evacuated tube solar collectors could achieve upto 70-80\%. As such, the difference in efficiencies could be much more distinct when operated in colder regions [129]. Based on the above mentioned facts, in the present study, an evacuated tube solar collector (ETC) was chosen as the heating device. The ETC was redesigned to meet the earlier mentioned design constraints.

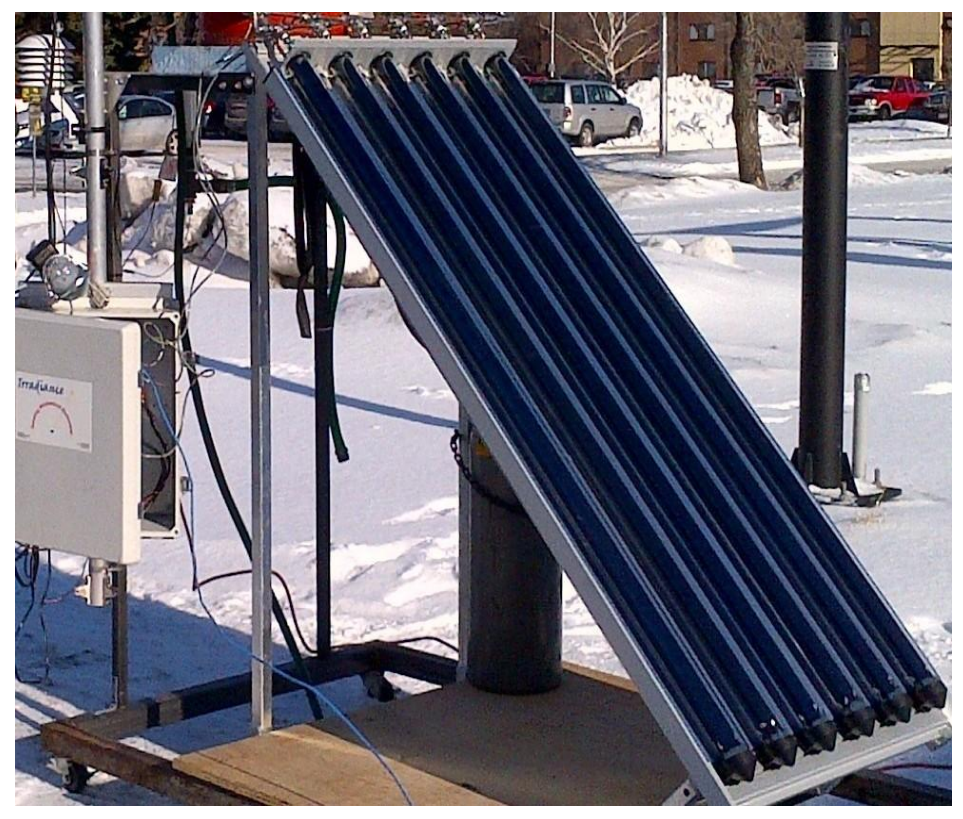

Figure 19: Evacuated tube collector 
In line with one of the objectives (residential SWH system) of the present study, it was targeted to choose a minimal collector area of $1 \mathrm{~m}^{2}$. Accordingly, six borosilicate glass-in-glass tubes were procured, and assembled together on an aluminum base to form the collector system (Fig. 19). The gross collector area of the ETC is $\mathbf{1 . 1 5} \mathbf{~ m}^{\mathbf{2}}$ (gross area) and Table 2 provides the specifications of the collector.

Table 2: Parameters for the glass evacuated tube solar collector

\begin{tabular}{|c|c|c|}
\hline Material & Parameters & Value \\
\hline \multirow[t]{2}{*}{ Absorbing coating } & Absorptivity & 0.92 \\
\hline & Emissivity & 0.19 \\
\hline \multirow{3}{*}{ Outer glass tube } & Outer diameter (m) & 0.047 \\
\hline & Inner diameter (m) & 0.038 \\
\hline & Thickness (m) & 0.0015 \\
\hline \multirow{3}{*}{ Air layer } & Conductivity $(\mathrm{W} / \mathrm{mK})$ & 1.2 \\
\hline & Thickness (m) & 0.001 \\
\hline & Conductivity (W/mK) & 0.03 \\
\hline \multirow[t]{2}{*}{ Copper fin } & Thickness (m) & 0.0006 \\
\hline & Conductivity (W/mK) & 307 \\
\hline \multirow{3}{*}{ U-tube } & Outer diameter $(\mathrm{m})$ & 0.006 \\
\hline & inner diameter $(\mathrm{m})$ & 0.003 \\
\hline & Thickness (m) & 0.015 \\
\hline Length of tubular collector (m) & & $3.65 \mathrm{~m}$ \\
\hline Bond conductance $(\mathrm{W} / \mathrm{mK})$ & & 30 \\
\hline
\end{tabular}




\subsubsection{U-tube Design}

The efficiency of a collector is also dictated by the shape of the absorber tube. For instance, Perez et al. [130] confirmed that the glass ETC with a semi-cylindrical shaped absorber tube could absorb approximately $16 \%$ more energy than an ETC with a flat-plate shaped absorber tube design. Kim and Seo [50] introduced several potential designs of the absorber tube and investigated the performance of the four different shapes of absorber tubes. The shapes include (i) a finned tube, (ii) an "U-tube" welded inside a circular fin, (iii) an "U-tube" welded on a copper plate. Among the different designs, an "U-tube" integrated with circular fin provided the best heat transfer performance. Based on the above information, an U-shaped absorber tube was designed, for the proposed ETC system.

As discussed previously in Chapter 3, high operating pressures (8 to $13 \mathrm{MPa}$ ) are experienced with $\mathrm{CO}_{2}$ as the working fluid compared to any other conventional refrigerants in the temperature range of $20{ }^{\circ} \mathrm{C}$ to $90{ }^{\circ} \mathrm{C}$ [115]. Hence, to ensure high pressure $\mathrm{CO}_{2}$ could be safely circulated through the ETC, a copper tube of $15 \mathrm{~mm}$ thick and $3.7 \mathrm{~m}$ long was bent to Ushape (Fig. 20) and was inserted in the inner ETC tube.

\subsubsection{Header Design}

In order to ensure uniform flow through the collector, input and output header pipes with an opposing $5^{\circ}$ angle, were fabricated to restrict reverse flow, as shown in Fig. 21. The copper tubing in the header section had an outer diameter of $0.009 \mathrm{~m}$ and an inner diameter of $0.006 \mathrm{~m}$, to handle the designed pressures. The length of the header section was $0.609 \mathrm{~m}$. The U-shaped copper tubes in the ETC were integrated with the headers using multiple stainless steel high pressure compression T-joints. 


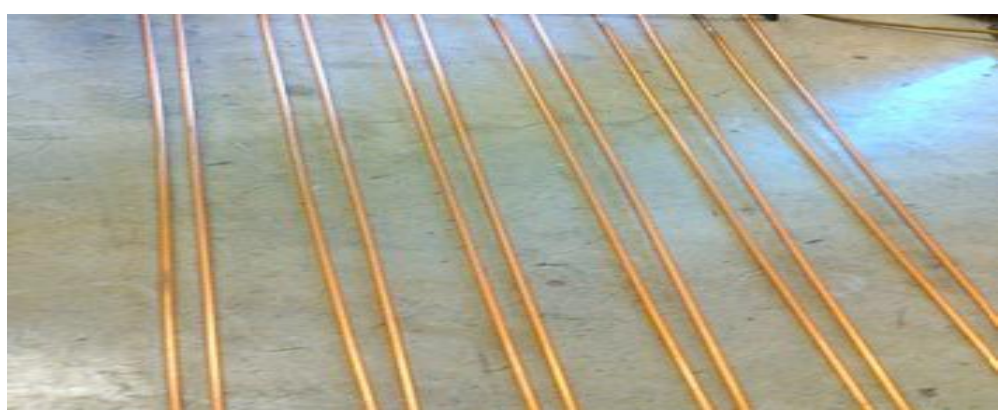

Figure 20: U-tubes design

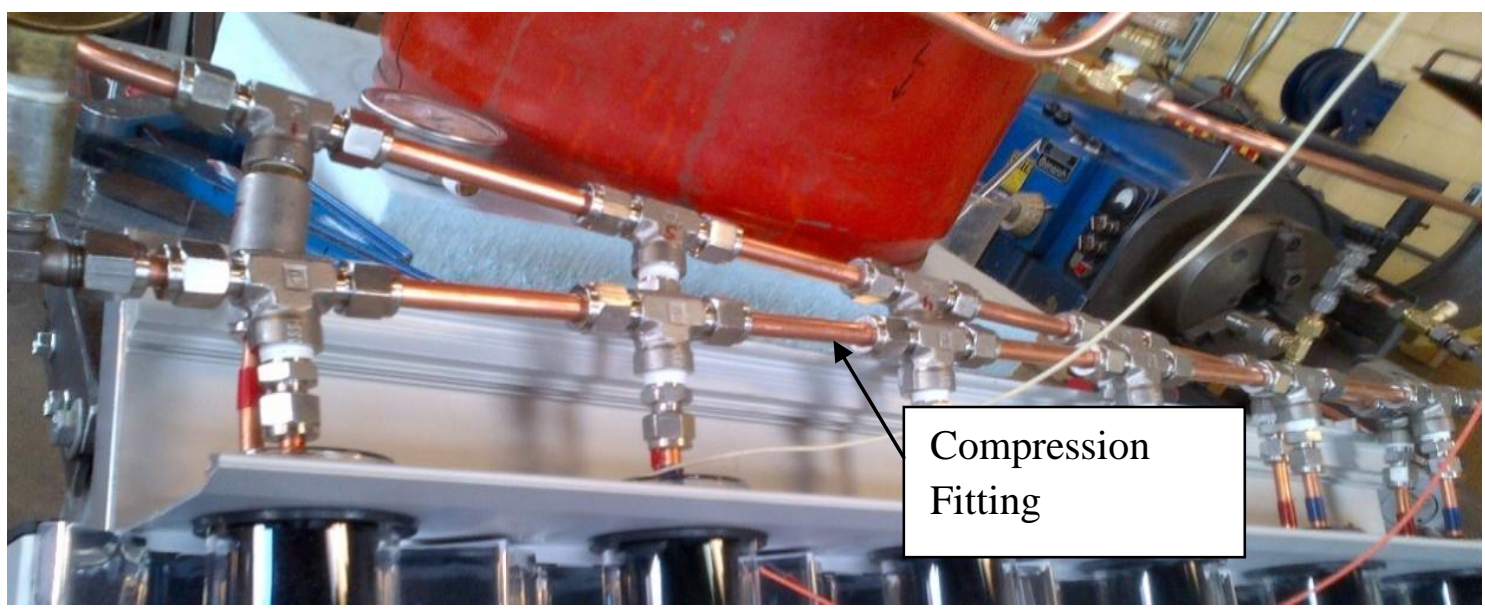

Figure 21: Input and output header

\subsubsection{Hot Water Storage Tank}

The storage tank is yet another essential component of the SWH system. It also plays a major role in dictating the system performance. A storage tank is used to store the absorbed solar thermal energy by the working fluid in the collector, in terms of raising the thermal capacity of the water in the storage tank. Storage tanks are generally constructed using steel, concrete, plastic, fiber glass or other suitable materials used to store hot water [116]. Among the types mentioned, steel tanks are most commonly employed since they are easy to install in the required sizes and are generally corrosion free. 
In addition to the material type, there are other design factors such as storage tank configuration and tank size that influence the performance of the storage tank. Several configurations of storage tanks (e.g., vertical and horizontal) have been investigated and their thermal performances are published in the literature (Chapter two). Studies have confirmed that in comparison to the horizontal tank, the thermal performance of vertical tank was superior. This is because of the fact that, horizontal geometry is more susceptible to degradation of thermal stratification due to its small vertical dimensions relative to its horizontal length [116]. Hence, it was decided to have a vertically oriented storage tank.

With regard to the tank size, the aspect ratio (Height/Diameter) of the tank plays an important role in dictating the overall heat loss coefficient. As the aspect ratio increases, the overall heat loss coefficient of the tank to the surrounding also increases, reflecting more surface area for the given volume of the tank. Hence, keeping the objective of the study, inorder to ensure that a loss from the tank is minimal, and the aspect ratio (Table 3) should be with 2 to 4 [131]. Based on these facts, a vertical steel storage tank having a volume of $60 \mathrm{~L}$ with an aspect ratio of around 2 was built (Fig. 22). The methodology adopted in arriving at the volume of the tank is presented below.

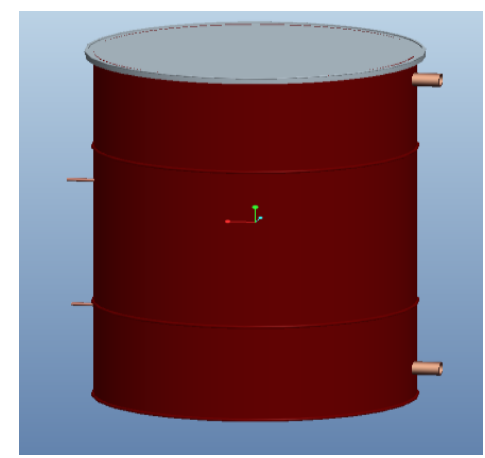

(a)

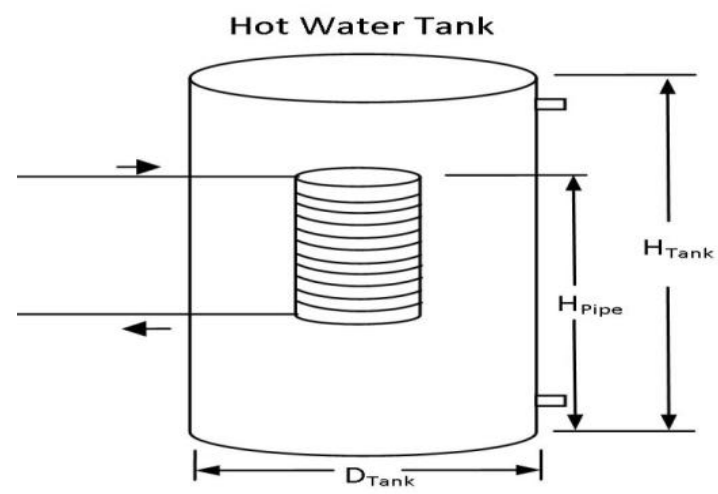

(b)

Figure 22: Picture and schematic of the designed storage tank 
Determination of Storage Tank Volume: The required volume of the tank was estimated based on the historical weather data of Fargo region and ETC as the heat design. Since it is intended to operate the SWH system on thermosyphon basis (density driven), preliminary calculations showed that, the system could not affect any useful heat in the harsh winter condition (Nov-Feb). Hence, the average hourly total radiation $\left(\mathrm{I}_{\mathrm{T}}\right)$ and the ambient temperature $\left(\mathrm{T}_{\mathrm{a}}\right.$ ), pertaining to spring (March, April, May), summer (June, July August), and fall (September, October) months, is around $700 \mathrm{~W} / \mathrm{m}^{2}$ and $15{ }^{\circ} \mathrm{C}$ respectively (Table 4) [132]. For the said input solar radiation and for a given collector area of $1.15 \mathrm{~m}^{2}$, the useful heat gain $\left(Q_{u}\right)$ of the solar collector is estimated using the following equation:

$$
Q_{u}=F^{\prime} A_{c}\left[I_{T}(\alpha \tau)-U_{L}\left(T_{f}-T_{a}\right)\right]
$$

where $I_{T}$ is the average hourly total solar radiation input, $U_{L}$ is the overall heat loss coefficient of an evacuated tube collector $\left(=1 \mathrm{~W} / \mathrm{m}^{2} \mathrm{~K}\right), T_{f}$ is the average temperature of the working fluid $\left(=45^{\circ} \mathrm{C}\right)[127]$ and $F^{\prime}$ is the collector efficiency factor $(=0.95)$ (Table 5) [56]. For these input values, the useful heat gain turns out to be around $600 \mathrm{~W} / \mathrm{m}^{2}$.

Confirmation Test: The estimated useful heat gain is cross checked by re-evaluating the net useful gain, using the following equation:

$$
\eta_{c o l}=\frac{Q_{u}}{I_{T} A_{c}}
$$

For the given collector area $\left(=1.15 \mathrm{~m}^{2}\right)$, average hourly total radiation $\left(740 \mathrm{~W} / \mathrm{m}^{2}\right)$, and the proven efficiency of the ETC of about 70\% [129], the predicted useful heat gain (600W) is in line with the previous estimated value. 
Table 3: Relation between diameter and height of the storage tank

\begin{tabular}{|c|c|c|}
\hline & & Aspect Ratio \\
\hline $\begin{array}{c}\mathbf{D} \\
(\mathbf{I n c h})\end{array}$ & $\begin{array}{c}\mathbf{H} \\
\text { (Inch) }\end{array}$ & (H/D) \\
\hline 14 & 23 & 1.6 \\
\hline 13 & 28 & 2.1 \\
\hline 12 & 32 & 2.6 \\
\hline
\end{tabular}

Based on the above given values, it was decided to choose the diameter as $13^{\prime \prime}(0.3 \mathrm{~m})$ and height as $28^{\prime \prime}(0.6 \mathrm{~m})$, respectively. However, to accommodate the thermal expansion while water getting heated up as well as since it is indented to study the effect of mass of water as one of the operating parameters, the volume set to 70L. Accordingly, the storage tank was designed and built with a $\mathrm{V}=70 \mathrm{~L}, \mathrm{D}=13^{\prime \prime}(0.3 \mathrm{~m}), \mathrm{H}=31^{\prime \prime}(0.8 \mathrm{~m})$.

Table 4: Monthly solar radiation and ambient temperature data, 2012 [132]

\begin{tabular}{|c|c|c|}
\hline Months & $\begin{array}{c}\text { Solar Radiation } \\
\left(\mathbf{W} / \mathbf{m}^{2}\right)\end{array}$ & $\begin{array}{c}\text { Ambient Temperature } \\
\left({ }^{\circ} \mathbf{C}\right)\end{array}$ \\
\hline March & 675 & 5 \\
\hline April & 759 & 8 \\
\hline May & 828 & 15 \\
\hline June & 930 & 21 \\
\hline July & 967 & 21 \\
\hline Aug & 861 & 23 \\
\hline Sept & 569 & 20 \\
\hline Oct & 356 & 13 \\
\hline Average & 740 & 15 \\
\hline
\end{tabular}


Table 5: Parameters used in the performance prediction $[56,119]$

\begin{tabular}{|l|l|}
\hline Thickness of copper fin $(\delta)$ & $0.0006 \mathrm{~m}$ \\
\hline Circumferential distance between U-tube $(\mathrm{W})$ & $0.108 \mathrm{~m}$ \\
\hline Total solar insolation $\left(\mathrm{I}_{\mathrm{T}}\right)$ & $740 \mathrm{~W} / \mathrm{m}^{2}$ \\
\hline Overall loss coefficient $\left(\mathrm{U}_{\mathrm{L}}\right)$ & $1 \mathrm{~W} /\left(\mathrm{m}^{2} \mathrm{~K}\right)$ \\
\hline Bond conductance $\left(\mathrm{C}_{\mathrm{B}}\right)$ & 30 \\
\hline Collector efficiency factor $\left(F^{\prime}\right)$ & 0.95 \\
\hline Fin efficiency of straight fin $(\mathrm{F})$ & 0.99 \\
\hline Acceleration due to gravity $(\mathrm{g})$ & $9.8 \mathrm{~m} / \mathrm{s}^{2}$ \\
\hline Thermal conductivity of water $\left(k_{w}\right)$ & $0.58 \mathrm{~W} / \mathrm{mK}$ \\
\hline Specific heat of water $\left(C_{p w}\right)$ & $4182 \mathrm{~J} / \mathrm{kg} \mathrm{K}$ \\
\hline Density of water $\left(\rho_{w}\right)$ & $1000 \mathrm{~kg} / \mathrm{m}^{3}$ \\
\hline
\end{tabular}

The predicted useful heat gain $(600 \mathrm{~W})$ is utilized in identifying the required volume of the storage tank. Due to the fact that, domestic needs, the temperature of hot water ranges between $60{ }^{\circ} \mathrm{C}$ to $70{ }^{\circ} \mathrm{C}$, an average value of $65^{\circ} \mathrm{C}\left(T_{w o}\right)$ was tested in the design calculations. Similarly, the temperature of city water in Fargo ranges between 15 to $20^{\circ} \mathrm{C}[133]$ and hence $T_{w i}$ $\left(=15^{\circ} \mathrm{C}\right)$ was used in the below given expression to evaluate the volume of the storage tank. With the above mentioned data for temperature rise of $50^{\circ} \mathrm{C}$, the storage tank volume turns out to be $60 \mathrm{~L}$, by evaluating following energy balance equation:

$$
Q_{u}=V \rho C_{p w}(\Delta T)
$$

Having identified the volume of the storage tank, the optimal dimensions in terms of diameter and height was arrived based on the aspect ratio. Table 3 gives the aspects ratio for various assumed height and diameter for 60L. Having identified the volume of the storage tank, the optimal dimensions in terms of diameter and height was arrived based on the aspect ratio. 


\subsubsection{Heat Exchanger/Condenser}

Having decided on the dimensions of the storage tank, the next important design element is the condenser coil. As illustrated earlier, an 'Indirect mode' of heating is adopted in the present study. In the 'Indirect mode,' a heat exchanger (HX) is utilized to transfer absorbed solar heat from the working fluid to the storage tank. The HXs are generally made from good conductive material such as aluminum, stainless steel, copper, steel, and bronze. To ensure good thermal conductivity and resistance to corrosion, copper is popularly used in SWH system. Several configurations of HXs have been designed for indirect water heating storage tanks (Chapter 2) and the one of the most common configuration is the immersed coil-in-tank heat exchanger [116]. This design is less expensive and at the same time more efficient [134]. Based on these facts, an immersed type heat exchanger was fabricated (Fig. 23) using the same type of copper piping used in fabricating the U-tubes of ETC. One of the main requirements of a heat exchanger is, it must facilitate the complete condensation of vapor thereby maximizing the heat rejection in the storage tank. This is largely influenced by the area of the condenser coil chosen. The methodology adopted in arriving at the area of the condenser coil is explained in this section.
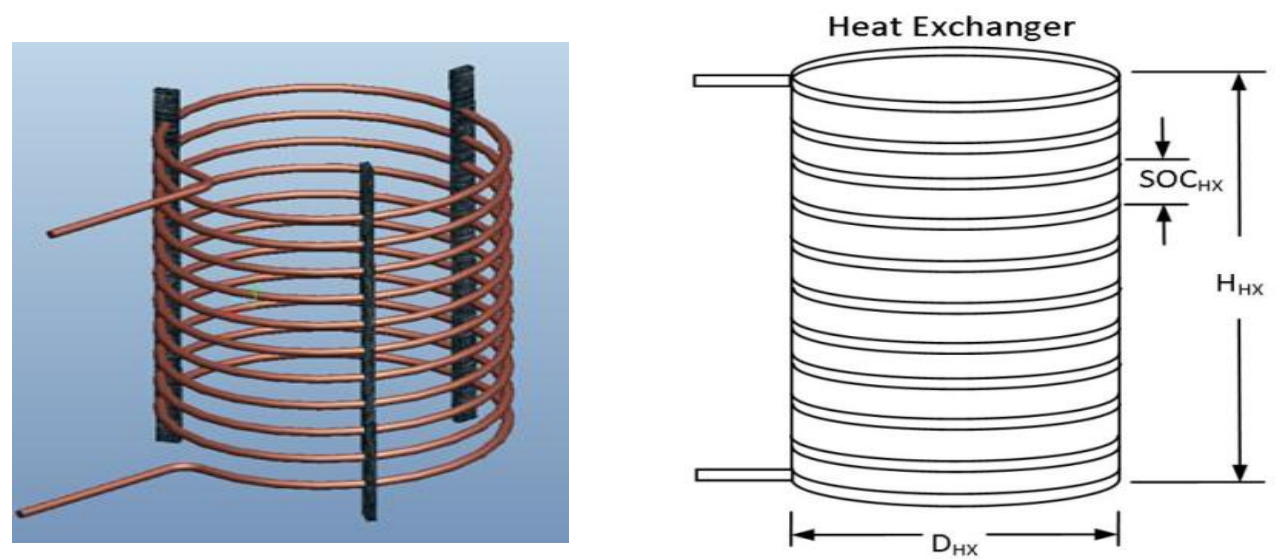

Figure 23: Picture and schematic of the designed Condenser and the cooling coil 
Determination of the Heat Exchanging/Condenser Area: The required condenser area was estimated based on the predicted average useful heat gain $\left(Q_{u}\right)$ by the collector during a typical one day operation. It should be pointed out here that in design analysis, neglecting the pipe losses, it is assumed the heat gained by $\mathrm{CO}_{2}$ at the evaporator (600W) is expected to be same $\mathrm{CO}_{2}$ working fluid that is available at the condenser

$$
Q_{\text {con }}=Q_{u}
$$

The heat rejected by the $\mathrm{CO}_{2}$ through the condenser can be expressed as

$$
Q_{\text {con }}=(U A)_{c o i l}\left(T_{c o n}-T_{w}\right)
$$

where $A_{\text {coil }}$ is the area of the cooling coil and $U_{\text {coil }}$ is the overall heat transfer from the condenser/cooling coil. The required total heat transfer area (cooling coil area), depends on the overall heat transfer coefficient $\left(U_{\text {coil }}\right)$. In general, the value of overall heat transfer coefficient varies considerably based on the thermal and transport properties of both fluids as well as on other conditions. The $U_{\text {coil }}$ is given by [135]:

$$
U_{\text {coil }}=\frac{1}{\left(B / h_{c o}\right) /\left(1 / h_{w}\right)}
$$

where, $B=1$

The heat transfer coefficient $\left(h_{c o}\right)$ of refrigerant inside the horizontal tubes during the condensation process for two-phase annular flow can be estimated using the following equation (Jordan and Priester [136]):

$$
h_{c o}=0.025 \frac{k_{r}}{d_{i}}\left(\frac{G_{r} d_{i}}{\mu_{r}}\right)^{0.8}\left(\frac{C_{p r} \mu_{r}}{k_{r}}\right)^{0.3}
$$


where $G_{r}$ is the mass velocity for two-phase flow, $k_{r}$ is the thermal conductivity of the refrigerant, $C_{p r}$ is the specific heat of the refrigerant, and $\mu_{r}$ is the dynamic viscosity of the refrigerant [135]. These properties are evaluated at the required condenser temperature $\left(T_{c o n}\right)$. As it is intended to build a SWH to meet the domestic hot water needs, in general the temperature varies from 60 to $70{ }^{\circ} \mathrm{C}$ [133]. Hence, for design calculations at value of $T_{\text {con }}=65$ ${ }^{\circ} \mathrm{C}$ was used, and the heat transfer coefficient of the refrigerant $\left(h_{c o}\right)$ turns out to be around $6000 \mathrm{~W} / \mathrm{m}^{2}$.

Similarly, the water side heat transfer coefficient $\left(h_{w}\right)$ is estimated by using the following equation [135]:

$$
h_{w}=0.5 \frac{k_{w}}{d_{o}}\left(\frac{g \beta_{w} \Delta t d_{o}^{3} \rho_{w}^{2} C_{p w}}{\mu_{w} k_{w}}\right)^{0.25}
$$

where $k_{w}$ is the thermal conductivity of the water, $g$ is the acceleration due to gravity, $\beta_{w}$ is the coefficient of thermal expansion of water, $C_{p w}$ is the specific heat of water, and $\mu_{w}$ is the dynamic viscosity of water. These properties are evaluated at the water temperature $\left(T_{w}\right)$ of $15^{\circ} \mathrm{C}$, equivalent to the city water temperature in Fargo. The various properties of water and carbon dioxide and their variation with the designed temperature and pressure conditions are presented in Table 5 [137].

Substituting the overall heat transfer coefficient of the coil estimated useful heat gain $(600 \mathrm{~W})$, temperature of the condenser coil $\left(T_{c o n}=65^{\circ} \mathrm{C}\right)$ and the temperature of water in the tank $\left(T_{w}=15^{\circ} \mathrm{C}\right)$, in Eq. (12), the required surface area of the coil $\left(A_{\text {coil }}\right)$, turns out to be $0.04 \mathrm{~m}^{2}$. 
Determination of the Coil Length and Number of Turns of the Coil: For the desired surface area of the coil $\left(0.04 \mathrm{~m}^{2}\right)$, and diameter of the coil $(0.003 \mathrm{~m})$, the overall length of the coil $\left(L_{\text {coil }}\right)$ turns out to be $5 \mathrm{~m}\left(196.8^{\prime \prime}\right)$.

$$
A_{\text {coil }}=\pi D_{i} L_{\text {coil }}
$$

Depending upon the predicted overall length of the coil and the allowable diameter of the each turn, the number of turns can be evaluated. The turn diameter depends on the diameter of the storage tank. As mentioned in section 5.12, the chosen diameter of the tank was set to $13^{\prime \prime}$ $(0.33 \mathrm{~m})$. Hence, giving a clearance of $2.5^{\prime \prime}(0.06 \mathrm{~m})$, from the inner wall of the tank, the allowable diameter of the each turn will be 8 " $(0.2 \mathrm{~m})$. Therefore, for the given total cooling coil length $\rightarrow$ the possible number of turns will be 9 turns.

In the view of effective heat transfer process from the condensing coil, it would be desirable to have the condenser coils be spaced in the tank which would enhance free convection currents. However, based on the chosen height (28") of the storage tank, the spread of the coil could not exceed the said height. However giving a clearance of 7" on either side of the condensing unit, the coil could be spread within a height of 14 " $(0.35 \mathrm{~m})$ only. This also ensures that, the condenser coil is immersed well within the desired volume of storage water (60L). It is well known that the condenser coil should be totally immersed in water, in order to take advantage of the greatest difference between the temperature of the storage fluid and the temperature of the fluid flowing through the condenser [134]. Based on this, the coil was located within the middle of the storage tank, with a clearance of $7 "(0.17 \mathrm{~m})$ at the either end of the tank. Depending on the height of the storage tank that is, $28^{\prime \prime}(0.71 \mathrm{~m})$, the inlet and the outlet of the HX was set at the storage tank height of $21^{\prime \prime}(0.53 \mathrm{~m})$ and $7 "(0.17 \mathrm{~m})$, respectively. 


\subsection{Data Acquisition and Processing System}

As per the design procedure detailed in the previous sections, a thermosyphon water heating system was built and the performance of the SWH system was monitored and controlled by a personal computer-based data acquisition system (Fig. 24). The system was installed with the essential instrumentation (Table 6) which was used to measure the key parameters of the system. Collector surface temperatures, storage water tank temperature, as well as temperature of $\mathrm{CO}_{2}$ at various locations of the system were measured by using J-type thermocouples with an accuracy of $\pm 0.2{ }^{\circ} \mathrm{C}$. The high $\mathrm{CO}_{2}$ pressures at various locations of the systems were measured, using pressure transmitters with an accuracy of $\pm 0.25 \%$.

Table 6: Instrumentation summary

\begin{tabular}{|c|c|c|c|c|}
\hline Label & Instrument & Manufacturer & Range & Accuracy \\
\hline$\square$ & Pressure Sensor & $\begin{array}{c}\text { WIKA Alexander } \\
\text { Wiegand SE \& Co. KG }\end{array}$ & $0-12 \mathrm{Mpa}$ & $\pm 0.25 \%$ \\
\hline$\square$ & Thermocouple & $\begin{array}{c}\text { Thermocouple } \\
\text { Technology, Inc }\end{array}$ & $\begin{array}{c}\text { Upto } \\
1250^{\circ} \mathrm{C}\end{array}$ & $\pm 0.2 \%$ \\
\hline & $\begin{array}{c}\text { CR-1000 Data } \\
\text { Logger }\end{array}$ & Irradiance, Inc & & \\
\hline
\end{tabular}

With respect to solar radiation, a solarimeter was utilized to measure the intensity of the global solar radiation from sun. The schematic diagram of the system is reproduce here for easy reference (Fig. 1), which details the locations of the instrumentation within the SWH system. Appendix A shows a detailed wiring diagram between the instrumentation and the data acquisition system. The following section provides a description of the instrumentation procedure carried out in this study. 


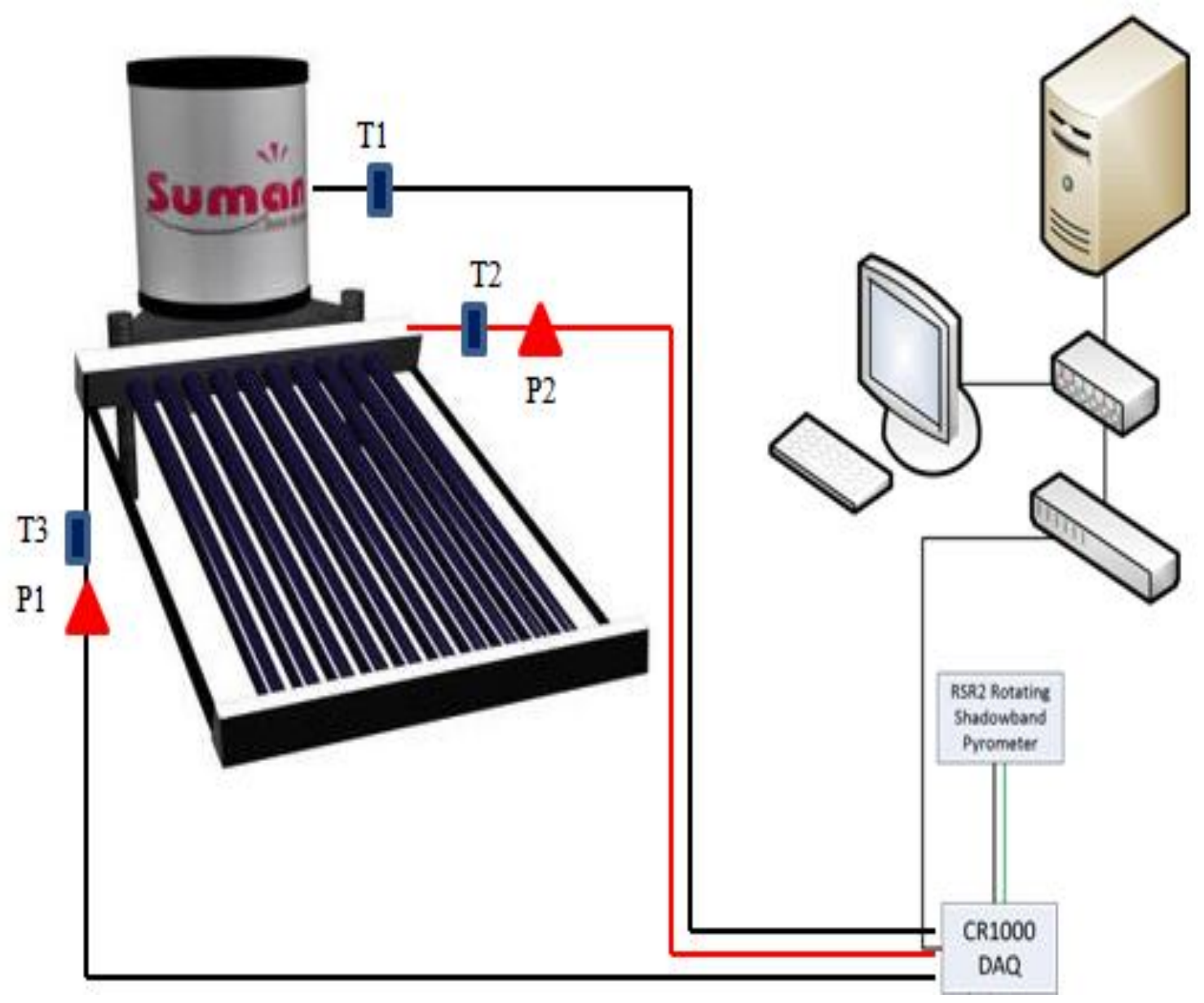

Figure 24: System testing set-up

The water temperature in the storage tank and $\mathrm{CO}_{2}$ temperature at various locations of the system were measured, using J-type thermocouples. Due to possible drift in the thermocouple readings as well as data acquisition errors associated with the reference temperature sensor, the error associated with the thermocouple readings was taken to be $\pm 0.2{ }^{\circ} \mathrm{C}$, as quoted on the J-type thermocouple wire specification sheet. Figure 25 shows the picture of a thermocouple installed within the flow. Three sensors, at the inlet and outlet of the collector and within the storage tank, were inserted in the respective location by a T-joint into the copper tubing, and to seal the thermocouple at the given location, a compression farrell fitting adaptor was used. 
Similarly, special pressure sensors were used to measure the pressure of the refrigerant at the inlet and outlet of the heat exchangers. Two pressure transducers (Fig. 25), with a range of $0-15 \mathrm{MPa}$ were used at the inlet and the outlet of the heat exchanger. The pressure output for each of the sensors was in the range of $0-10 \mathrm{~V}$. Calibration procedure and the interpretation of data from pressure transducers are described in Appendix B.

Initially, one main problem was encountered with the pressure sensor. The chosen pressure sensors can read only current and hence it was unable to communicate with the data logger (CR1000), as data logger could interpret only voltage reading. Therefore, in order to facilitate that the data logger could interpret with the pressure sensor data, a $100 \mathrm{ohm}$ resistor was used to convert current reading to voltage reading (Fig. 26).
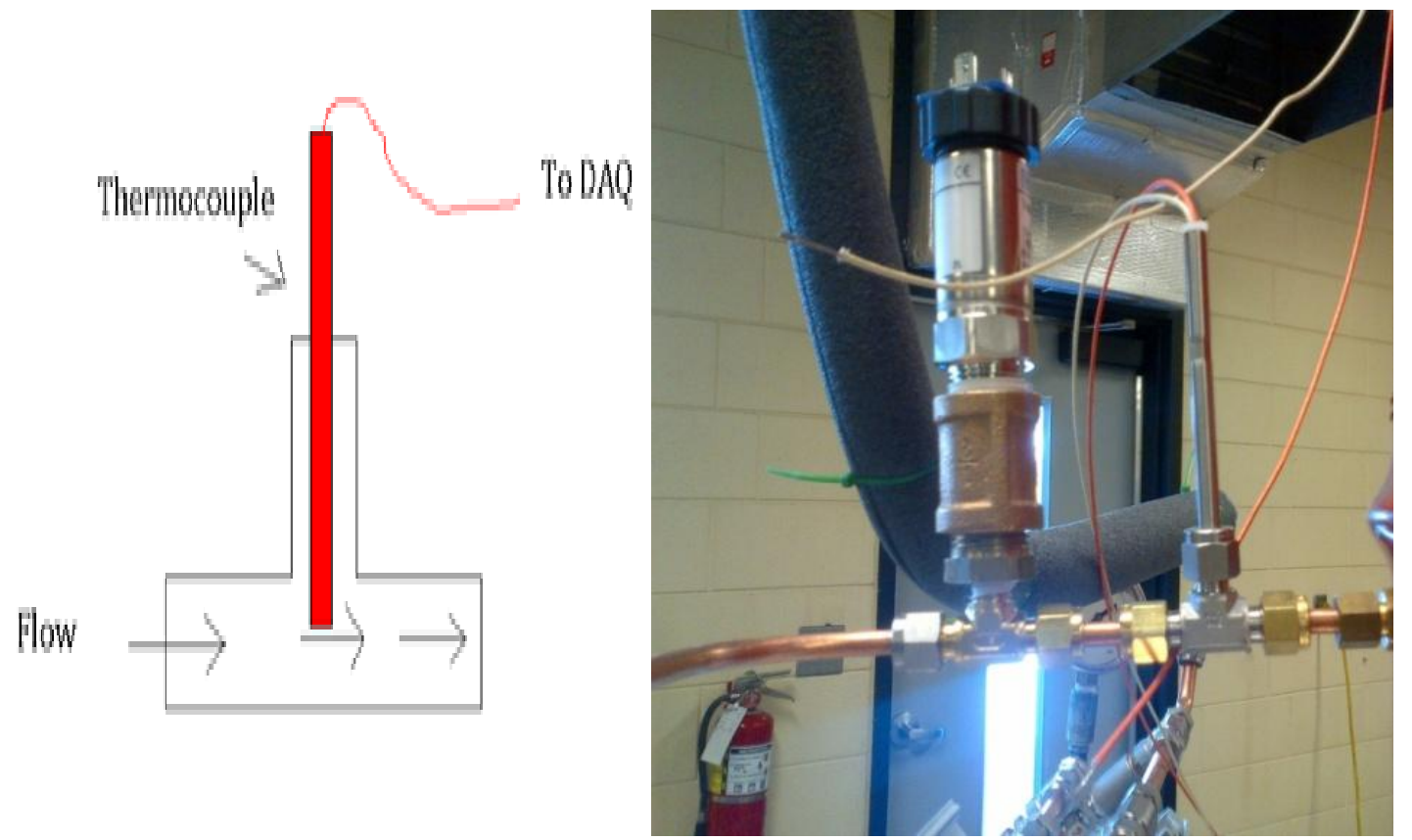

Figure 25: Schematic and picture of temperature sensor installed into the flow 


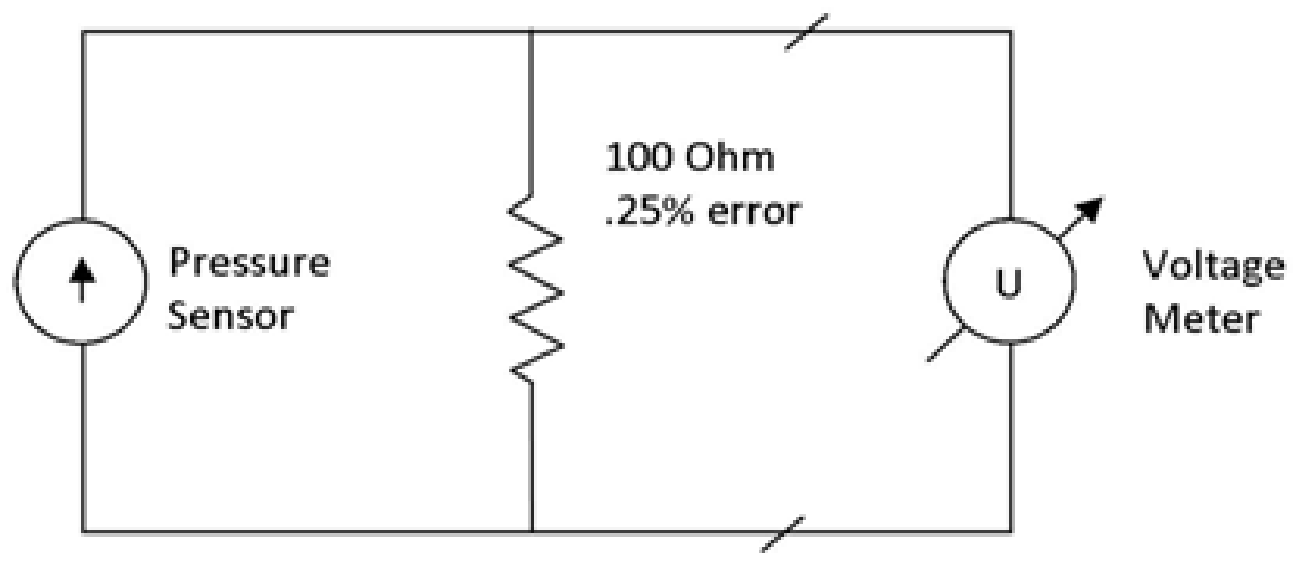

Figure 26: Wiring of the pressure sensor with the resistor
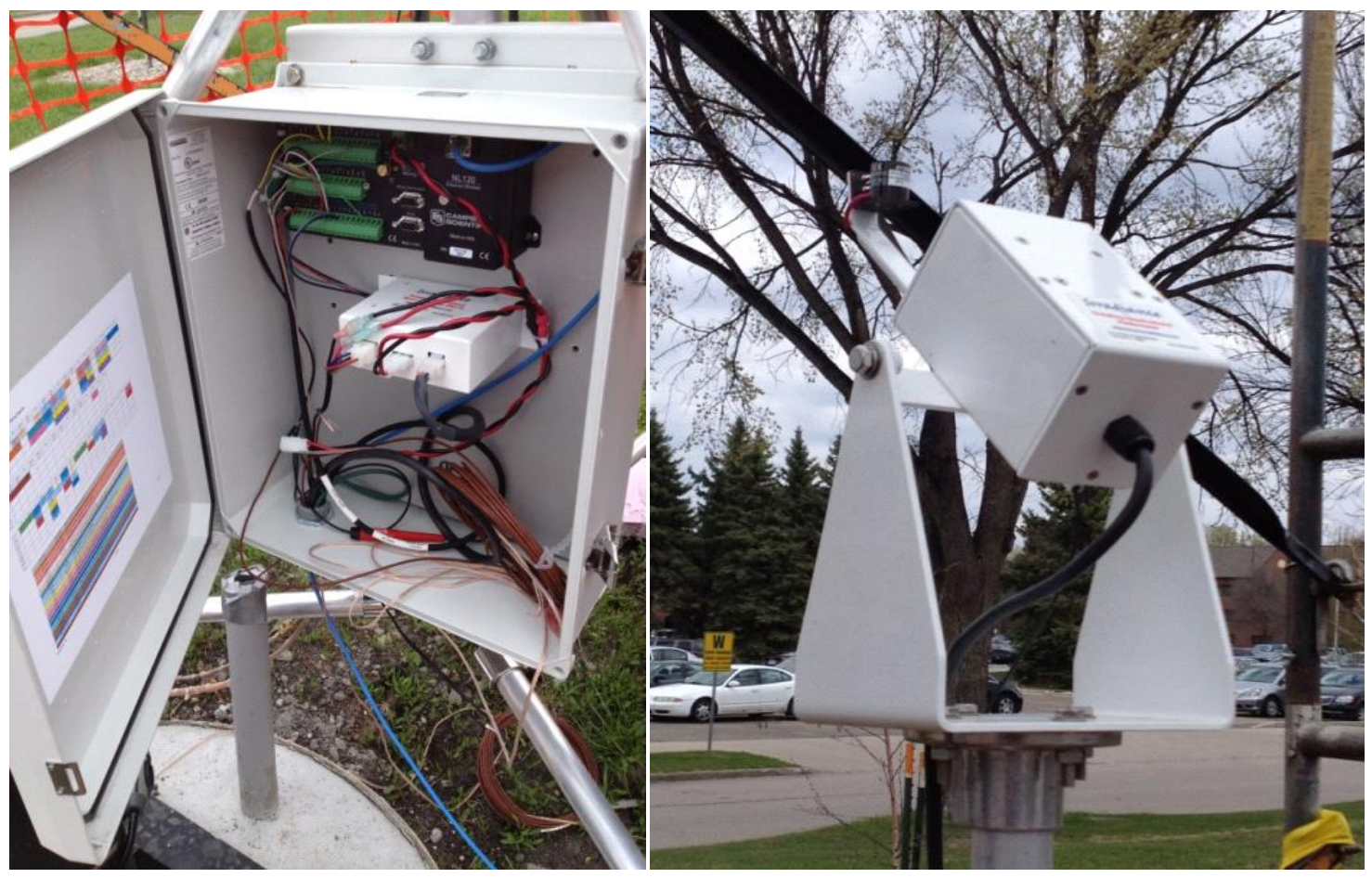

Figure 27: RSR CR1000 logger net software used in the prototype

The RSR2 shown in Fig. 27 is a rotating shadowband radiometer which was used in this study to measure the global radiation, ambient temperature, wind speed as well its direction, and 
relative humidity. The data measured was retrieved and processed using RSR CR1000 (Fig. 27) logger net software from the various sensors.

The heart of the monitoring system was a personal compatible computer which was connected through a USB cable to the data acquisition system and was utilized to record the data. The data recorded in a new file was used to calculate a variety of performance parameters (discussed in Chapter 4) for each test. The experimental procedure followed for the tests run is described in the next section.

\subsection{Experimental Procedure}

Based on the design procedure described in the previous sections, a prototype of a simple thermosyphon SWH system using supercritical $\mathrm{CO}_{2}$ as the working fluid was designed and installed at the North Dakota State University. The details of the major components of the system are shown in Fig 18. The system employs a high performance evacuated tube collector as a heat collecting device, a hot water storage tank $(60 \mathrm{~L})$ with an immersed heat exchanger $(\mathrm{HX})$ as a condenser $\left(0.04 \mathrm{~m}^{2}\right)$, a set of valves, high-accuracy sensors, and a data acquisition system.

A $\mathrm{CO}_{2}$ cylinder of capacity $7 \mathrm{~kg}$ with hand operated valve was used to charge the U- shaped heat removal tubes. The cylinder was connected to main heat removal circuit through high pressure stainless steel valve which could withstand up to $40 \mathrm{MPa}$. As shown in Fig. 1, Valve 1 (vent valve) helps to relieve the $\mathrm{CO}_{2}$ pressure, which facilitates the disconnection of the $\mathrm{CO}_{2}$ reservoir. Valve 2, is a high pressure needle valve which was installed at the inlet of the solar collector to charge the system from the $\mathrm{CO}_{2}$ supply. Initially, Valve 1 and Valve 2 were kept open while charging the system, and once the pressure got stabilize to $6 \mathrm{Mpa}$, the valve of the supply tank, Valve 1 and Valve 2 shut off. However, Valve 1 was immediately released, to vent the excessive $\mathrm{CO}_{2}$ in the supply line connecting the $\mathrm{CO}_{2}$ reservoir. 
Once the collection system had been charged with $\mathrm{CO}_{2}$, the system was exposed to sun to gain thermal energy. The collector was located at the North of Dolve hall facing south at a tilt angle of $45^{\circ} \mathrm{N}$ (optimized for the latitude of Fargo, ND); also it was positioned in such way that it was fully illuminated avoiding any shadows effects.

A typical cycle begins with, R744 $\left(\mathrm{CO}_{2}\right)$ set in motion by thermosyphon action. It gets heated in the evacuated tube solar collector. The heating in the solar collector aids a rise in $\mathrm{CO}_{2}$ temperature, creating a supercritical $\mathrm{CO}_{2}$ high temperature state. This supercritical $\mathrm{CO}_{2}$ passes through the outlet header pipe to the storage tank. The high temperature and high pressure $\mathrm{CO}_{2}$ vapor then rejects the heat to the water through the condenser in the storage tank. Once heat is transferred, low temperature $\mathrm{CO}_{2}$ exits the condenser and move back down to the collector system through the inlet header pipe. One cycle of the operation is thus completed and the system is now ready for the next cycle. Circulation of $\mathrm{CO}_{2}$ from the collector to the storage tank and vice-versa is affected by buoyancy forces.

Collector surface temperature, storage water tank temperature, and temperature of $\mathrm{CO}_{2}$ at various locations of the system were measured, using J-type thermocouples. The high $\mathrm{CO}_{2}$ pressures at various locations of the systems were measured, using pressure transmitters. A solarimeter was used to measure the intensity of the global solar radiation incident on the collector surface. The above measuring processes were controlled and monitored by personal computer-based data acquisition software. The data was recorded at 5 min intervals in a data logger, which was used for the data analysis.

Before carrying out the actual test, preliminary testing was carried out for possible trouble shoots. Later, a range of tests were performed to determine the performance of thermosyphon SWH system under various conditions The experiments were mainly conducted: 
(i) to focus on the characteristics of the supercritical $\mathrm{CO}_{2}$-based solar collector including $\mathrm{CO}_{2}$ temperature and pressure, (ii) to analyze the thermal performance of the solar collector, for the Fargo weather conditions, and (iii) to study the influence of various operating parameters such as storage volume, initial tank temperature etc. on the overall performance of a $\mathrm{CO}_{2}$ assisted $\mathrm{SWH}$ system. A summary of the parametric study has been presented in Table 7.

Table 7: List of various operational parameters

\begin{tabular}{|c|c|c|c|c|c|c|c|c|}
\hline \multirow[t]{2}{*}{ Test Conditions } & \multicolumn{4}{|c|}{ Initial tank temperature } & \multicolumn{4}{|c|}{ Storage Tank Volume } \\
\hline & $5^{\circ} \mathrm{C}$ & $7^{\circ} \mathrm{C}$ & $10^{\circ} \mathrm{C}$ & $15^{\circ} \mathrm{C}$ & $65 \mathrm{~L}$ & 55L & $60 \mathrm{~L}$ & 45L \\
\hline & & & & $\mathrm{x}$ & $\mathrm{X}$ & & & \\
\hline \multirow{4}{*}{$\begin{array}{l}\text { (a) When storage } \\
\text { volume changes } \\
\text { and the inlet water } \\
\text { temperature } \\
\text { remain constant }\end{array}$} & & & & $\mathrm{X}$ & & $\mathrm{X}$ & & \\
\hline & & & & $\mathrm{X}$ & & & $\mathrm{x}$ & \\
\hline & & & & $\mathrm{x}$ & & & & $\mathrm{x}$ \\
\hline & & & & $\mathrm{X}$ & & & & \\
\hline \multirow{5}{*}{$\begin{array}{l}\text { (b) Volume remain } \\
\text { constant but the } \\
\text { inlet temperature } \\
\text { varies }\end{array}$} & & & & & & & & \\
\hline & $\mathrm{X}$ & & & & & & $\mathrm{X}$ & \\
\hline & & $\mathrm{X}$ & & & & & $\mathrm{X}$ & \\
\hline & & & $\mathrm{X}$ & & & & $\mathrm{X}$ & \\
\hline & & & & $\mathrm{X}$ & & & $\mathrm{X}$ & \\
\hline
\end{tabular}




\section{RESULTS AND DISSCUSSIONS}

Experiments were carried out to study the feasibility and performance of the proposed system using $\mathrm{CO}_{2}$ as working fluid for Fargo, ND weather conditions. Given the time frame (Graduate study), experiments were performed, for about five months from February upto June 2013. However, the thermosyphon system could not be tested entire day length because both winter and early spring of the year 2013 in North Dakota experienced harsh weather conditions compared to previous years. Most of the days were cloudy and could not get sufficient solar radiation to conduct the test. Even during summer, often the weather was inconsistent due to frequent rain and cloudy conditions. Since it was not practical to carry out experiments for the entire day length, only the operation histories of "1-2" hours during winter, "2-4' hours (spring), and "6-8" (summer) for typical days are presented for illustration.

\subsection{Temperature and Pressure of $\mathrm{CO}_{2}$}

The characteristics of supercritical $\mathrm{CO}_{2}$-based solar collector, including $\mathrm{CO}_{2}$ temperature and pressure plays an important role in dictating the overall performance of the proposed thermosyphon solar water heating system. Hence testing was carried out under stagnation conditions; that is, energy collected by the concentrator was used to raise the temperature of working fluid to its stagnation temperature, to analyze the characteristics of the working fluid $\left(\mathrm{CO}_{2}\right)$. Experiments were conducted in the first week of June 2013, to understand the nature of supercritical $\mathrm{CO}_{2}$ in the collector. This period was selected for conducting the experiments mainly because the system can be tested for full day length period.

The collection system consisting of a collector $1.15 \mathrm{~m}^{2}$ exposed area was initially filled with $\mathrm{CO}_{2}$. The collector, kept facing south at the angle of $45^{\circ}$ to the horizontal (equal to the latitude of Fargo), was exposed to solar radiation from 8:00 hours. No carbon dioxide vapor was 
being used for the end uses purposes. The carbon dioxide in the system was allowed to be heated continuously by the thermosyphon action. The temperatures of the carbon dioxide were periodically measured using J-type thermocouple at the inlet and the out of the collector. The high $\mathrm{CO}_{2}$ pressures at various locations of the systems were measured, using pressure transmitters. The global radiation intensity incident on the collector surface was measured using solarimeter. The above measuring processes were monitored and recorded at frequent intervals of time.

The results of the experiments conducted on June 7, 2013 and the typical set of results obtained from the experiments is furnished in Table 8 . The $\mathrm{I}_{\mathrm{T}}$ was taken as $775 \mathrm{~W} / \mathrm{m}^{2}$, which is the maximum solar radiation intensity recorded by the solarimeter at the 14:00 hours on the day of experiments. In the experiments, the collector was exposed to the sun at 08.00 hours. Figure 28 shows the variation in $\mathrm{CO}_{2}$ temperature with time. It is seen that temperature increases rapidly to begin with, the reason being (i) the intensity of the radiation on the collector increasing continuously and (ii) the losses from the collector were small as the collector temperature was low initially. Beyond 12.00 hours, the temperature increases slowly. This was due to the fact that not only does the solar radiation intensity increase slowly, but also the losses from the collector were high because of the higher temperature in the system. Beyond 14.00 hours the increase was very small. Actually there should be a fall in temperature beyond 14.00 hours as the radiation intensity was on decrease. But, the effect of reducing radiation is compensated until 15:00 hour by the heat capacity effect of the collector and $\mathrm{CO}_{2}$ in it. $\mathrm{CO}_{2}$ reaches a maximum of $90{ }^{\circ} \mathrm{C}$ at around 15:00 hours. 


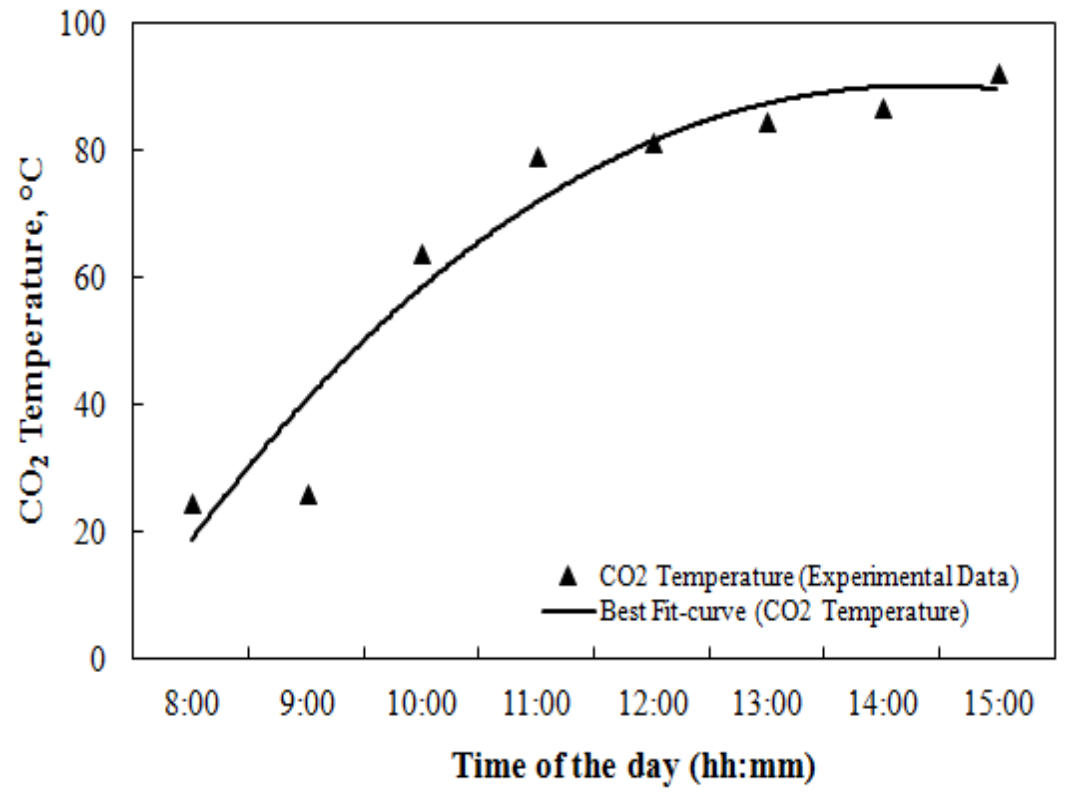

Figure 28: Variation of $\mathrm{CO}_{2}$ temperatures with time

Figure 29 shows the corresponding variation of pressure with time. The $\mathrm{CO}_{2}$ pressure varies largely with the solar radiation in the collector. A maximum pressure of around $13 \mathrm{Mpa}$ was recorded at 15:00 hours. Beyond 15.00 hours the temperature and pressure fall with the decrease of the solar radiation.

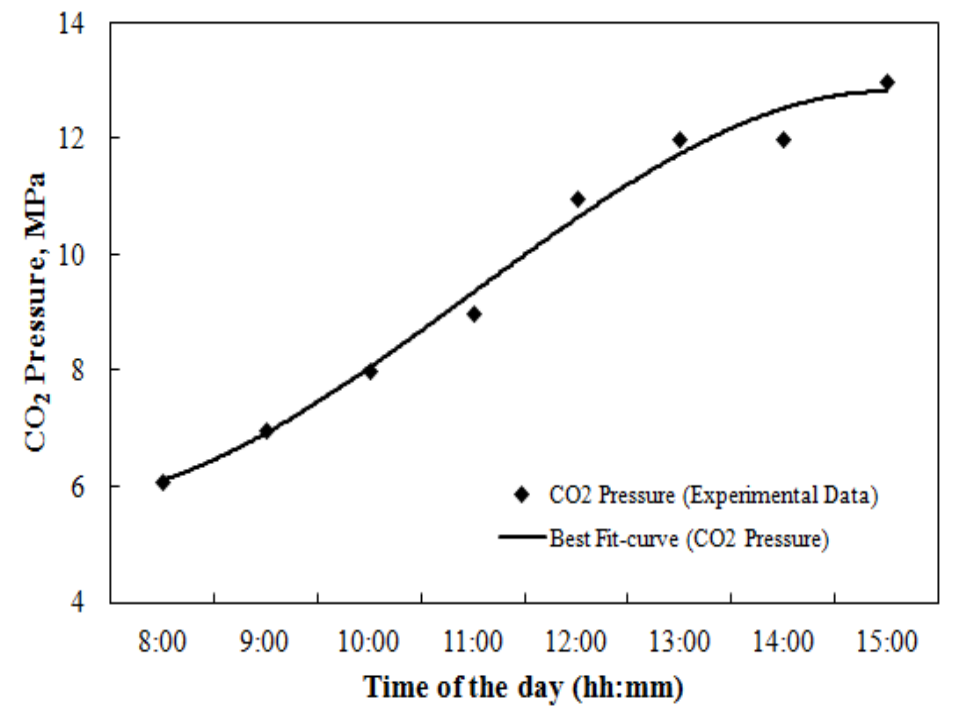

Figure 29: Variation of $\mathrm{CO}_{2}$ pressure with time 
Based on the above discussion, it can be concluded that for $\mathrm{CO}_{2}$-based collector, not only the $\mathrm{CO}_{2}$ temperature but also the $\mathrm{CO}_{2}$ pressure in the collector was influenced by the solar radiation, which makes the collector characteristics more complicated than traditional collectors using water as working fluid.

Table 8: Typical experimental values

\begin{tabular}{|c|c|c|c|c|}
\hline $\begin{array}{c}\text { Time } \\
(\text { Hours })\end{array}$ & $\begin{array}{c}\mathbf{I}_{\mathbf{T}} \\
\left(\mathrm{W} / \mathrm{m}^{2}\right)\end{array}$ & $\begin{array}{c}\mathbf{C O}_{\mathbf{2}} \text { Temperature } \\
\left({ }^{\circ} \mathrm{C}\right)\end{array}$ & $\begin{array}{c}\mathbf{C O}_{\mathbf{2}} \mathbf{p r e s s u r e} \\
(\mathrm{MPa})\end{array}$ & $\begin{array}{c}\mathbf{T}_{\mathbf{a}} \\
\left({ }^{\circ} \mathbf{C}\right)\end{array}$ \\
\hline $08: 00$ & 370 & 24.51 & 6.1 & 17.42 \\
\hline $09: 00$ & 501 & 25.97 & 7.4 & 18.37 \\
\hline $10: 00$ & 569 & 63.78 & 8.2 & 21.64 \\
\hline $11: 00$ & 686 & 78.86 & 11.1 & 22.61 \\
\hline $12: 00$ & 650 & 81.17 & 12.5 & 22.66 \\
\hline $13: 00$ & 650 & 86.34 & 12.6 & 23.45 \\
\hline $14: 00$ & 775 & 89.55 & 13 & 23.61 \\
\hline $15: 00$ & 724 & 90.16 & & \\
\hline
\end{tabular}

(i) Date of experiment: 6.7.2013

(ii) Time of Exposure of the collector to the sun: 08:00 hours

\subsection{Performance of ETC}

The performance of the evacuated tube U-pipe solar collector (as detailed in Chapter 4) was determined by obtaining values of instantaneous efficiency for a large combination of values of incident insolation, ambient temperature and inlet fluid temperature. This requires experimentally measuring the rate of incident solar radiation onto the collector as well as the rate of energy addition to the heat transfer fluid. The testing of the collector was conducted in such a 
way that an "efficiency curve" was determined for the collector under stagnation conditions. Experimental results pertaining to 7th June, 2013, were utilized to produce efficiency profile of evacuated tube U-pipe solar collector.

The efficiency values calculated were plotted against parameter $\left(T_{f}-T_{a}\right) / I_{T}$. Figure 30 shows the efficiency varies profile of the evacuated tube U-pipe solar collector. The maximum global solar radiation intensity recorded by the solarimeter on the day of experiment was 775 $\mathrm{W} / \mathrm{m}^{2}$. As seen in the Figure 30, experimental data points are clearly scattered about the straight line.

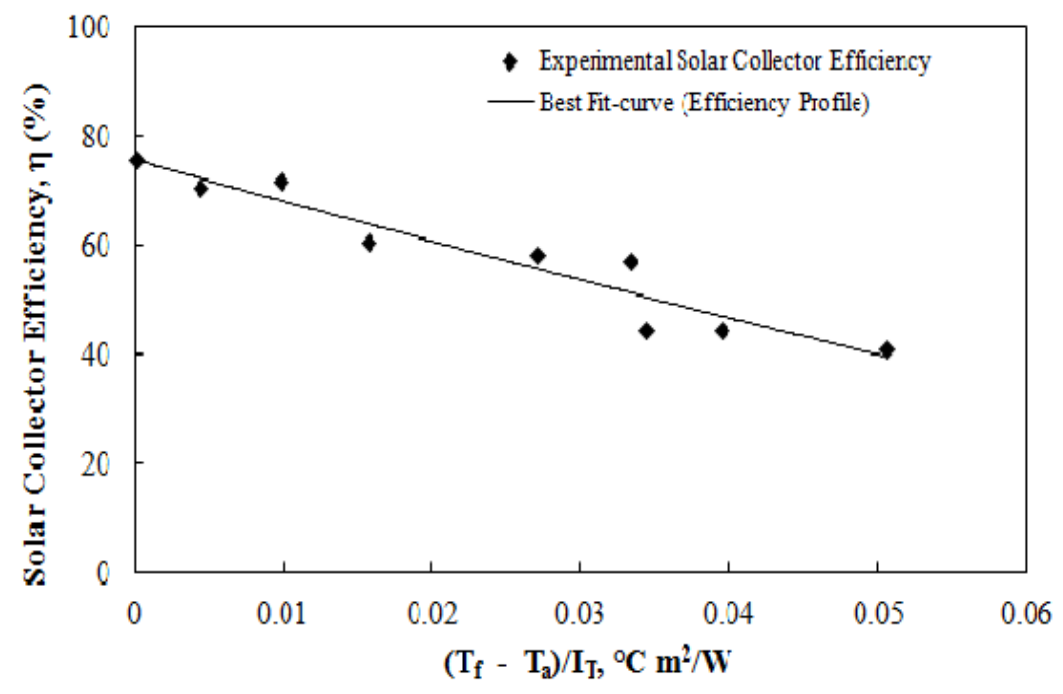

Figure 30: Performance of an evacuated tube collector

Figure 30 also shows that efficiency reduces linearly with an increase in the parameter $\left(T_{f}-T_{a}\right) / I_{T}$. The slope of the profile is negative, as the difference between the working fluid and ambient temperature rises, the radiation and convection losses from the collector also increases. In general, as per the law of conservation of energy, the collector performance can be further 
improved by increasing energy transmission through the collector to the working fluid (useful energy) and minimizing the collector heat losses, with improved insulation techniques.

\subsection{Typical Results}

There are several characteristics of $\mathrm{CO}_{2}$ that contributes to the high efficiency of $\mathrm{CO}_{2}$-based collector compared to traditional collectors using water as working fluid. Experimental data under stagnation conditions shows that the $\mathrm{CO}_{2}$ could reach as high as $90{ }^{\circ} \mathrm{C}$, on a typical sunny day. These results indicate that $\mathrm{CO}_{2}$ can be used as working fluid, instead of the conventionally used water or other refrigerants. The $\mathrm{SWH}$ system utilizing $\mathrm{CO}_{2}$ as working fluid was tested during the month of Feb-June.

The results presented in this section pertain to one day measured data for a typical sunny day. The data obtained in the month of June, for full day length has been chosen for illustration. Experiments were conducted on two consecutive, clear sky days to obtain consistency in the results.

To begin with, the complete collector assembly was evacuated. The collection system was then charged with $\mathrm{CO}_{2}$ (as explained earlier in Section 5.3). The extent to which the U-tubes were filled was noted by the level of the pressure in analogue pressure gauge connected to it. The collector was exposed to sun from 8:00 hours on June 15, 2013.

The instantaneous global solar radiation on the collector, the $\mathrm{CO}_{2}$ fluid pressure at the inlet and the outlet of the collector, $\mathrm{CO}_{2}$ fluid temperature at the inlet and the outlet of the heat exchanger, as well as the temperature of the storage tank were measured. The collected data was used to determine the performance factors such as the collector inlet/outlet temperature difference, useful energy gain, collector efficiency and the heat recovery efficiency of the system. 
Figure 31 shows the typical meteorological data of June 15, 2013. This figure clearly shows that during the test day, sky was clear and sunny. The time-averaged ambient temperature and solar radiation values were $21{ }^{\circ} \mathrm{C}$ and $600 \mathrm{~W} / \mathrm{m}^{2}$, respectively.

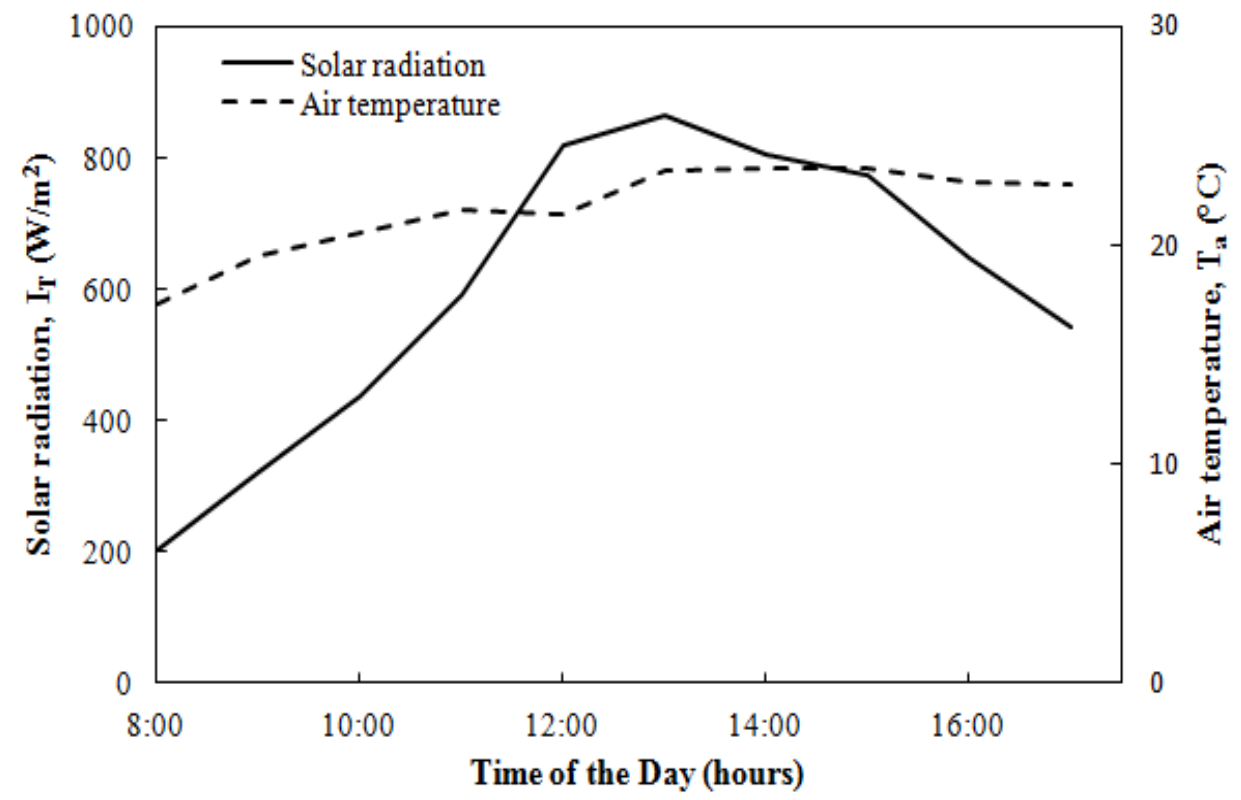

Figure 31: Variation of solar radiation and ambient temperature Vs Time of Day

Thermocouples were used to monitor the temperature of $\mathrm{CO}_{2}$ refrigerant. During the initial hours of exposure, a steady rise in $\mathrm{CO}_{2}$ temperature and pressure was noticed. Measured values of $\mathrm{CO}_{2}$ temperature both at the inlet and the outlet of the collector are plotted in Fig. 32 . During the test period, the $\mathrm{CO}_{2}$ temperature at the collector outlet varied from $27{ }^{\circ} \mathrm{C}$ to $92{ }^{\circ} \mathrm{C}$. At such high temperatures, supercritical $\mathrm{CO}_{2}$ can serve as a useful solar thermal source for hot water supply. Literature shows that, it is difficult to achieve such temperature gain, with conventional flat plate collectors with water as working fluid [127]. This improved design has successfully generated approximately a $65{ }^{\circ} \mathrm{C}$ rise in the $\mathrm{CO}_{2}$ temperature. It is due to the fact 
that, when $\mathrm{CO}_{2}$ temperature is close to its supercritical state, even a small change in pressure and temperature results in dynamic changes in its thermo-physical properties.

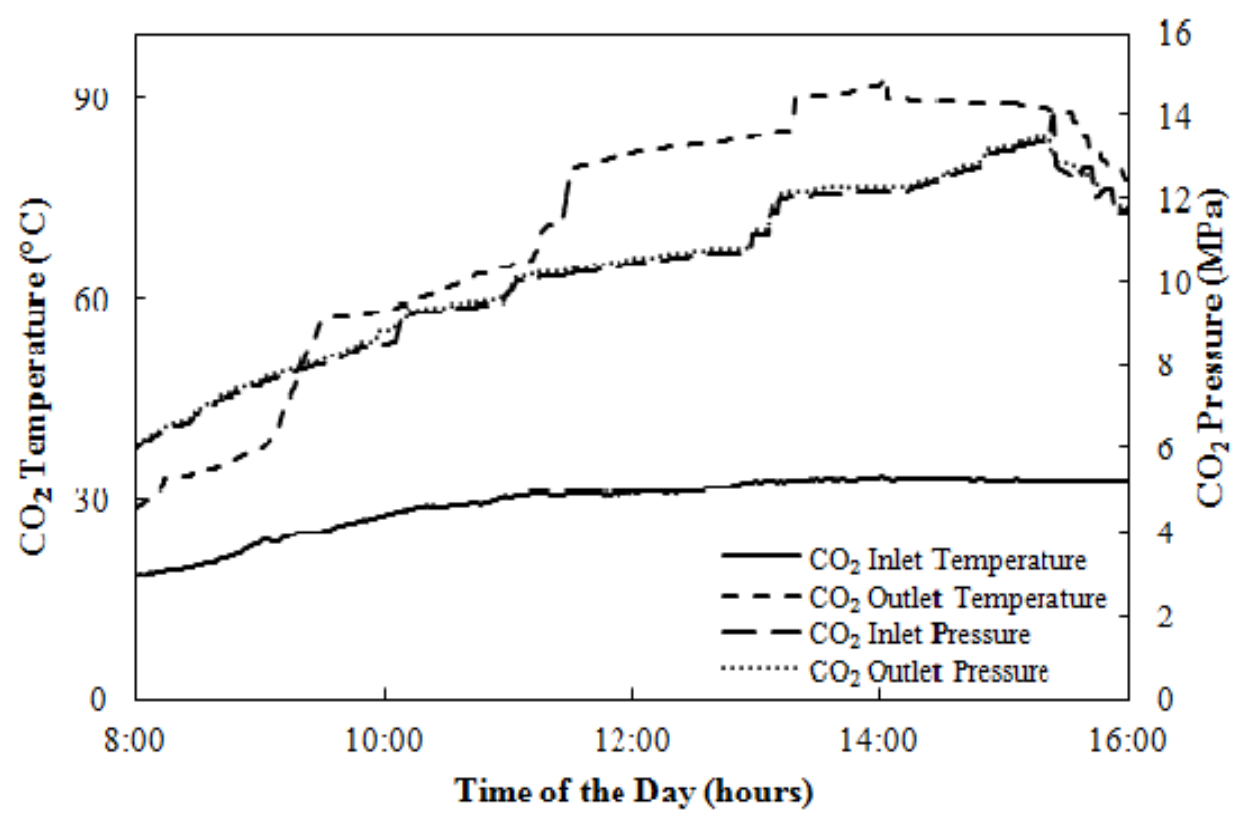

Figure 32: Variation of $\mathrm{CO}_{2}$ temperature and pressure Vs Time of Day

Figure 32 also shows the variation in pressure of $\mathrm{CO}_{2}$, both at inlet and outlet conditions of the collector. During test hours, it was noticed that not only $\mathrm{CO}_{2}$ temperature, but also $\mathrm{CO}_{2}$ pressure in the collector, was influenced by solar radiation. The changes in the $\mathrm{CO}_{2}$ pressure at the collector inlet and o utlet have similar trends. It could be seen that the $\mathrm{CO}_{2}$ pressure at the solar collector rises from $6 \mathrm{MPa}$ to $13 \mathrm{MPa}$ within 08:00 to 15:00 hours. During the most time of the test period, $\mathrm{CO}_{2}$ fluid in the collector was above the critical point of $\mathrm{CO}_{2}$ (7.3 MPa). Beyond 16:00 hours with the decrease in solar radiation, the $\mathrm{CO}_{2}$ pressure also drops sharply and hence not been plotted.

The relationship between temperature, pressure, enthalpy, and entropy are shown in pressure-enthalpy diagram in Figure 33. In this figure, the critical point "C.P." is located at the 
peak of the vapor dome. As stated earlier, $\mathrm{CO}_{2}$ is a supercritical fluid at temperatures above 31.1 ${ }^{\circ} \mathrm{C}$ and pressure above 7.3 $\mathrm{MPa}$. The fluid states of $\mathrm{CO}_{2}$, both at the inlet and outlet of the collector, are shown in the figure. It can be seen that during the entire test period, at the inlet of the collector, the $\mathrm{CO}_{2}$ was in liquid state. On the other hand, at the collector outlet, $\mathrm{CO}_{2}$, initially was in liquid phase, and then enters into supercritical state. However, beyond the 16:00 hours $\mathrm{CO}_{2}$ enters the mixed zone due to low solar radiation input.

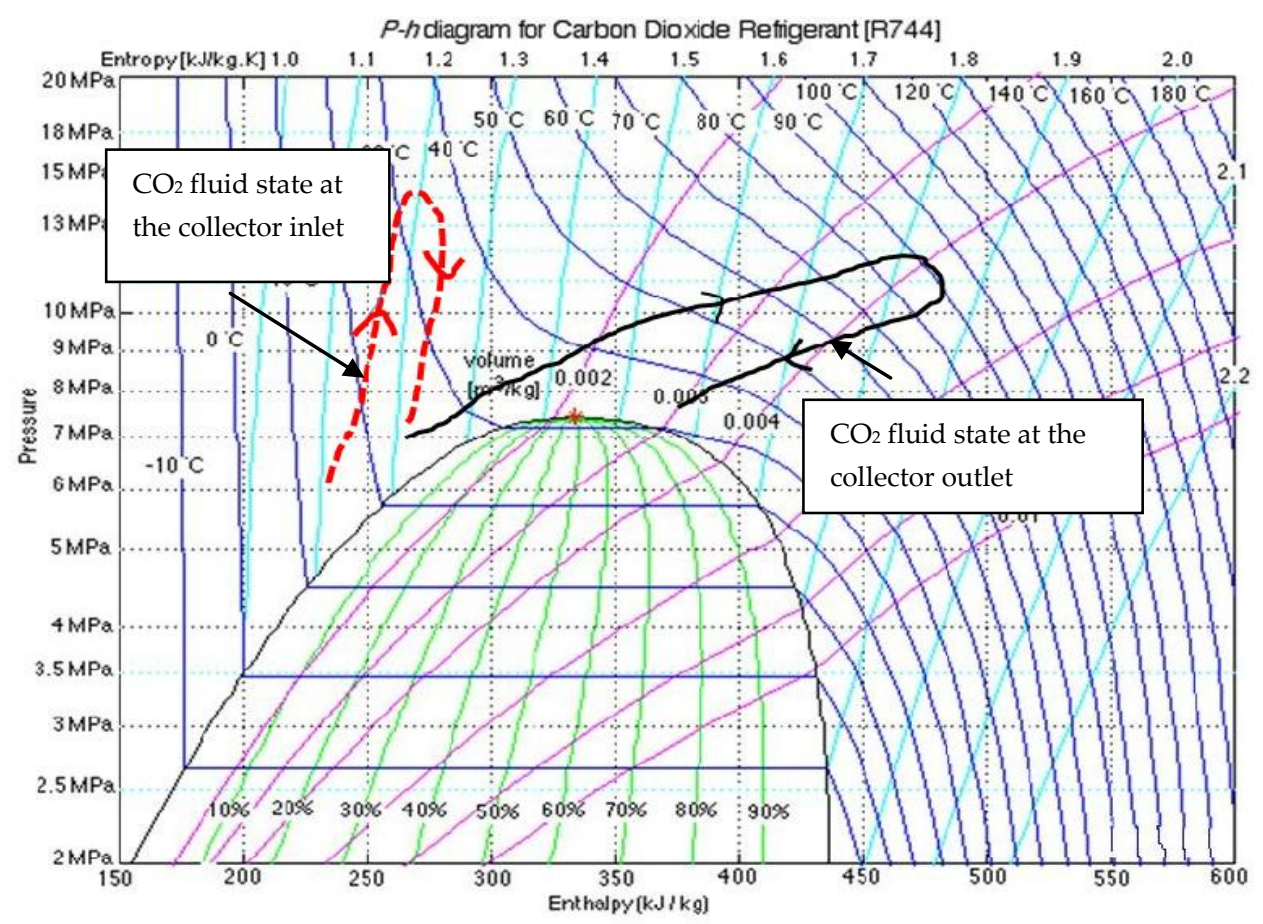

Figure 33: $\mathrm{CO}_{2}$ Pressure-enthalpy diagram showing $\mathrm{CO}_{2}$ fluid stated during the test period

As seen in Figure 34, during the test day the initial water temperature in the storage tank was at $15{ }^{\circ} \mathrm{C}$. The gain in solar insolation and an increase in $\mathrm{CO}_{2}$ temperature are reflected in terms of rise in storage rank water temperature. The system attained a maximum temperature of about $50{ }^{\circ} \mathrm{C}$. The improved design generated a $35^{\circ} \mathrm{C}$ rise in storage tank temperature, which was in line with the previous study [127]. However, it should be pointed out that, the expected 
storage tank water temperature was lower compared to the gain in the $\mathrm{CO}_{2}$ temperature at the outlet of the collector. Several factors such as the insulation, condenser design, and wind effect might have contributed to such differences. Given the severe Fargo winter weather conditions, the designed heat exchanger was not an optimal one. Along with the heat exchanger design, choice of the insulation also plays a major role in ensuring the better increase in the storage tank temperature by avoiding the heat losses. Generally, water heaters are available with insulation rating ranging R-6 to R-24 [138]. For the proposed design, fiber glass insulation (R-13 of 3.5 inch thickness) was used to minimize the heat losses. As seen in the Fig. 34, beyond 15:00 hours the storage tank temperature was continuously dropping from $50{ }^{\circ} \mathrm{C}(15: 00$ hours $)$ to $44^{\circ} \mathrm{C}$ (16:00 hours). This $6{ }^{\circ} \mathrm{C}$ drop reflects the fact that fiber glass insulation used in the study could not meet the requirement for Fargo weather conditions. Hence, it is recommended to use higher $\mathrm{R}$-value rating insulation (minimum of $\mathrm{R}-30$ ) along with vapor barrier techniques when exposed to such weather conditions. Therefore, to attain higher heat recovery efficiency, storage tank and condenser design must be optimized, in addition to the utilization of an appropriate insulation.

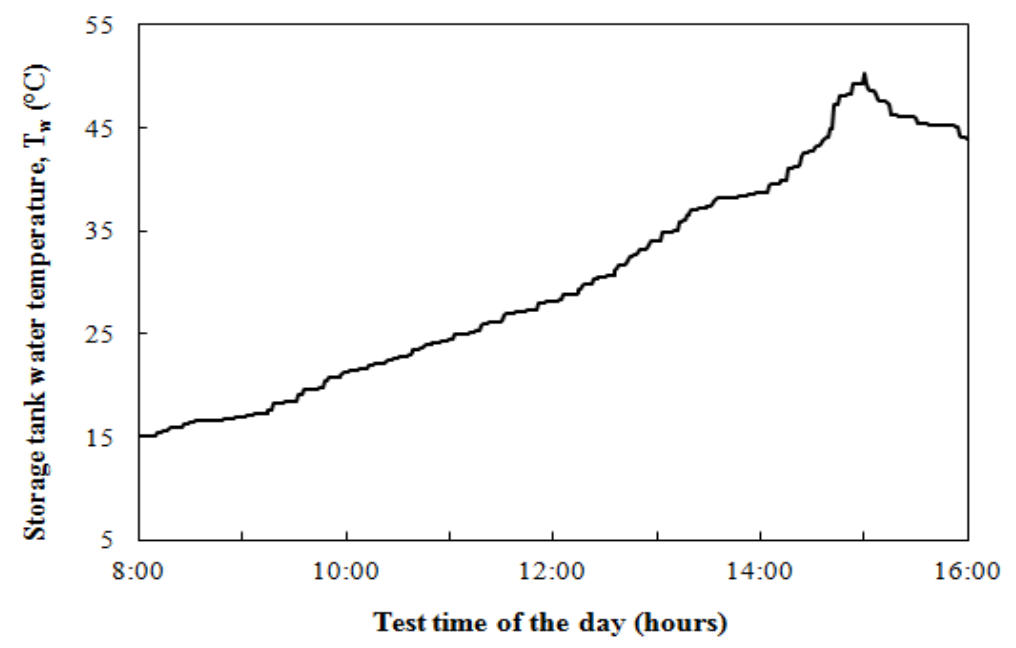

Figure 34: Variation of storage tank water temperature Vs Time of Day 
The above discussed factors have an influence on the collector useful heat gain $\left(Q_{u}\right)$ as well as the heat recovered $\left(Q_{w}\right)$ by the water in the storage tank (Fig. 35). As seen in the Fig. 35, the solid line indicates the useful heat gain by the collector $\left(Q_{u}\right)$, the dash line indicates the recovered heat by the water in the storage tank.

With an increase in solar insolation levels, the collector heat gain also steadily increases accordingly and attains a maximum value of $700 \mathrm{~W}$. The values of the heat quantity recovered oscillate greatly and the time-averaged heat quantity recovered was evaluated to be about $340 \mathrm{~W}$. Based on the data obtained, the time-averaged collector efficiency $\left(\eta_{\text {col }}\right)$ and heat recovery efficiency $\left(\eta_{\text {RE }}\right)$ was calculated to be $63 \%$ and $48 \%$ respectively, and are shown in Fig. 36.

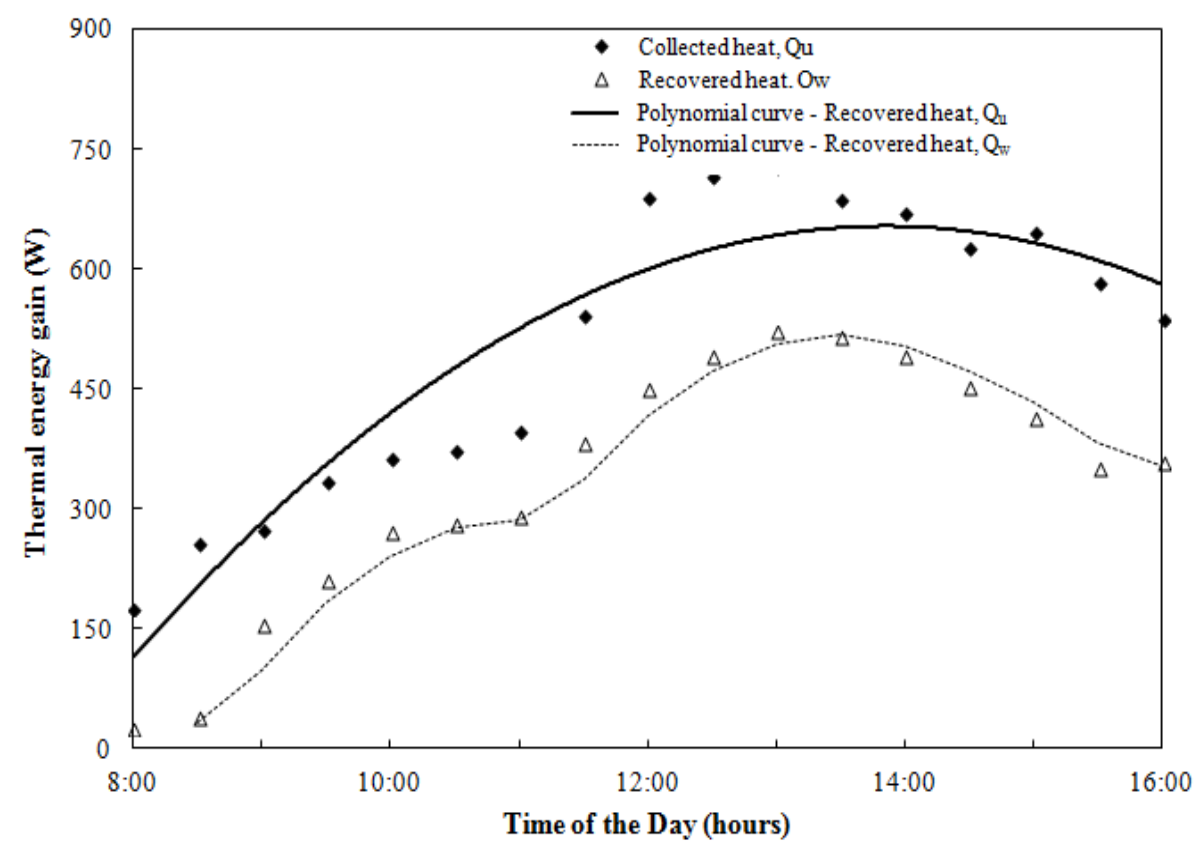

Figure 35: Variation of collector useful heat gain and recovered heat quantity Vs Time of Day 


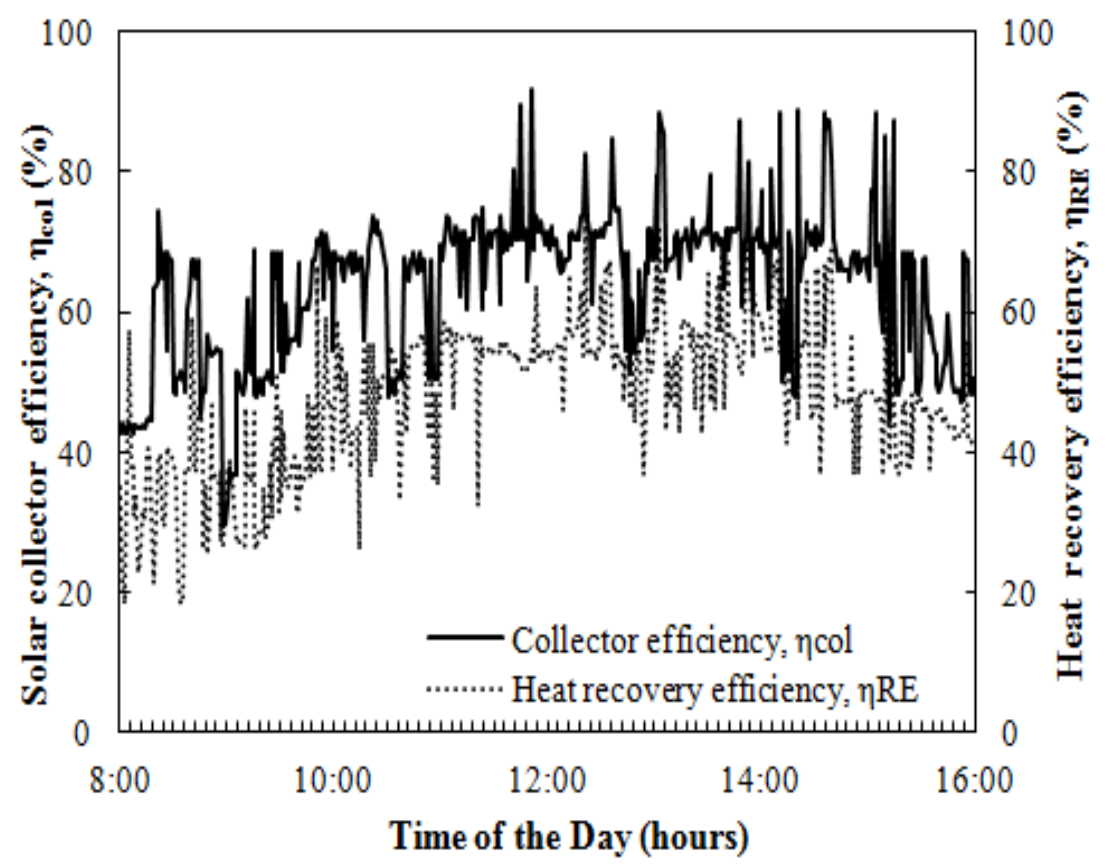

Figure 36: Variation of collector efficiency and heat recovery efficiency Vs Time of Day

The above discussed data corresponding to the experiments conducted on June 15, 2013, are provided in the following Table 9. The quantities listed in the Table refer to the following operating performance parameters:

$\mathrm{I}_{\mathrm{T}} \quad: \quad$ Total solar radiation

$\mathrm{T}_{\mathrm{CO} 2}: \quad \mathrm{CO}_{2}$ temperature at the collector outlet

$\mathrm{T}_{\mathrm{a}} \quad: \quad$ Ambient temperature

$\mathrm{P}_{\mathrm{CO} 2}: \quad \mathrm{CO}_{2}$ pressure at the collector outlet

$\mathrm{Q}_{\mathrm{u}} \quad$ : $\quad$ Useful heat gain by the collector

$\mathrm{Q}_{\mathrm{w}} \quad$ : $\quad$ Heat quantity recovered by the storage tank 
Table 9: Experimental results for a sunny day

\begin{tabular}{|c|c|c|c|c|c|c|c|}
\hline $\begin{array}{c}\text { Time } \\
(\text { Hours })\end{array}$ & $\begin{array}{c}\mathbf{I}_{\mathbf{T}} \\
\left(\mathrm{W} / \mathrm{m}^{2}\right)\end{array}$ & $\begin{array}{c}\mathbf{T}_{\mathbf{C O} 2} \\
\left({ }^{\circ} \mathrm{C}\right)\end{array}$ & $\begin{array}{c}\mathbf{T}_{\mathbf{a}} \\
\left({ }^{\circ} \mathrm{C}\right)\end{array}$ & $\begin{array}{c}\mathbf{P}_{\mathbf{C O 2}} \\
(\mathrm{MPa})\end{array}$ & $\begin{array}{c}\mathbf{T}_{\mathbf{w}} \\
\left({ }^{\circ} \mathrm{C}\right)\end{array}$ & $\begin{array}{c}\mathbf{Q}_{\mathbf{u}} \\
(\mathrm{W})\end{array}$ & $\begin{array}{c}\mathbf{Q}_{\mathbf{w}} \\
(\mathrm{W})\end{array}$ \\
\hline $08: 00$ & 202 & 28.1 & 17.4 & 6.1 & 15.09 & 173.8 & 72.7 \\
\hline $09: 00$ & 322 & 37.4 & 18.3 & 7.4 & 17.01 & 273.1 & 113.6 \\
\hline $10: 00$ & 436 & 58.2 & 19.5 & 8.2 & 21.23 & 362.2 & 229.6 \\
\hline $11: 00$ & 590 & 65.3 & 21.6 & 9.7 & 24.4 & 493.4 & 316.8 \\
\hline $12: 00$ & 819 & 81.9 & 22.6 & 11.1 & 28.14 & 688.1 & 419.7 \\
\hline $13: 00$ & 863 & 84.4 & 22.6 & 12.5 & 34.04 & 725.6 & 520.8 \\
\hline $14: 00$ & 803 & 92.4 & 23.4 & 12.6 & 39.36 & 669.4 & 513.74 \\
\hline
\end{tabular}

(i) Date of experiment: 15.06 .2013

(ii) Time of exposure of the collector to the sun: 08:00 hours

Although, the results obtained pertain to one day measured data, other parametric studies carried out during similar weather conditions showed the similar time-averaged collector efficiencies of about $65 \%$.

\subsection{Effect of Various Parameters on the System}

Having established a set of typical results on the performance of the system, the effect of varying individual parameters such as storage tank volume, tank inlet temperature etc., was studied subsequently. Several operating parameters are varied to obtain the optimal performances of the system in terms of useful heat gain, heat recovery efficiency, and collector efficiency. 


\subsubsection{Effect of Storage Tank Volume}

The results discussed so far pertain to the tank volume of $60 \mathrm{~L}$. The design detail of this volume is mentioned in Chapter 5. To ensure the reliability of the system design, a proper size of the storage is essential. In order to study the effect of tank volume on the system performance, tank volume of sizes $45 \mathrm{~L}$ to $65 \mathrm{~L}$ were chosen to carry out the experiments.

Figures 37-39 illustrates the effect of storage tank volume on the useful heat gain by the collector, collector efficiency and heat recovery efficiency. From Figure 37, it can be clearly seen that, with increase in the tank volume, the energy gain by the collector also increases. This is because, for a given collector area, if the storage tank volume increases the condensing temperature decreases which results in marginal decrease in evaporating temperature. Hence, this causes an increase energy gain by the collector, which positively influences the system performance (Fig. 38). As the storage tank volume increases from $45 \mathrm{~L}$ to $65 \mathrm{~L}$ the timeaveraged heat recovery efficiency increases from 40 to $50 \%$.

On the other hand, the lower evaporating temperature of the refrigerant in the solar collector reflects lower heat loss, which results in higher collector efficiencies. With the increase in the storage volume, the time-averaged collector efficiency increases from $45 \%$ to $70 \%$ (Fig. 39). However, beyond the storage tank volume above 65 liters the performance parameters $\left(\eta_{c o l}\right)$ do not vary much. This indicates that, for a given collector area an optimum size of storage

tank should be chosen and 60-65 liters $\mathrm{m}^{-2}$ turns out to be the optimum size for the proposed design. 


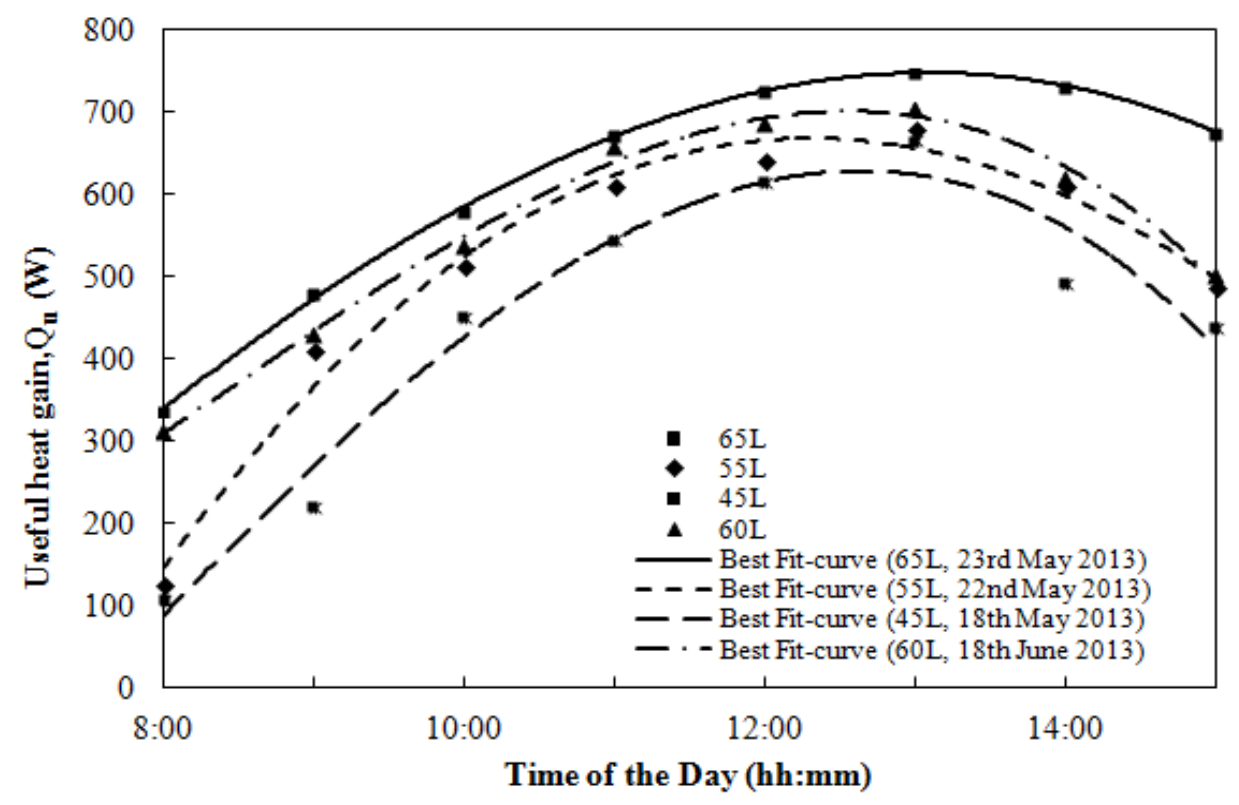

Figure 37: Effect of storage volume on the useful heat gain

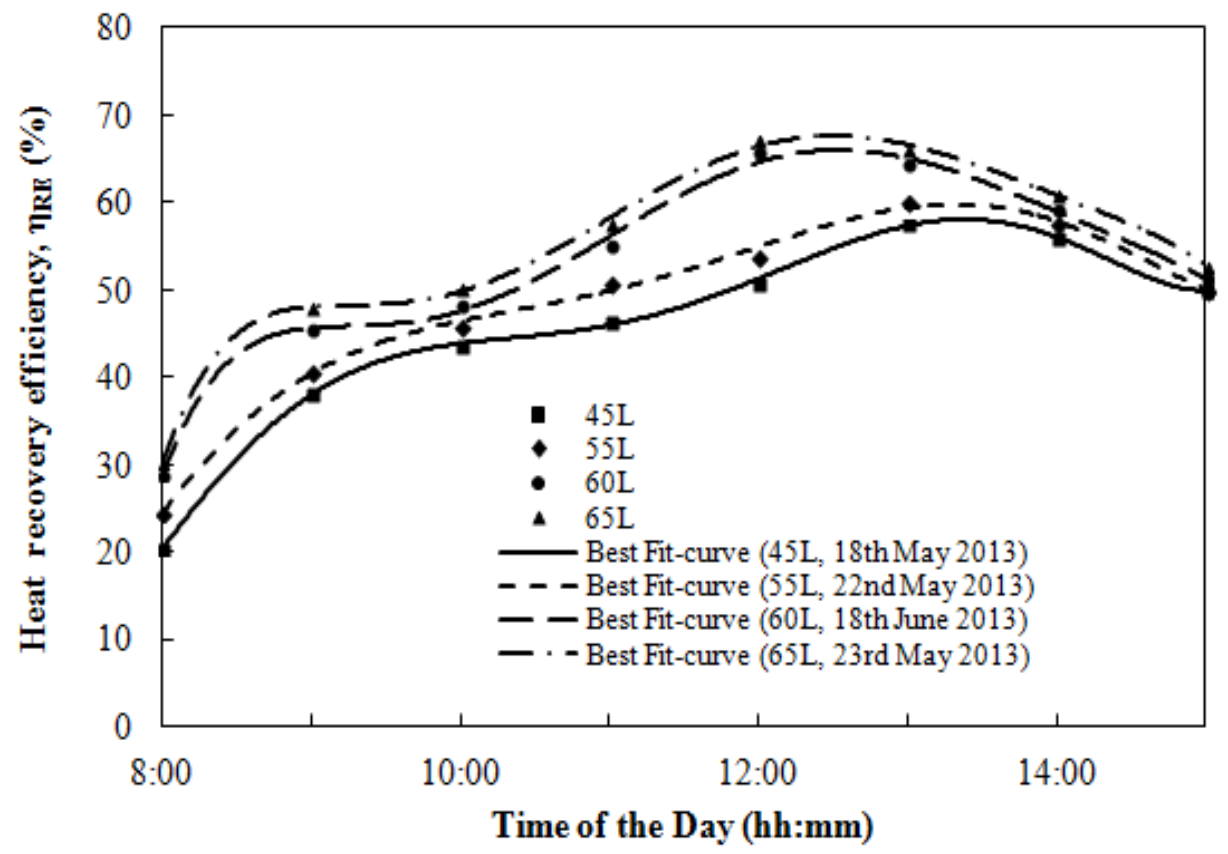

Figure 38: Effect of storage tank volume on heat recovery efficiency 


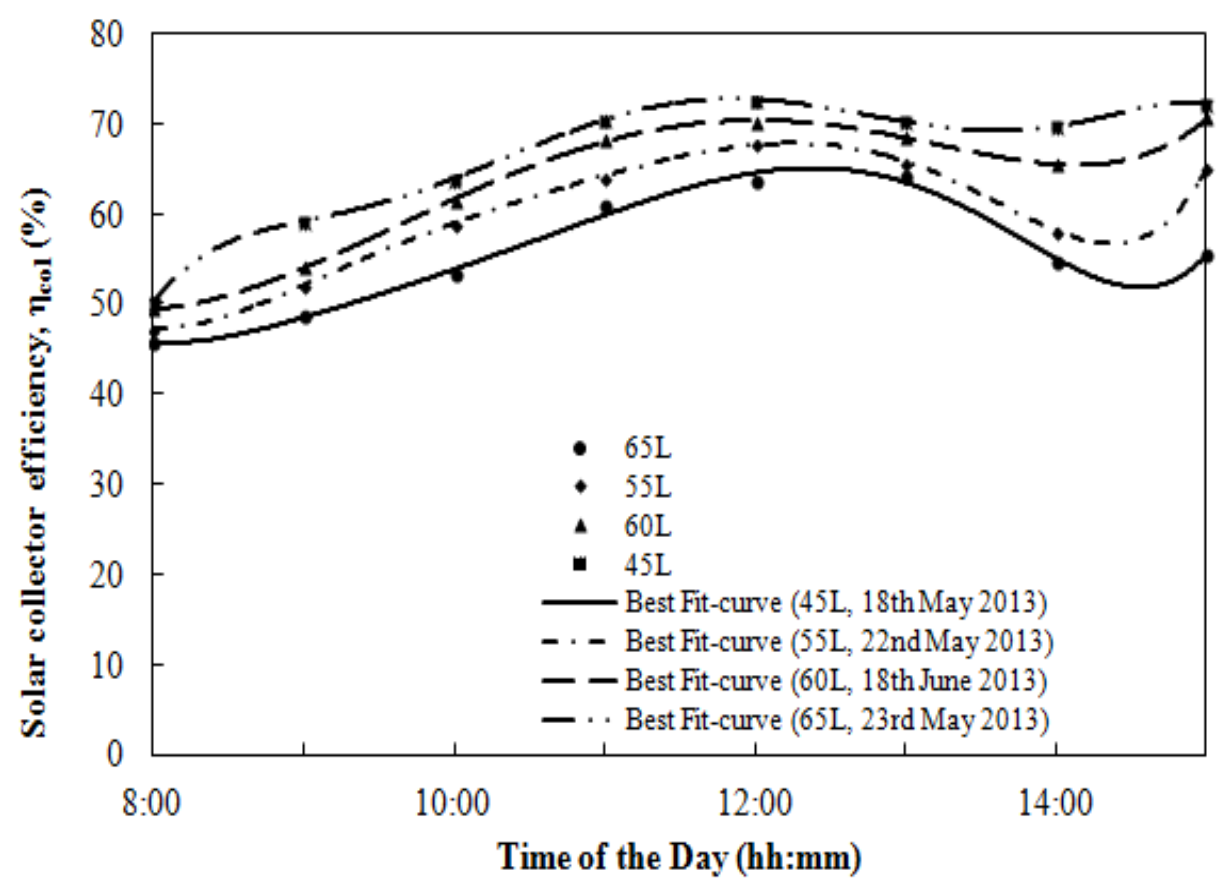

Figure 39: Effect of storage volume on solar collector efficiency

\subsubsection{Effect of Inlet Tank Temperature}

To determine the effect of inlet tank temperature on the system performance different inlet tank temperature between $5{ }^{\circ} \mathrm{C}$ to $15{ }^{\circ} \mathrm{C}$ were chosen for comparison. For a given tank volume of $60 \mathrm{~L}$, the effect of different inlet tank temperature on the system performance are shown in Figs. 40-41. From Fig. 40, it should be noted that, lower the initial tank temperature, the rise in storage tank temperature reduces. For an initial tank temperature of $15{ }^{\circ} \mathrm{C}$, the system attained a maximum temperature of about $50{ }^{\circ} \mathrm{C}$, against of only $40{ }^{\circ} \mathrm{C}$ (for initial tank temperature of $5{ }^{\circ} \mathrm{C}$ ). This is because, if the initial water temperature in the storage tank is low, the rate of condensing temperature decreases which leads to marginal decrease in evaporating temperature. 


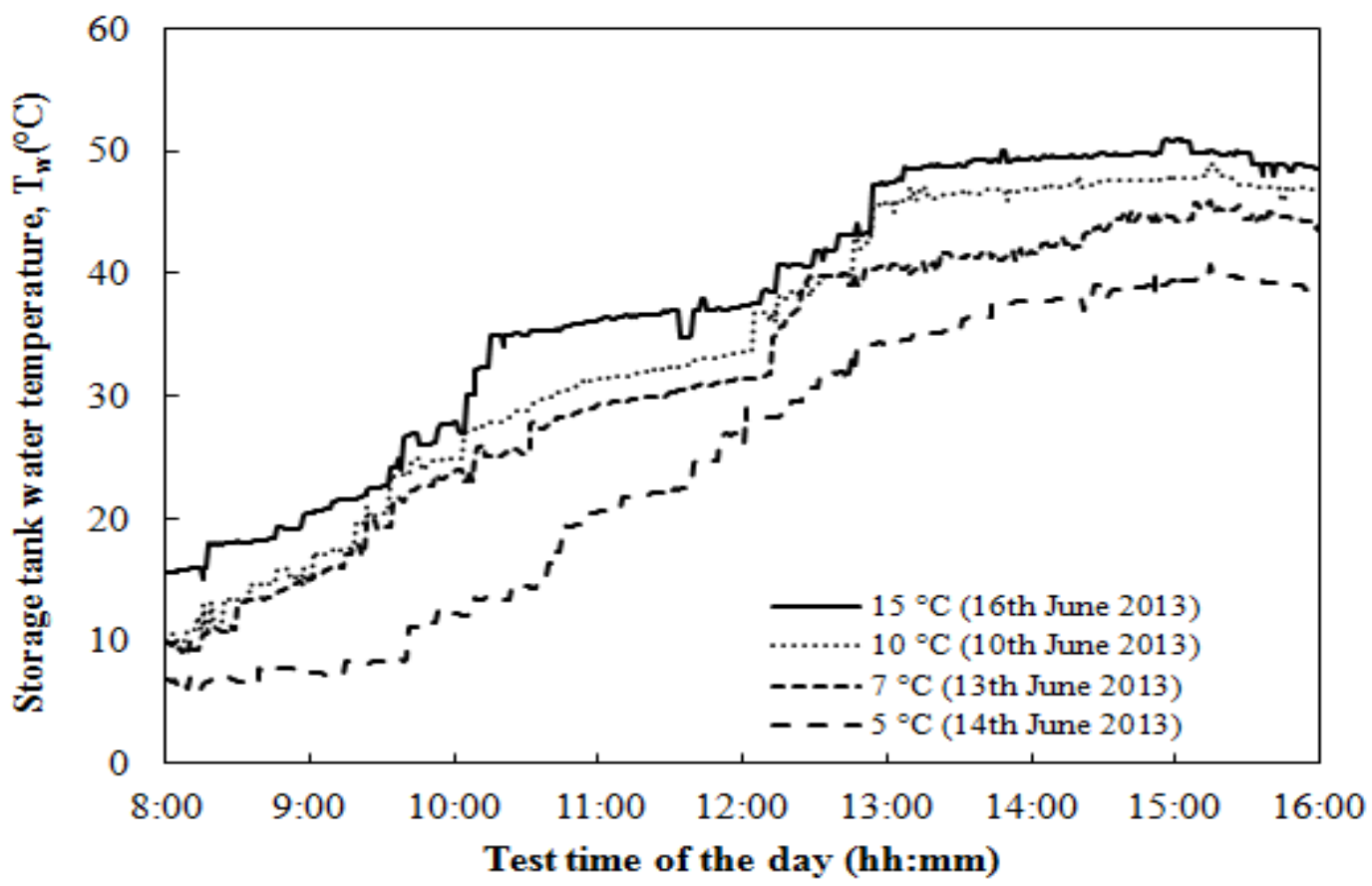

Figure 40: Effect of initial tank temperature on rise in tank water temperature

Also, it could be apparent from Fig. 41, that for low initial tank temperatures the performance of the system is higher compared to relatively high initial tank temperature. Hence it is clear from the trend that an increase in initial tank temperatures affects the decrease in system efficiency and marginal decrease in collector efficiency. As the initial tank temperature decreases from $15^{\circ} \mathrm{C}$ to $5^{\circ} \mathrm{C}$, the time-averaged collector efficiencies increases from $55 \%$ to $70 \%$. It is due to the fact that the temperature difference between the condensation and evaporation for the low inlet tank conditions is particularly lower compared to the high initial water temperature in the tank. 


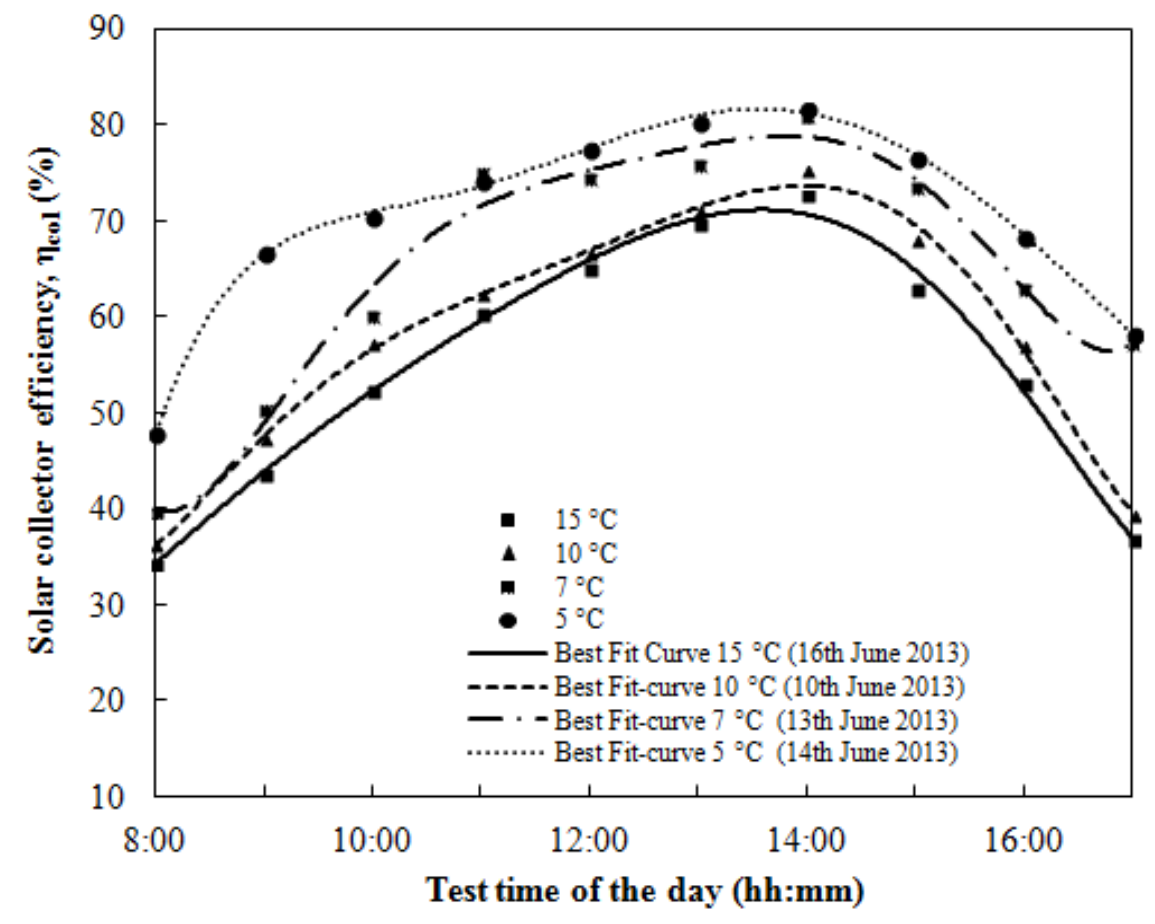

(a)

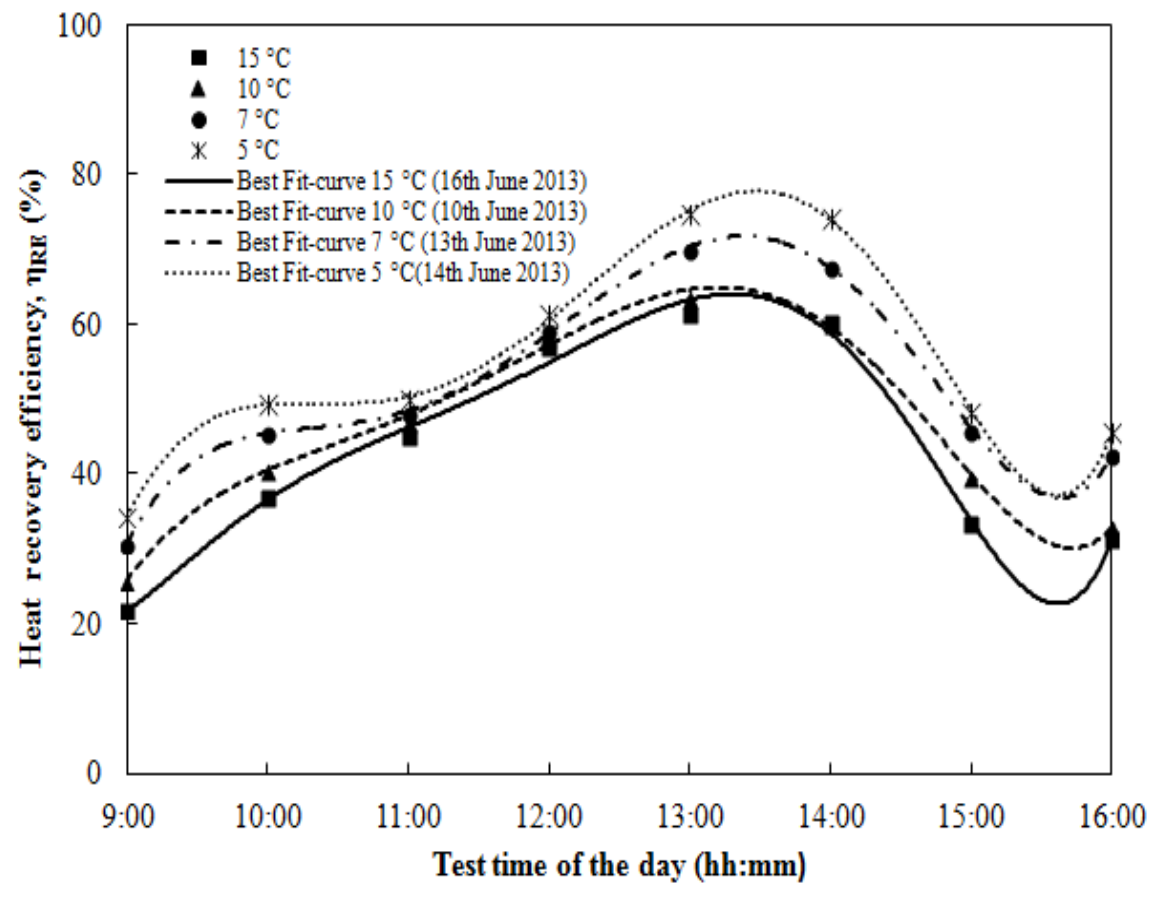

(b)

Figure 41: Effect of initial tank temperatures on the system performance:

(a) solar collector efficiency (b) heat recovery efficiency 


\subsubsection{Seasonal Performance of the System}

Figure 42 shows the performance of a $\mathrm{CO}_{2}$ assisted water heating system on typical days with clear sunshine during the sequential months of Feb-June 2013. It can be seen that in late winter (February), although the $\mathrm{CO}_{2}$ has an increase in temperature, it cannot effectively heat the water in the storage tank. This is because, the fiberglass insulation used for the storage tank could not prevent heat losses when exposed to extremely low ambient temperatures (around $\left.-10{ }^{\circ} \mathrm{C}\right)$. Preliminary results have indicated that even during extreme winter conditions it is possible to affect $\mathrm{CO}_{2}$ heating. Thus, the energy gain can be effectively harnessed for water heating purposes through the heat pump technique. However, it is evident from the calculated results that a thermosphoning system is not suitable for solar adverse regions (Fargo, ND) even during late winter and early spring months. However, the $\mathrm{CO}_{2}$ assisted water system could provide useful heat gain during the late spring as well as summer period. Testing during May and June show a significant increase in storage tank water temperature, compared to the late winter and early spring months of February, March, and April.

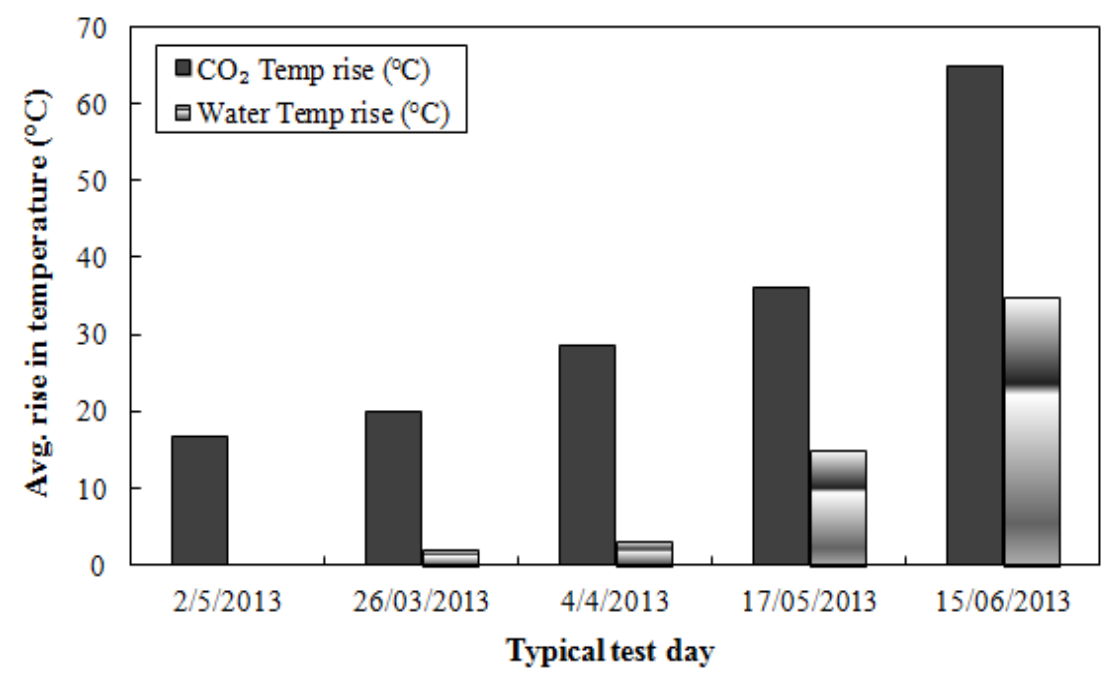

Figure 42: $\mathrm{CO}_{2}$ temp and the correspondence avg rise in tank temp for typical days of different month 
Furthermore, the variations in the performance factors, such as: the averaged solar collector efficiencies and heat recovery efficiencies on typical days for the period of April to June are shown in Fig. 43. The time-averaged collector efficiencies varies from 40\%-65\%.

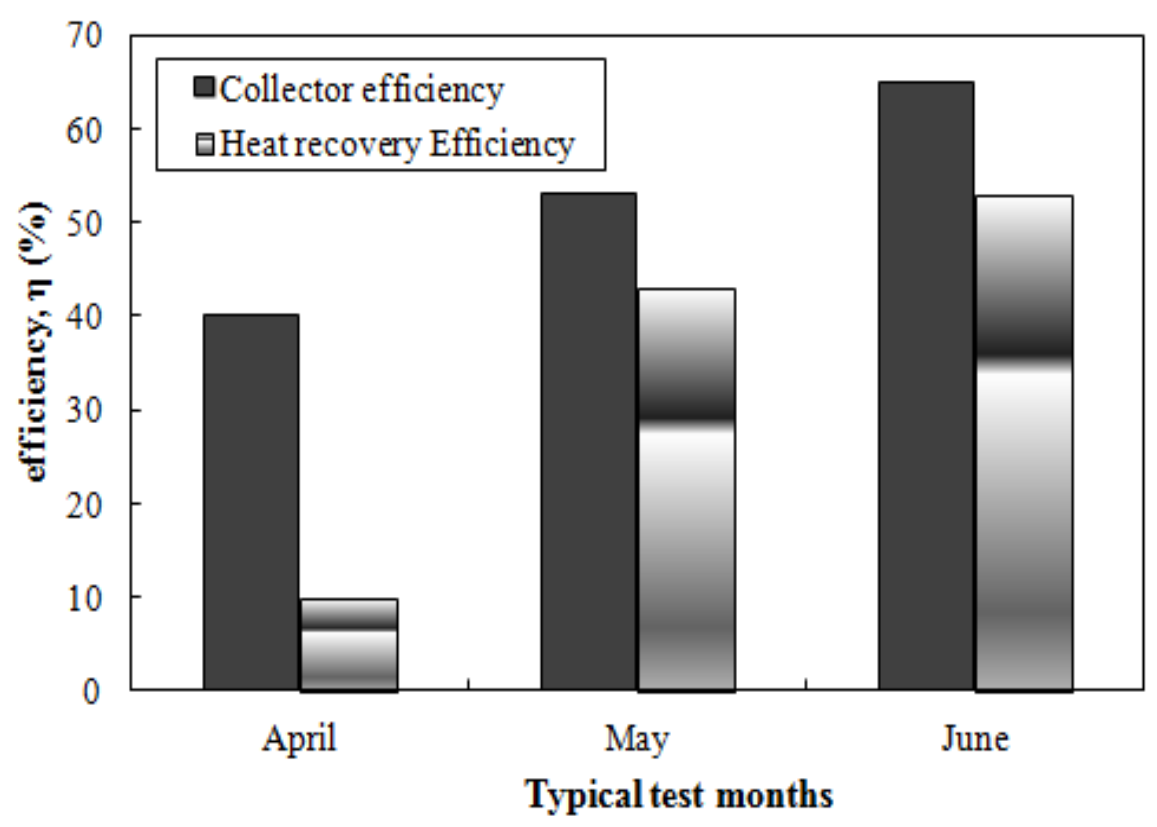

Figure 43: Time-avg collector and heat recovery efficiencies for typical days of different month 


\section{CONCLUSION}

The focus of the present study is to experimentally investigate the performance of the simple thermosyphon solar water heater using $\mathrm{CO}_{2}$ as working fluid. The entire work that has been done can be summarized as follows:

In order to introduce the fundamental understanding on various types of SWH systems, and to identify an optimal design of a SWH system, a detailed review of literature has been carried out. To develop a reliable and efficient SWH system for solar adverse regions, constraints derived from low ambient temperatures and low solar radiation intensity have to be met. The main design considerations include the type of collector chosen, storage tank design, and the selection of the working fluid. The extensive literature survey has helped in identifying the key parameters in designing the solar collector and in studying the influence of different working fluids on collector performance.

Three main modifications are proposed in this study in order to enhance the performance of the existing hybrid system. Modifications include: (i) employing a modified evacuated tube (U-tube) collector in order to eliminate convection and conduction heat transfer losses (ii) optimizing a heat exchanger design (immersed type heat exchanger) to facilitate the complete condensation of vapor, thereby maximizing the heat rejection in the storage tank, and (iii) utilizing $\mathrm{CO}_{2}$ as working fluid because of its environmental benign nature and higher heat transfer properties.

A $\mathrm{CO}_{2}$ assisted water heating system using U-tube evacuated tube collector has been investigated for Fargo, ND, weather conditions. The thermal performance of the system was determined based on the measured collector temperature and water temperature in the storage tank, under different weather conditions. The results indicate that, the measured collector $\left(\eta_{\text {col }}\right)$ 
and heat recovery efficiencies $\left(\eta_{\mathrm{RE}}\right)$ were calculated around $65 \%$ and $55 \%$ respectively. Experiments have shown the potential of using $\mathrm{CO}_{2}$ as the working fluid in $\mathrm{SWH}$ systems when need to be operated in solar adverse regions. However, thermosyphon based SWH system is not recommended for winter conditions. A suggestion for further studies is to investigate the heat pump based $\mathrm{CO}_{2}$ driven $\mathrm{SWH}$ system when subjected to solar adverse condition (very low $\mathrm{T}_{\mathrm{a}}$ and wind chill temperature). Also, an exact economic analysis is required to be done to estimate its market feasibility, especially compared to conventional solar water heater. 


\section{REFERENCES}

[1] Energy Information Administration, Energy consumption and expenditure tables of the 2005 residential energy consumption survey, EIA, Washington, DC (2005) Accessed January 2001. http:www.cia.gov/emcu/recs/2005/c\&e/detailed_tables2005 c\&e.html.

[2] Renewable Energy Policy Network, Renewable 2011: Global Status Report. http://www.ren21.net/gsr.

[3] S.J. Jeong and K.S.Lee. An experimental study of a carbon dioxide-filled thermosyphon for acquition of low-temperature waste enrgy. Int. J. Energy Res. 2010; 34: 454-461.

[4] X.R.Zhang and H. Yamaguchi. An experimental study on evacuated tube solar collector using supercritical CO2. Applied Thermal Engineering 28 (2008) 1225-1233.

[5] Kemp CM. US patents no 451384, April 28, 1891. (Patent Records).

[6] Schmidt C, Goetzberger A. Single-tube integrated collector storage systems with transparent insulation and involute reflector. Solar Energy 1990; 45 (2):93-100.

[7] http://en.wikipedia.org/wiki/Solar_water_heating.

[8] Kalogirou SA. Solar thermal collectors and applications. Progress in Energy and Combustion Science. 2004;30:231-95.

[9] Close DJ. The performance of solar water heaters with natural circulation. Solar Energy. 1962;6:33-40.

[10] Ong KS. An improved computer program for the thermal performance of a solar water heater. Solar Energy. 1976;18:183-91.

[11] Sodha MS, Tiwari GN. Analysis of natural circulation solar water heating systems. Energy Conversion and Management. 1981;21:283-8. 
[12] Grossman G, Shitzer A, Zvirin Y. Heat transfer analysis of a flat-plate solar energy collector. Solar Energy. 1977;19:493-502.

[13] Huang BJ. Similarity theory of solar water heater with natural circulation. Solar Energy. 1980;25:105-16.

[14] K. C. Ng, C. Yap, T. H. Khor, Outdoor testing of evacuated-tube heat-pipe solar collectors, Proceedings of the Institution of Mechanical Engineers 2000; 214(part E): 23-30. (Article).

[15] Redpath DAG, Eames PC, Lo SNG, Griffiths PW. Experimental investigation of natural convection heat exchange within a physical model of the manifold chamber of a thermosyphon heat-pipe evacuated tube solar water heater. Solar Energy. 2009;83:988-97.

[16] Budihardjo I, Morrison GL. Performance of water-in-glass evacuated tube solar water heaters. Solar Energy. 2009;83:49-56.

[17] Huang J, Pu S, Gao W, Que Y. Experimental investigation on thermal performance of thermosyphon flat-plate solar water heater with a mantle heat exchanger. Energy. 2010;35:3563-8.

[18] Jaisankar S, Radhakrishnan TK, Sheeba KN. Experimental studies on heat transfer and friction factor characteristics of forced circulation solar water heater system fitted with helical twisted tapes. Solar Energy. 2009;83:1943-52.

[19] Jaisankar S, Radhakrishnan TK, Sheeba KN, Suresh S. Experimental investigation of heat transfer and friction factor characteristics of thermosyphon solar water heater system fitted with spacer at the trailing edge of Left-Right twisted tapes. Energy Conversion and Management. 2009;50:2638-49.

[20] Li Z, Chen C, Luo H, Zhang Y, Xue Y. All-glass vacuum tube collector heat transfer model used in forced-circulation solar water heating system. Solar Energy. 2010;84:1413-21. 
[21] Chong KK, Chay KG, Chin KH. Study of a solar water heater using stationary V-trough collector. Renewable Energy. 2012;39:207-15.

[22] Chaturvedi SK, Chen DT, Kheireddine A. Thermal performance of a variable capacity direct expansion solar-assisted heat pump. Energy Conversion and Management. 1998;39:181-91.

[23] Kuang YH, Sumathy K, Wang RZ. Study on a direct-expansion solar-assisted heat pump water heating system. International Journal of Energy Research. 2003;27:531-48.

[24] Li YW, Wang RZ, Wu JY, Xu YX. Experimental performance analysis on a directexpansion solar-assisted heat pump water heater. Applied Thermal Engineering. 2007;27:2858-68.

[25] Chyng JP, Lee CP, Huang BJ. Performance analysis of a solar-assisted heat pump water heater. Solar Energy. 2003;74:33-44.

[26] Huang BJ, Lee JP, Chyng JP. Heat-pipe enhanced solar-assisted heat pump water heater. Solar Energy. 2005;78:375-81.

[27] Xu G, Zhang X, Deng S. A simulation study on the operating performance of a solar-air source heat pump water heater. Applied Thermal Engineering. 2006;26:1257-65.

[28] http://en.wikipedia.org/wiki/Solar_thermal_collector\#Flat_plate_collectors.

[29] Hottle HC, Whiller A, Evaluation of flat-plate solar collector performance, vol.2. Transaction of Conference on the use of Solar Energy, University of Arizona; 1958 p. 74 104. (Conference Paper).

[30] Ljiljana T.Kostic, Zoran T. Pavlovic, Optimal position of flat plate reflectors of solar thermal collector, Energy and Buildings,2011. 
[31] Matrawy KK, Farkas I. Comparison study for three types of solar collectors for water heating. Energy Conversion and Management. 1997;38:861-9.

[32] Duffie, J. A.,Beckman, W.A., Solar Engineering of Thermal Processes, Wiley \& Sons, New York, 1980. (Article).

[33] Tripanagnostopoulos Y, Souliotis M, Nousia T. Solar collectors with colored absorbers. Solar Energy. 2000;68:343-56.

[34] Rommel M, Moock W. Collector efficiency factor $\mathrm{F}^{\prime}$ for absorbers with rectangular fluid ducts contacting the entire surface. Solar Energy. 1997;60:199-207.

[35] Alvarez A, Cabeza O, Muñiz MC, Varela LM. Experimental and numerical investigation of a flat-plate solar collector. Energy. 2010;35:3707-16.

[36] Rittidech S, Wannapakne S. Experimental study of the performance of a solar collector by closed-end oscillating heat pipe (CEOHP). Applied Thermal Engineering. 2007;27:197885.

[37] Kovarik M. Optimal distribution of heat conducting material in the finned pipe solar energy collector. Solar Energy. 1978;21:477-84.

[38] Hollands KGT, Stedman BA. Optimization of an absorber plate fin having a step-change in local thickness. Solar Energy. 1992;49:493-5.

[39] Kundu B. Performance analysis and optimization of absorber plates of different geometry for a flat-plate solar collector: a comparative study. Applied Thermal Engineering. 2002;22:999-1012.

[40] O'Brien-Bernini FC, McGowan JG. Performance modeling of non-metallic flat plate solar collectors. Solar Energy. 1984;33:305-19. 
[41] Sopian K, Zulkifli R, Sahari J, Othman MY. Thermal performance of thermoplastic natural rubber solar collector. Journal of Materials Processing Technology. 2002;123:179-84.

[42] Liu W, Davidson J, Mantell S. Thermal Analysis of Polymer Heat Exchangers for Solar Water Heating: A Case Study. Journal of Solar Energy Engineering. 2000;122:84-91.

[43] Tsilingiris PT. Back absorbing parallel plate polymer absorbers in solar collector design. Energy Conversion and Management. 2002;43:135-50.

[44] Dorfling C, Hornung CH, Hallmark B, Beaumont RJJ, Fovargue H, Mackley MR. The experimental response and modelling of a solar heat collector fabricated from plastic microcapillary films. Solar Energy Materials and Solar Cells. 2010;94:1207-21.

[45] Furbo S, Jivan Shah L. Thermal advantages for solar heating systems with a glass cover with antireflection surfaces. Solar Energy. 2003;74:513-23.

[46] Akhtar N, Mullick SC. Computation of glass-cover temperatures and top heat loss coefficient of flat-plate solar collectors with double glazing. Energy. 2007;32:1067-74.

[47] Whiller A, Plastic covers for solar collectors (Book).

[48] http://www.solarpanelsplus.com/evacuated-tube-collectors/.

[49] Hossain MS, Saidur R, Fayaz H, Rahim NA, Islam MR, Ahamed JU, et al. Review on solar water heater collector and thermal energy performance of circulating pipe. Renewable and Sustainable Energy Reviews. 2011;15:3801-12.

[50] Kim Y, Seo T. Thermal performances comparisons of the glass evacuated tube solar collectors with shapes of absorber tube. Renewable Energy. 2007;32:772-95.

[51] Shah LJ, Furbo S. Vertical evacuated tubular-collectors utilizing solar radiation from all directions. Applied Energy. 2004;78:371-95. 
[52] Morrison GL, Budihardjo I, Behnia M, Water-in-glass evacuated tube solar water heaters. In: Saman W.Y. Charters W.W.S. (Eds), Proceedings of ISES Solar World Congress, Adelaide, Australia, pp. 545-550. (Article).

[53] Liang R, Ma L, Zhang J, Zhao D. Theoretical and experimental investigation of the filledtype evacuated tube solar collector with U tube. Solar Energy. 2011;85:1735-44.

[54] Rittidech S, Donmaung A, Kumsombut K. Experimental study of the performance of a circular tube solar collector with closed-loop oscillating heat-pipe with check valve (CLOHP/CV). Renewable Energy. 2009;34:2234-8.

[55] Diaz G, 2008, Performance analysis and design optimization of a mini-channel evacuated tube solar collector, In Proceedings of ASME IMECE, October 31-November 6, 2008. Boston, Massachusetts, USA. (Article).

[56] Ma L, Lu Z, Zhang J, Liang R. Thermal performance analysis of the glass evacuated tube solar collector with U-tube. Building and Environment. 2010;45:1959-67.

[57] Kaiyan H, Hongfei Z, Tao T. A novel multiple curved surfaces compound concentrator. Solar Energy. 2011;85:523-9.

[58] Rabl A, O'Gallagher J, Winston R. Design and test of non-evacuated solar collectors with compound parabolic concentrators. Solar Energy. 1980;25:335-51.

[59] Oommen R, Jayaraman S. Development and performance analysis of compound parabolic solar concentrators with reduced gap losses-'V' groove reflector. Renewable Energy. 2002;27:259-75.

[60] Winston R. Ideal flux concentrators with reflector gaps. Appl Opt. 1978;17:1668-9. 
[61] Oommen R, Jayaraman S. Development and performance analysis of compound parabolic solar concentrators with reduced gap losses - oversized reflector. Energy Conversion and Management. 2001;42:1379-99.

[62] Rönnelid M, Karlsson B. Experimental investigation of heat losses from low-concentrating non-imaging concentrators. Solar Energy. 1996;57:93-109.

[63] Rabl A. Comparison of solar concentrators. Solar Energy. 1976;18:93-111.

[64] Tripanagnostopoulos Y, Yianoulis P, Papaefthimiou S, Zafeiratos S. CPC Solar Collectors With Flat Bifacial Absorbers. Solar Energy. 2000;69:191-203.

[65] Rönnelid M, Perers B, Karlsson B. Construction and testing of a large-area CPC-collector and comparison with a flat plate collector. Solar Energy. 1996;57:177-84.

[66] Eames PC, Norton B. Thermal and optical consequences of the introduction of baffles into compound parabolic concentrating solar energy collector cavities. Solar Energy. 1995;55:139-50.

[67] Altuntop N, Arslan M, Ozceyhan V, Kanoglu M. Effect of obstacles on thermal stratification in hot water storage tanks. Applied Thermal Engineering. 2005;25:2285-98.

[68] Rhee J, Campbell A, Mariadass A, Morhous B. Temperature stratification from thermal diodes in solar hot water storage tank. Solar Energy. 2010;84:507-11.

[69] Dehghan AA, Barzegar A. Thermal performance behavior of a domestic hot water solar storage tank during consumption operation. Energy Conversion and Management. 2011;52:468-76.

[70] Andersen E, Furbo S, Fan J. Multilayer fabric stratification pipes for solar tanks. Solar Energy. 2007;81:1219-26. 
[71] Furbo S, Andersen E, Thür A, Jivan Shah L, Dyhr Andersen K. Performance improvement by discharge from different levels in solar storage tanks. Solar Energy. 2005;79:431-9.

[72] Han YM, Wang RZ, Dai YJ. Thermal stratification within the water tank. Renewable and Sustainable Energy Reviews. 2009;13:1014-26.

[73] Shah LJ, Furbo S. Entrance effects in solar storage tanks. Solar Energy. 2003;75:337-48.

[74] Dehghan, A.A, M.H. Hosni, S.H. Shiryazdi (2005), Experimental evaluation of the thermal behavior of a vertical solar tank using energy and exergy analysis, Proceeding of IMECE2005, Florida, USA. (Article).

[75] A. Barzegar, A.A. Dehghan, Transient thermal behavior of a vertical solar storage tank with a mantle heat exchanger during no-flow operation, Journal of Applied Fluid Mechanics, Vol.2, No.1, pp.55-69, 2009. (Article).

[76] Alizadeh S. An experimental and numerical study of thermal stratification in a horizontal cylindrical solar storage tank. Solar Energy. 1999;66:409-21.

[77] Helwa NH, Mobarak AM, El-Sallak MS, El-Ghetany HH. Effect of hot-water consumption on temperature distribution in a horizontal solar water storage tank. Applied Energy. 1995;52:185-97.

[78] Hasan A. Thermosyphon solar water heaters: effect of storage tank volume and configuration on efficiency. Energy Conversion and Management. 1997;38:847-54.

[79] Farrington R.B, Bingham C.E, Testing and analysis of load-side immersed heat exchangers for solar domestic hot water systems, Technical Report. Golden, CO, USA: Solar Energy Research Inst: October 1, 1987. (Article).

[80] Spur R, Fiala D, Nevrala D, Probert D. Performances of modern domestic hot-water stores. Applied Energy. 2006;83:893-910. 
[81] James \& James, Planning and installing solar thermal systems: a guide for installers, architects and engineers; 2005.

[82] Parent MG, Van der Meer TH, Hollands KGT. Natural convection heat exchangers in solar water heating systems: Theory and experiment. Solar Energy. 1990;45:43-52.

[83] Buenconsejo Jr N.S, Experimental study of annular free convection heat exchangers: the flow characteristics in the annular gap. Australia: School of Mechanical and Manufacturing Engineering, University of New South Wales; 1994. (Article).

[84] Nasr A, Morrison GL, Behnia M, Computational study of flow and heat transfer characteristics of annular and vertical cavities, In: Proceedings of 2nd CASCM' 97; 1997. (Article).

[85] Morrison GL, Nasr A, Behnia M, Rosengarten G. Analysis of horizontal mantle heat exchangers in solar water heating systems. Solar Energy. 1998;64:19-31.

[86] Baur JM, Klein SA, Beckman WA, Simulation of water tanks with mantle heat exchangers. In, Proceedings of ASES annual conference, Solar: 93;1993.p.286-91.

[87] Shah L.S, Furbo S. (1996), Optimization of mantle tanks for low flow solar heating systems, EuroSun 96, Special Issues S-9601. (Article).

[88] Knudsen S, Morrison GL, Behnia M, Furbo S. Analysis of the flow structure and heat transfer in a vertical mantle heat exchanger. Solar Energy. 2005;78:281-9.

[89] Shi J, Wang JD, Yu GZ, Chemical Engineering Handbook, Chemical Engineering Press, Beijing, 1996 (in Chinese).

[90] Wang X, Wang R, Wu J. Experimental investigation of a new-style double-tube heat exchanger for heating crude oil using solar hot water. Applied Thermal Engineering. 2005;25:1753-63. 
[91] http://energy.gov/energysaver/articles/heat-transfer-fluids-solar-water-heating-systems

[92] O' Dell MP, Mitchell JW, Beckman WA, Design method and performance of heat pump with refrigerant-filled solar collectors.

[93] Soin RS, Raghuraman S, Murali V. Two-phase water heater: Model and long term performance. Solar Energy. 1987;38:105-12.

[94] Soin RS, Rao KS, Rao DP, Rao KS. Performance of flat plate solar collector with fluid undergoing phase chance. Solar Energy. 1979;23:69-73.

[95] Radhwan AM, Zaki GM. Analysis of refrigerant-charged solar collectors with phase change. Heat Recovery Systems and CHP. 1993;13:429-39.

[96] Farrington R, Deangelis M, Morrison L and Dougherty D, Performance evaluation of a refrigerant-charged thermosyphon solar DHW system. In Proc. AS/ISES Annual Meeting, Philadelphia, published by the ISES, American Section 1981; 4: 676-680.

[97] Joudi KA, Al-tabbakh AA. Computer simulation of a two phase thermosyphon solar domestic hot water heating system. Energy Conversion and Management. 1999;40:77593.

[98] Esen M, Esen H. Experimental investigation of a two-phase closed thermosyphon solar water heater. Solar Energy. 2005;79:459-68.

[99] Fanney AH, Terlizzi CP. Testing of refrigerant-charged solar domestic hot water systems. Solar Energy. 1985;35:353-66.

[100] Akyurt M. AWSWAH - the heat pipe solar water heater. Journal Name: J Eng Appl Sci; (United States); Journal Volume: 3:1/2. 1986:Medium: X; Size: Pages: 23-38.

[101] Kamal W, Performance evaluation of a refrigerant-charged solar collector, In Energex. (Pergamon Press, Regina, Saskatchewan) 1984; 84: 193-197. (Article). 
[102]http://www.heatpumpcentre.org/en/aboutheatpumps/heatpumpworkingfluids/Sidor/default. aspx.

[103] Payakaruk T, Terdtoon P, Ritthidech S. Correlations to predict heat transfer characteristics of an inclined closed two-phase thermosyphon at normal operating conditions. Applied Thermal Engineering. 2000;20:781-90.

[104] Kim M-H. Performance evaluation of R-22 alternative mixtures in a breadboard heat pump with pure cross-flow condenser and counter-flow evaporator. Energy. 2002;27:16781.

[105] Chaichana C, Aye L, Charters WWS. Natural working fluids for solar-boosted heat pumps. International Journal of Refrigeration. 2003;26:637-43.

[106] Charters WWS, Megler VR, Urma I, and Lu Aye, Propane as working fluid is domestic heat pumps. In: IIR/IIF-Melbourne 1996, Refrigeration, Climate Control and Energy Conversation. 1996 February 11-14; Melbourne, Australia. Melbourne: International Institute of Refrigeration, 1996.

[107] Urma I, Propane as a replacement for domestic application, MEngSc thesis, Department of Mechanical and Manufacturing Engineering, The University of Melbourne; 1997. (Article).

[108] Stoecker WF, Comparison of ammonia with other refrigerants for districts cooling plant chillers, ASHRAE Trans 1994; 100(2):1126-35. (Article).

[109] Kim M-H, Pettersen J, Bullard CW. Fundamental process and system design issues in $\mathrm{CO}_{2}$ vapor compression systems. Progress in Energy and Combustion Science. 2004;30:11974. 
[110] Nekså P, Rekstad H, Zakeri GR, Schiefloe PA. $\mathrm{CO}_{2}$-heat pump water heater: characteristics, system design and experimental results. International Journal of Refrigeration. 1998;21:172-9.

[111] White SD, Yarrall MG, Cleland DJ, Hedley RA. Modelling the performance of a transcritical $\mathrm{CO}_{2}$ heat pump for high temperature heating. International Journal of Refrigeration. 2002;25:479-86.

[112] Cecchinato L, Corradi M, Fornasieri E, Zamboni L. Carbon dioxide as refrigerant for tap water heat pumps: A comparison with the traditional solution. International Journal of Refrigeration. 2005;28:1250-8.

[113] Kim SG, Kim YJ, Lee G, Kim MS. The performance of a transcritical $\mathrm{CO}_{2}$ cycle with an internal heat exchanger for hot water heating. International Journal of Refrigeration. 2005;28:1064-72.

[114] Laipradit P, Tiansuwan J, Kiatsiriroat T, Aye L. Theoretical performance analysis of heat pump water heaters using carbon dioxide as refrigerant. International Journal of Energy Research. 2008;32:356-66.

[115] Zhang XR, Yamaguchi H. An experimental study on evacuated tube solar collector using supercritical $\mathrm{CO}_{2}$. Applied Thermal Engineering. 2008;28:1225-33.

[116] Shukla, R., K. Sumathy, Erickson, P, Gong, J., Recent Advances in the Solar Water Heating Systems: A Review. Renewable and Sustainable Energy Reviews 19 (2013) 173190.

[117] N.P. Vestergaard, M. Robinson. $\mathrm{CO}_{2}$ in Refrigeration Applications. [Internet] Air Conditioning Heating Refrigeration News. October 2, 2003; Accessed: October 2009. 
[118] Taira, S. "The Development of Heat Pump Water Heaters Using $\mathrm{CO}_{2}$ Refrigerant." Daikin Industries Ltd Japan (No Date).

[119] Brian T.Austin and K.Sumathy. (2011) "Parametric study on the performance of a direct expansion geothermal heat pump using carbon-dioxide," Applied Thermal Engineering, 31:3774-3782.

[120] Junlan Yang, Yitai Ma, Shengchun Liu, Xianyang Zeng, Comparison investigation on the heat transfer characteristics for supercritical $\mathrm{CO} 2$ fluid and conventional refrigerants. $7^{\text {th }}$ IIR Gustav Lorentzen Conference on Natural Working Fluids at Trondheim, Norway, 2006.

[121] Thermophysical properties of fluid systems. 2008. U.S. Secretary of Commerce. Retrieved May 14, 2010, from National Institute of Standard and Technology: http://webbook.nist.gov/chemistry/fluid.

[122] Oh, H.K., C.H. Son. "New correlation to predict the heat transfer coefficient in tube cooling of supercritical $\mathrm{CO}_{2}$ in horizontal tubes." Experimental Thermal and Fluid Science, 34 (2010): 1230-1241.

[123] Pettersen, J., A. Hafner, and G. Skaugen. "Development of compact heatexchangers for $\mathrm{CO}_{2}$ air-conditioning systems." International Journal of Refrigeration 21 (1998): 180-193.

[126] X.R. Zhang, H. Yamaguchi, D. Uneno, K. Fujima, M. Enomoto and N. Sawada. Analysis of a novel solar-energy-powered Rankine cycle for combined power and heat generation using supercritical carbon dioxide. Renewable Energy. 31,1839-1854 (2006).

[127] H. Yamaguchi, N.Sawada, H.Suzuki, H.Ueda, X.R. Zhang. Preliminary Study on a solar water heater using supercritical Carbon dioxide as working fluid. Journal of Solar Energy Engineering, Vol.132, 2010. 
[128] R. Shukla, K.Sumathy, S. Khan. Performance improvement of heat pump assisted solar water heating system. International confenrence in renewable energies and power quality.(Conference paper).

[129] http://www.energymatters.com.au/renewable-energy/solar-power/solar-hot-water/flat-vsevacuated.php

[130] Perez R, Seals R, Anderson J, Menicucci D. Calculating Solar Radiation Received by Tubular Collectors. Journal of Solar Energy Engineering. 1995;117:341-4.

[131] Abdunnabi and Loveday, Optimization of Thermosyphon Solar Water Heaters Using TRNSYS.Part2: Parametric Study Using a Modified TRNSYS Model, International Conference on Future Environment and Energy.

[132] http://ndawn.ndsu.nodak.edu/

[133] http://www.engineeringtoolbox.com/design-hot-water-system-d_92.html

[134] J. Dahm, C. Bales, K. Lorenz and J.-O. Dalenba, Evaluation of storage configuration with internal heat exchanger, Solar Energy Vol. 62, No. 6, p. 407-417, 1998.

[135] Kuang, Y.H., Sumathy, K., and Wang, R.Z.,”Study on a direct -expansion solar assisted heat pump water heating system,'”nternational J. of Energy Research, Vol.27, pp.531-548, 2003.

[136] RC Jordan and GB Priester, Refrigeration and air conditioning. Prentic-Hall, Inc: New York, 1948.

[137] http://www.engineeringtoolbox.com/heat-transfer-coefficients-exchangers d450.html

[138] http://en.wikipedia.org/wiki/Hot water_storage_tank 


\section{APPENDEX A. WIRING OF CR1000}

CR1000 Wiring Diagram for FinalProgram.SCW

Type J (iron-constantan) Thermocouple (1)

CR1000 White

$1 \mathrm{H}$

Red

$1 \mathrm{~L}$

Type J (iron-constantan) Thermocouple (2)

CR1000 White

$2 \mathrm{H}$

Red $2 \mathrm{~L}$

Type J (iron-constantan) Thermocouple (3) White CR1000 White $3 \mathrm{H}$

\begin{tabular}{|ll} 
White & $3 \mathrm{H}$ \\
\hline Red & $3 \mathrm{~L}$
\end{tabular}

Type J (iron-constantan) Thermocouple (4) $3 \mathrm{~L}$ White

CR1000 Red $4 \mathrm{H}$

\begin{tabular}{ll}
\hline Red & 4 \\
\hline
\end{tabular}

CS215 Temperature \& Relative Humidity Sensor $4 \mathrm{~L}$

\begin{tabular}{|lc}
\multicolumn{1}{|c|}{ Clear } & $\frac{1}{-}$ (Ground) \\
\hline White & \\
\hline Black & \\
\hline Red & \\
\hline Green & \\
\hline & \\
\hline
\end{tabular}

$\begin{array}{ll}\text { Single-Ended Voltage (1) } & \text { CR1000 }\end{array}$

\begin{tabular}{|ll}
\multicolumn{1}{c|}{ Shield } & $\frac{\perp}{\overline{ }}$ (Ground) \\
\hline Ground & $\frac{1}{=}$ (Ground) \\
\hline Signal & $5 \mathrm{H}$
\end{tabular}

$\begin{array}{ll}\text { Single-Ended Voltage (2) CR1000 } & \text { CR10 }\end{array}$ Shield Ground $\stackrel{\perp}{=}$ (Ground) Signal $\frac{1}{-}$ (Ground) $5 \mathrm{~L}$ 
Type J (iron-constantant) Thermocouple (1)

1H: White

1L: Red

Type J (iron-constantant) Thermocouple (2)

2H: White

2L: Red

Type J (iron-constantant) Thermocouple (3)

3H: White

3L: Red

Type J (iron-constantant) Thermocouple (4)

4H: White

4L: Red

CS215 Temperature \& Relative Humidity Sensor

Ground: Clear

G: White

G: Black

12V: Red

C7: Green

Single-Ended Voltage (1)

Ground: Shield

Ground: Ground

5H: Signal

Single-Ended Voltage (2)

Ground: Shield

Ground: Ground

5H: Signal

Measurement

Default Measurement

BattV

Wiring Panel Temperature

Reference

Type J (iron-constantan) Thermocouple (1)

CO2In 
Type J (iron-constantant) Thermocouple (2) $\mathrm{CO} 2 \mathrm{Out}$

Type J (iron-constantant) Thermocouple (3)

WaterIn

Type J (iron-constantant) Thermocouple (4)

WaterOut

CS215 Temperature \& Relative Humidity Sensor AirTC

$\mathrm{RH}$

Single-Ended Voltage (1)

P_CO2OUT

Single-Ended Voltage (1)

P_CO2IN

Measurements Lables, Created by Math Expression

15 P CO2I

18 P_CO2O 


\section{APPENDEX B. SENSOR CALIBRATION}

The pressure sensors were calibrated for pressure before being installed in the thermosyphon SWH system. The pressure output was calibrated using an analog pressure reader installed in the system. The voltage was measured and was compared to the analog pressure gauge using equation $(\mathrm{V}=\mathrm{Pa}+\mathrm{b})$. The calibration curves are displayed below.

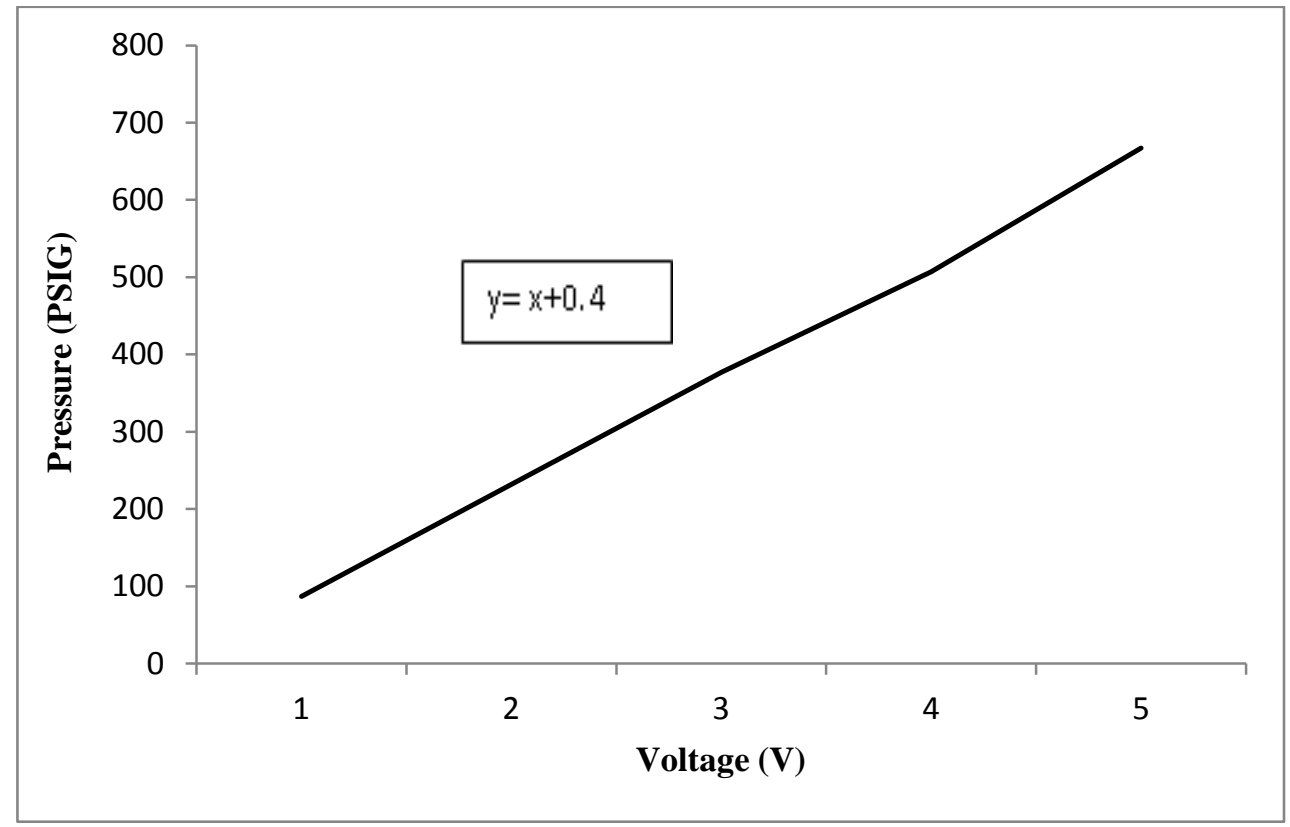




\section{APPENDEX C. LIST OF PUBLICATIONS}

1. R.Shukla and K.Sumathy, "Experimental Investigation on Thermosyphon Solar Water Heater using $\mathrm{CO}_{2}$ as working fluid", American Solar Energy Society conference (ASES 2013), Baltimore, US, April 15-20, 2013.

2. R.Shukla and K.Sumathy, "Performance Evaluation of a Thermosyphon Solar Water Heater Using Supercritical $\mathrm{CO}_{2}$ as Working Fluid", International conference on advances in engineering sciences and applied mathematics (ICAESAM' 2013), Cape Town, Nov. 30-Dec.1, 2013.

3. R.Shukla, K. Sumathy and Samee Ullah Khan, "Performance Improvement of a Heat Pump Assisted Solar Water Heating System”, Int. Conference on Renewable Energy and Power Quality (ICREPQ12), CD-Rom Proceedings, Santiago de Compostela, pp 1-5, Spain, March 28-30, 2012.

4. R.Shukla, K.Sumathy and M. Raisul Islam," An Experimental Study on a Density Driven Solar Water Heating System Using Supercritical $\mathrm{CO}_{2}$ as Working Fluid", International Journal of Environment and Resource, 2014 edition (Accepted).

5. R. Shukla, K.Sumathy, Phillip Erickson and Jiawei Gong, "Recent advances in the solar water heating systems: A review", Renewable and Sustainable Energy Reviews, 19 (2013) 173-190. 